\title{
FORESTS FOR PARTICIPATORY DEMOCRACY: \\ EMERGENT PATTERNS IN THE INTERACTION \\ OF ACTORS AND SPACE IN A COMMUNITY-BASED \\ SUSTAINABLE FORESTRY PROJECT IN \\ SAN FRANCISCO LIBRE, NICARAGUA
}

by

Lauren Sinreich

Thesis

ENVIRONMENTAL STUDIES 593

[December, 2009]

A 90 point thesis submitted to Victoria University of Wellington, as partial fulfillment of requirements for the degree of

Master of Environmental Studies

School of Geography, Environment and Earth Sciences

Victoria University of Wellington

[December 2009] 

Forests for Participatory Democracy:

Emergent patterns in the interaction of actors and space in a community-based sustainable forestry project in San Francisco Libre, Nicaragua

by

\author{
Lauren Sinreich
}

\begin{abstract}
The host of literature on community-based sustainable forestry initiatives cites a profound schism between theory and the actual devolution of power and conservation of natural environments. This thesis set out to analyze the workings of power in a decentralized sustainable forestry project in San Francisco Libre, Nicaragua, and to account for how the myriad relevant actors influence, and are influenced, by the interactions and opportunities that arose. Taking a co-constructivist, relational approach, the case study undertaken found sustainable forestry and participatory democracy to be co-constitutive. However, where modernity has been touted for freeing society from the constraints of the natural world through science and technology, the very democracy and sustainability these initiatives are striving for are constrained by the modern framework upon which many of our institutions are built. By abandoning such nature vs. society dichotomous frameworks, socio- political initiatives can better account for the place-based, relational agency human and non-human actors share, and therefore create more effective, participative democratic institutions.
\end{abstract}

Key words: actor network theory, agency, Nicaragua, participatory democracy, sustainable forestry 


\section{Dedication}

To realizing the inherent power in us all.

\section{Acknowledgements}

First and foremost I would like to thank my supervisors, Julie Cupples and Sara Kindon, for their support, and for making this thesis possible. I would also like to acknowledge the flexibility and cooperation the faculty at Victoria University of Wellington showed while ironing out the details of my thesis. The people at Instituto de Investigación y Gestión Social (INGES) in Managua and in San Francisco Libre went above and beyond what I could have possibly asked of them, and were an immense help in facilitating my research throughout my time in the field. In addition, the people I came to know in San Francisco Libre were integral to the outcome of my thesis and the experiences I enjoyed while in Nicaragua. I am deeply grateful to them for their generosity and warmth, and for welcoming me into their communities, homes and forest. Finally, but certainly not least, I would like to thank my sister, Michelle, for always being a breath of fresh air when I needed it most. 
A king of Ancient India, oppressed by the roughness of the earth upon soft human feet, proposed that his whole territory should be carpeted with skins. However, one of his wise men pointed out that the same result could be achieved far more simply by taking a single skin and cutting off small pieces to bind beneath the feet. These were the first sandals... The point of this story is not its obvious illustration of technical ingenuity. It is a parable of two different attitudes to the world...the progressive and traditional types of culture. Only in this case the more technically skillful solution represents the traditional culture, in which it is felt that it is easier for man [sic] to adapt himself to nature than to adapt nature to himself. (Watts, 1958:60) 


\section{Table of Contents}

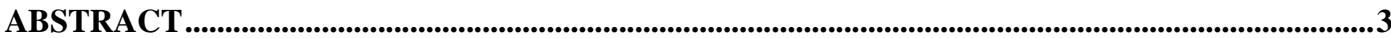

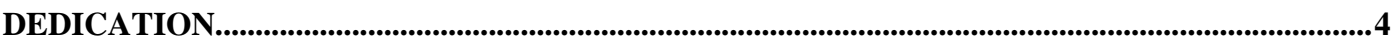

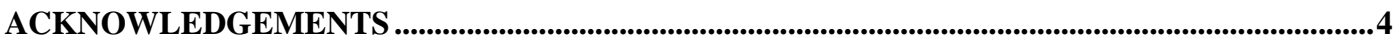

LIST OF ACRONYMS .....................................................................................................................

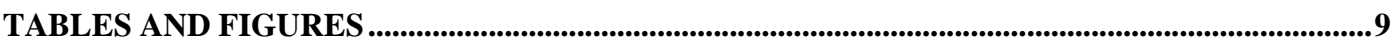

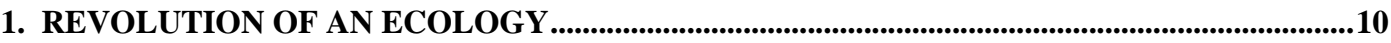

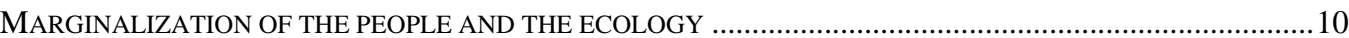

CHANGING ROLE OF ECOLOGY IN NICARAGUA ………….............................................................11

DEVELOPING SAN FRANCISCO LIBRE: TREES OR PEOPLE? .....................................................................13

RECOGNIZING THE SOCIAL IN “NATURAL” DISASTER ……………………………………………......15

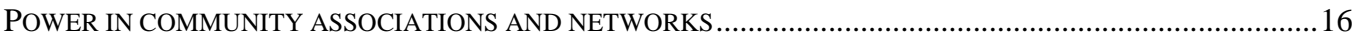

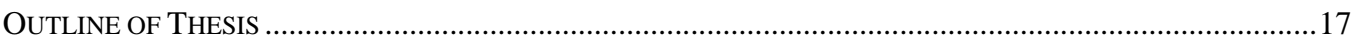

2. SOCIAL DICHOTOMY, NATURAL COMMONALITY ..................................................................18

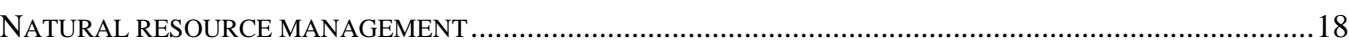

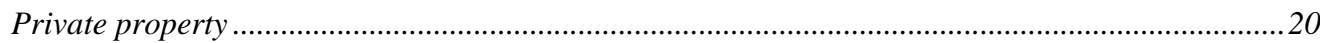

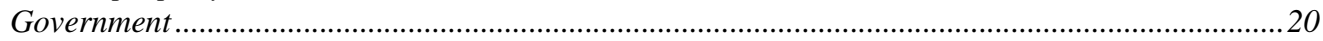

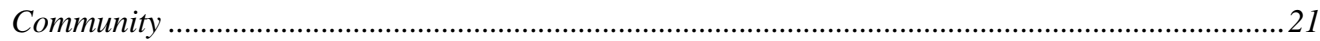

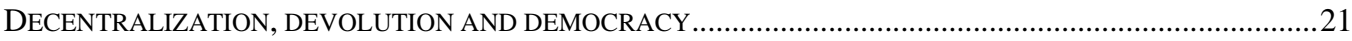

Participation and power ………………………………………………………………….....2

TOWARDS A MORE COMPREHENSIVE ACCOUNT OF PARTICIPATION AND POWER ………………………....25

Theoretical and epistemological dualisms - real or social nature? ...................................................26

The problem with dualities: blurred boundaries and static categories..............................................27

ACTOR NETWORK THEORY: A RELATIONAL UNDERSTANDING OF NON-DUALITY ......................................28

Power, agency and subjectivity - Opening up to a more inclusive democratic participation .............30

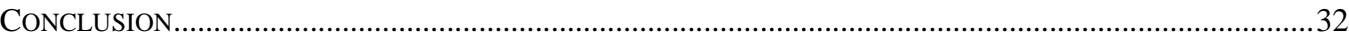

3. INTERACTING NETWORKS OF METHODS AND METHODOLOGY ......................................33

GROUNDED THEORY AND THE IMPORTANCE OF CONTEXT …………………………...............................33

CHOICE OF THEORY AND EPISTEMOLOGY: SYMMETRY AND NON-DUALISM.................................................35

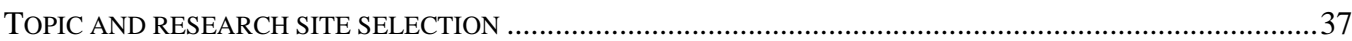

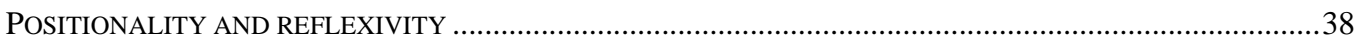

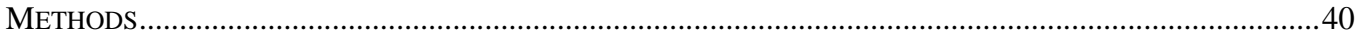

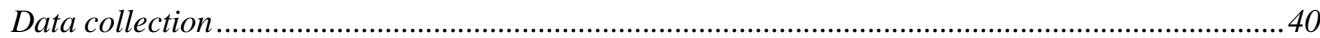

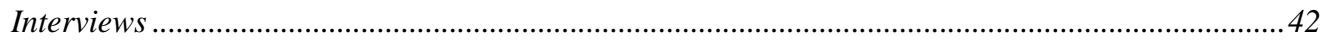

Participant observation ...............................................................................................................44

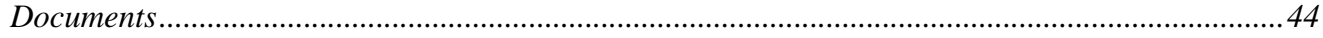

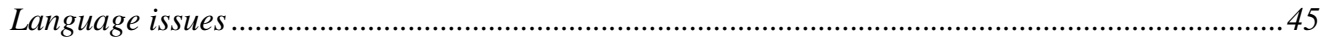

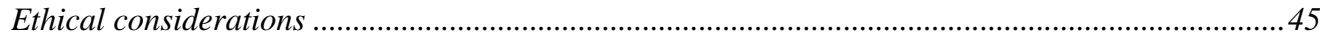

Data analysis and presentation .......................................................................................................46

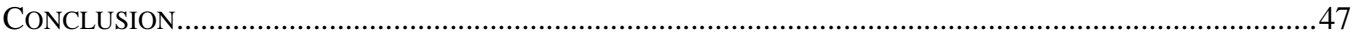

4. CO-CREATING CONTEXT FOR THE “UNIVERSAL LAW” '....................................................49

PARALLEL VULNERABILITY OF THE PEOPLE AND ECOLOGY OF SAN FRANCISCO LIBRE ..........................49

ASYMMETRICAL DISCOURSES AND ELUSIVE EQUILIBRIUMS ........................................................51

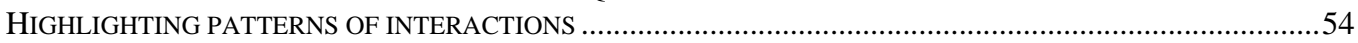

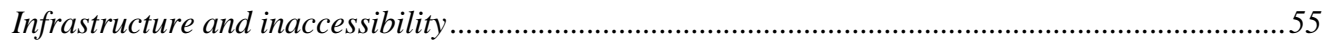

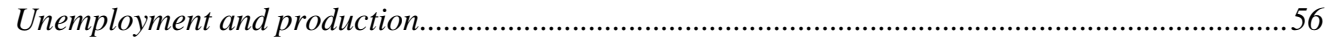

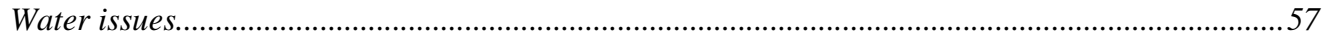

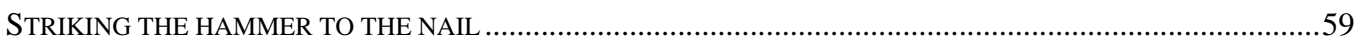

Integral Municipal Development Plan - Human scale development and local management of risk59

Forestry Plan Ordinance of San Francisco Libre - Diagnosis of the forests' potential ...................62

Fomenting Sustainable Forestry Management And Increased Aggregated Value of Forest

Producers In The Municipality of San Francisco Libre - NGOs' initiative .......................................63

THE MEANING IN-BETWEEN: EMBRACING THE IMPORTANCE OF INTERACTION .......................................64 


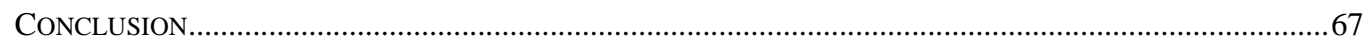

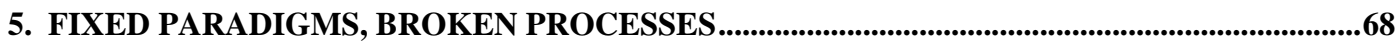

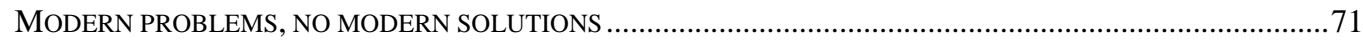

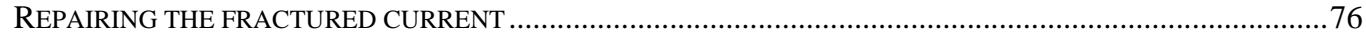

WHICHEVER WAY ITS BRANCHES ARE PRUNED, SO LEANS THE TREE ................................................8

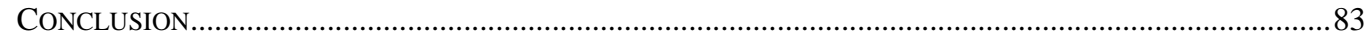

6. EMBRACING A DYNAMIC NATURE-SOCIETY FOR PARTICIPATORY DEMOCRACY.84

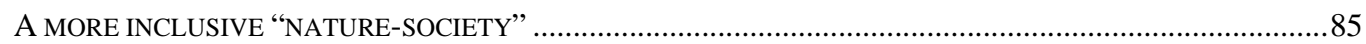

NEW POLITICAL STRUCTURES: NEW PARTICIPATION OPPORTUNITIES ..................................................85

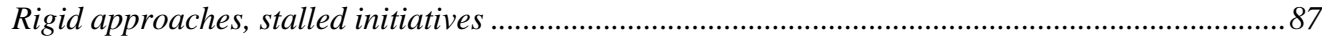

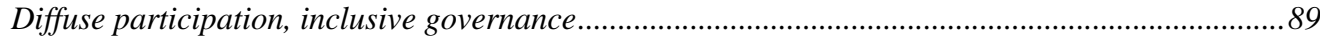

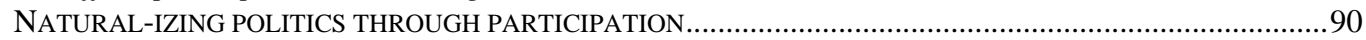

POTENTIALS FOR COMMUNITY FORESTRY AND NATURAL RESOURCE MANAGEMENT ..............................91

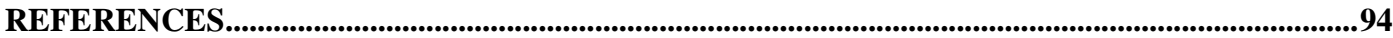




\section{List of Acronyms}

ANT actor network theory

CBFRM Community-based forest resource management

CBNRM Community-based natural resource management

COPROFOR Cooperativa de Productos Forestales, or Cooperative of Forest Products

CPR Common Pool Resource

FORESTAN Forestadores Associados de Nicaragua, or Associated Foresters of Nicaragua

FSLN Frente Sandinista de Liberación Nacional, or Sandinista National Liberation Front

ICDP Integrated conservation development project

INAFOR Instituto Nacional Forestal, or National Forestry Institute

INGES Instituto de Investigación y Gestión Social, or Institute of Investigation and Social Management

MARENA Ministerio de Ambiente y Recursos Naturales, or Ministry of Environment and Natural Resources

NRM Natural resource management

PDM Plan de Manejo, or Forest Management Plan

PID Plan Integral de Desarollo, or Integral Municipal Development Plan

POA Plan Operativa Annual, or Annual Operative Plan

POSAFII Programa Socioambiental-Forestal II, or Environment and Social Forestry Project 


\section{Tables and Figures}

Figure 1 View of Volcano Momotombo and Lake Managua from San Francisco Libre

Figure 2 Location of San Francisco Libre, Nicaragua.

Figure 3 Lake Managua's increased water levels still encroach lakefront homes 11 years after Mitch’s flooding .16

Figure 4 Arnstein's Ladder of Participation. 24

Figure 5 Interdependence of politics, economy, society and environment in creating a nature-society .30

Figure 6 Map of San Francisco Libre, Nicaragua...............................42

Table 1 Interviews Cited.......................................................43

Table 2 Documents Referenced.............................................. 45

Figure 7 San Francisco Libre’s dry landscape...................................50

Figure 8 View from atop the bus of the only dirt road linking San Francisco Libre to the Pan-American Highway. .56

Figure 9 Workers loading the truck with firewood from San Francisco Libre's forests for transport to Managua's markets...........................................57

Figure 10 Dried river bed in an outer-lying community of San Francisco Libre..........59

Figure 11 Administrative restructuring initiative of the Integral Development Plan.....62 Figure 12 COPROFOR meeting at its workshop in San Francisco Libre's urban center. .70

Figure 13 Articulation of the chain of wood production............................71

Figure 14 Livestock serve as an alternative means of earnings......................73

Figure 15 Much of COPROFOR's machinery out of production and still in their boxes .75

Figure 16 Members of the rural community La Trinidad work together to hand-dig a well. ... 79

Figure 17 One of the few remaining Jeniceros in La Trinidad serves as a reminder of the common future they share with the forest.... 80

Figure 18 Tropical dry forest of La Trinidad. .82 


\section{Revolution of an ecology}

Throughout the past century, the well-being of Nicaragua's citizens has been largely entwined with the ecology of the environments amongst and upon which they have lived. Together, they have survived poverty, repression, exploitation and degradation throughout the Somoza Dictatorship and the demands of the international commodities market. In spite of their parallel marginalization, together they revolted, both politically and ecologically, in the government coup of 1979. Nicaragua's Minister of Culture in 1986, Father Ernesto Cardenal I, said of the Sandinista Revolution in 1979, "Not only humans desired liberation. The entire ecology cried for it. The revolution is also for lakes, rivers, trees and animals” (Faber, 1999:45). Unfortunately the revolution of 1979 failed to materialize its goals of an "ecological democracy," but in the aftereffects of Hurricane Mitch in 1998, the people and the ecology once again rose to voice their needs.

\section{Marginalization of the people and the ecology}

The Sandinista Revolution and subsequent Contra War $^{1}$ continue to have much influence over Nicaragua's identity. From 1939 to 1979, the Somoza Dynasty dominated Nicaragua's policy, military, economy, abundant natural resources and social capital for the personal gain of a privileged minority. This exploitation, supported by foreign interests, was driven by the monetary gains promised by the capitalization and globalization of Nicaragua's markets and resources. Somoza, in partnership with U.S. political and economic support, drove Nicaragua to become a source of cheap natural resources and agricultural products by the late 1950's and early 1960's (Faber, 2002; Walker, 1982). The most fertile agricultural land was assumed as state property and used for driving up revenues, dispersing profits between those with close ties to the Somoza leadership. With centralized control over natural resources, large-scale concessions were granted to international logging firms allowing cut-and-run forestry practices that left Nicaragua’s forests seriously degraded (Castilleja, 1993). Its exportbased economy drove the annual gross national product average to $\$ 800$ U.S. per capita by 1979, though profits hardly reached the lower economic classes (Walker, 1982). Campesinos were forced onto marginalized lands as Somoza instituted economic and

\footnotetext{
${ }^{11}$ Rebellion against the Sandinista government that led to a civil war throughout the 1980's.
} 
land tenure policies benefiting a diminishing minority, with few options but to employ farming techniques that augmented deforestation, soil erosion and general land degradation (Cupples, 2004). Though the rural and urban proletariat had historically shared neither political nor economic power, revolution brewed as the bourgeoisie, too, began to lose their land (Equipo Envío, 1984). On July 19, 1979, with 62 percent of the population living in poverty (Hawkesworth and Pérez, 2003), the Sandinista National Liberation Front (FSLN) led a mass revolution overthrowing the Somoza regime.

\section{Changing role of ecology in Nicaragua}

Making up only half a percent of the Earth's land mass, Nicaragua contains seven percent of the world's biodiversity within an array of ecosystems including mountainous semi-evergreen forests, coastal tropical rainforests and scarce tropical dry forests (Hawkesworth and Pérez, 2003; Sabogal, 1992). It is home to the largest freshwater lake in Central America, and is known as the "land of lakes and volcanoes,” as can be seen in Figure 1. Because of its diverse terrain, the landscape has boasted rich agricultural, mineral and natural energy resources. With approximately 2.5 million hectares of tropical

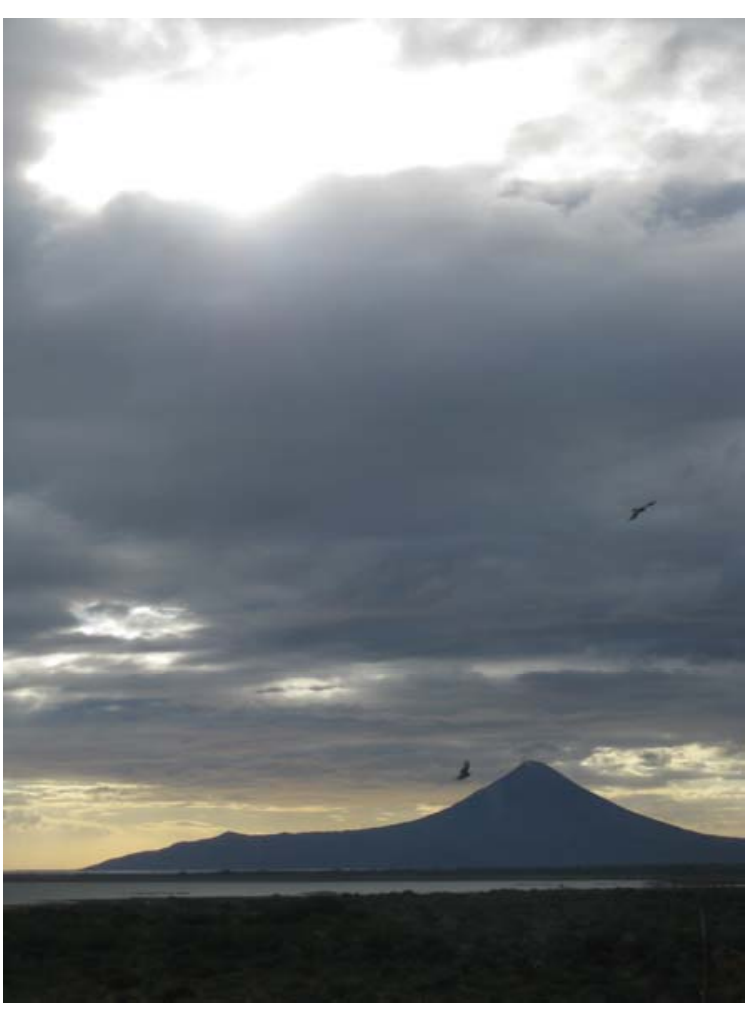

Figure 1 View of Volcano Momotombo and Lake Managua from San Francisco Libre hardwood forests, Nicaragua is home to one of the largest expanses of production forests in all of Central America (Castilleja, 1993). However, Somoza's export-focused economy converted much of the fertile land for livestock pastures and agricultural purposes, growing coffee, cotton, sugar and tobacco cash crops. Between 1950 and 1970, half of the country's forests were lost (Hawkesworth and Pérez, 2003). In the 1970's alone, 30 percent of the nation's vast tropical rainforests were lost to cattle ranching (Faber, 1999). In addition, the agriculture intensive industry depended on chemical pesticides and fertilizers that further depleted soil fertility and resulted in gross 
contamination of the lands and waterways (Faber, 1999; Hawkesworth and Pérez, 2003).

In attempt to address the interrelated environmental, social, economic and political injustices that ultimately resulted in the revolution, the FSLN initiated a series of comprehensive programs aimed at social and environmental justice through national sovereignty and control over natural resources. Faber (2002) argues that the reforms put in place by the FSLN were the most comprehensive programs intended to improve living standards for its citizens and protect its environment that the entire Third World had ever seen. The new leadership abolished Somoza's natural resources concessions system, restructured land tenure, resource distribution and administrative organization granting decentralized power to municipalities, and also achieved environmental successes "unprecedented" in the history of developing nations (Faber, 2002). Ultimately, its reform goals were too vast with too many obstacles, including the U.S. sponsored "Contra” guerilla war and economic collapse. Its drastic policy transformations caused forestry revenue to fall from US \$70 million to $\$ 500,000$ over the first 7 years of the FSLN leadership (Castilleja, 1993). While it was unsuccessful in national development and substantial long-term environmental gains, it established Nicaragua's first national environmental agency and a set of ecological reserves, and planted the seeds for sustainable, decentralized development processes to grow (Cupples, 2004; Hawkesworth and Pérez, 2003).

The ten year span of Sandinista leadership ended with the election of the Chamorro government into office in 1990. Burdened by extensive debt and fiscal shortages from Somoza's corrupt economic policy, Nicaragua ranked the poorest nation in the hemisphere after Haiti. The new government turned to international aid and redirected Nicaragua's economic policies toward the private sector, focusing on agricultural and forestry exports in an effort to stabilize the economy. Cupples (2004) cites in her work on gender, neoliberalism and environmental risk in El Hatillo, Nicaragua the disastrous effects of overexploitation of natural resources coupled with structural adjustment programs. Reversing the land tenure and human rights progress gained throughout the 80's, farmers were forced onto marginal lands again, with little choice but to employ techniques that further degraded Nicaragua's fragile and overexploited land for subsistence (Cupples, 2004). Large-scale logging initiatives resumed. From 1992 to 1995 , the volume of wood exported from Nicaragua rose from $4,650 \mathrm{~m}^{3}$ to 55,390 $\mathrm{m}^{3}$ (Hawkesworth and Pérez, 2003). Fortunately, the foundation laid by the Sandinista 
government empowered grassroots efforts (Hawkesworth and Pérez, 2003) to unite local and national environmental organizations against Chamorro's natural resource policies. A new forestry regulation resulted that granted ownership of the forest to the private landowners and created a new ministry charged with the administration of public forests. The new regulation continued to focus on an export-based economic model, but nonetheless established a set of procedures for large-scale logging operations that emphasized environmental protection and the rights of local communities (Castilleja, 1993).

\section{Developing San Francisco Libre: Trees or people?}

Nicaragua's environmental policies and initiatives range from protectionist, preserving natural resources in reserves, to development-oriented processes that deem natural resources a means of alleviating poor living conditions. However, Nicaragua's rich natural resources have historically served as the foundation of economic activity and rural communities' survival (Barahona, Faurby, andZeledon, 2003), and conservation attempts that do not consider the population's dependency upon local natural resources ultimately fail (Wilshusen, Brechin, Fortwangler, andWest, 2002). San Francisco Libre is a prime example of the dependence on products derived from the land, forests and waterways, which is now experiencing the consequences an overexploited landscape can have on the environment and the population's quality of life. 


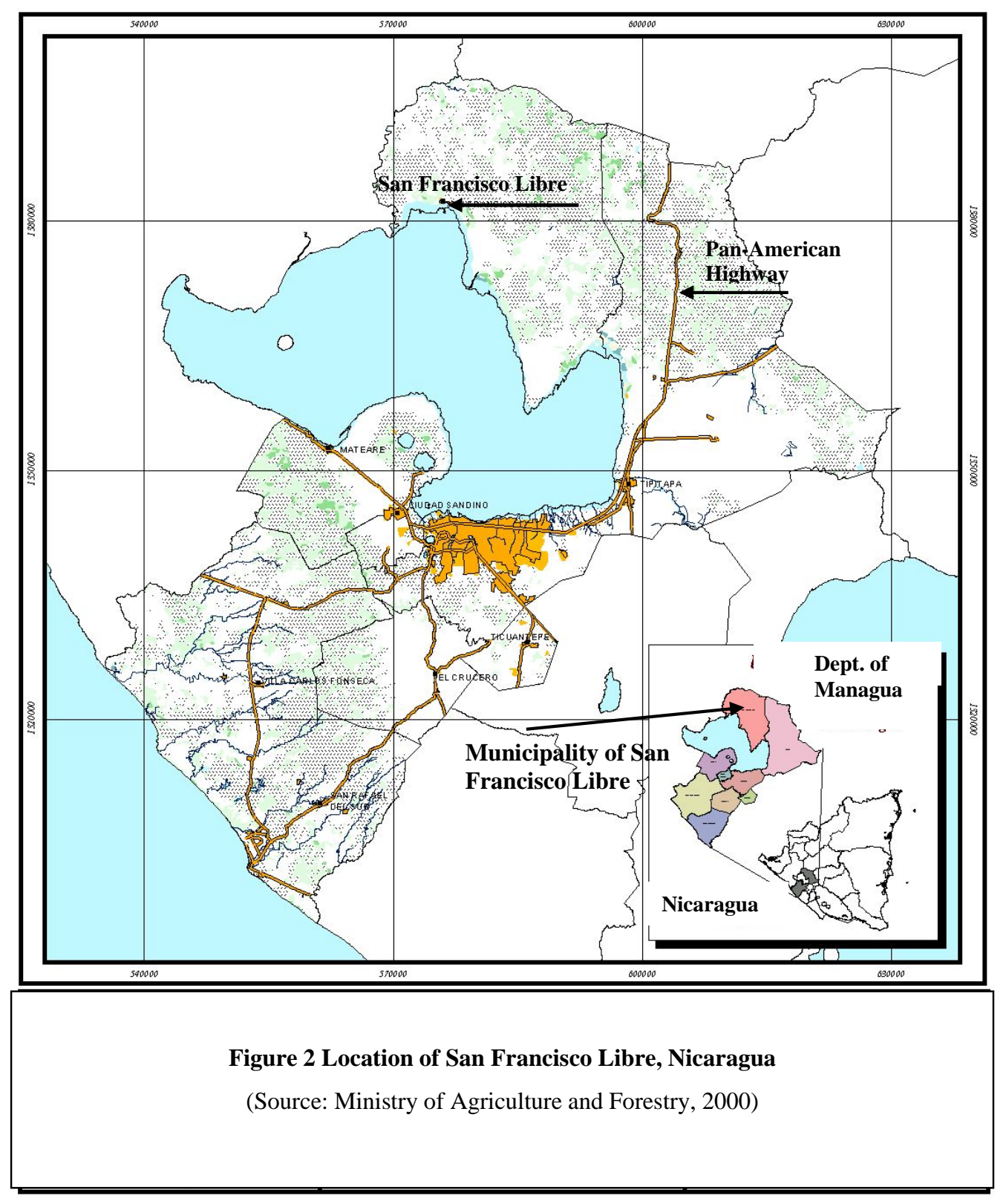

San Francisco Libre is located just 80 kilometers away from Nicaragua's capital, Managua, along the Pan-American Highway, shown in Figure 2. Fluctuating between poverty and extreme poverty levels, a mere 4,800 people of its over 10,000 inhabitants are economically active. A rural municipality, it has a low population density for the region with just 14 habitants per square kilometer. In the first half of the $20^{\text {th }}$ century, what is now the municipality's urban center, coined El Puerto or The Port, served as a port to transport goods to Managua, to the south of Lake Managua. With the demographic and consumer growth of Managua and the construction of the PanAmerican Highway in 1945, the town was forced to refocus its economy on forestry 
products, cattle raising, and large-scale cotton and coffee production (Alcaldía Municipal de San Francisco Libre, 2003; INIFOM, 2007; Rocha, 1999).

The abundant dry forests were over-exploited as major sources of convertible land for its growing agro-economy, wood for fire, poles and timber, as well as hunting (González-Rivas, Tigabu, Gerhardt, Castro-Marín, andOdén, 2006; Hawkesworth and Pérez, 2003). To date extracting firewood has been San Francisco Libre’s main economic activity: as much as 15 percent of Managua's firewood consumption is supplied by San Francisco Libre’s forests (Alcaldía Municipal de San Francisco Libre, 2003; INGES-FORESTAN, 2005; Rocha, 1999). As the global markets turned in the 1980's, these local agricultural economies crashed leaving many people unemployed and the land exploited to the point of desertification. Local communities were left to live off the forests for subsistence and livelihood, further degrading what was left of the forests (Carr, Barbieri, Pan, andIravani, 2006; Hawkesworth and Pérez, 2003; Rocha, 1999). According to a Food and Agriculture Organization study, indiscriminate deforestation resulted in a drop in rainfall, temperature increase, reduced crop yield and the evaporation of shallow rivers (Rocha, 1999). Not only had the majority of its once vast natural resources been depleted, but its population began to emigrate because of the catalytic effect widespread deforestation had on the loss of economic alternatives and desertification of the land.

\section{Recognizing the social in "natural” disaster}

In addition to the country's political and economic instability, the region's exposure to extreme natural events has hindered the municipality's efforts to raise its population out of poverty. In November 1998, Hurricane Mitch's rains and subsequent flooding and landslides killed thousands and decimated decades of investment in infrastructure and agricultural lands (Rocha, 1999). An estimated five thousand acres of San Francisco Libre's pasture and agricultural land were inundated by the nearly four meter water level rise of Lake Managua. The municipality's people experienced gross losses to their prime sources of survival: 88 percent of reforested areas, 85 percent of its corn, 70 percent of its sorghum, 80 percent of its bean and 100 percent of its sesame crops. In addition, 2,800 head of cattle, 4,000 pigs and 10,000 chickens drowned (Rocha, 1999). 


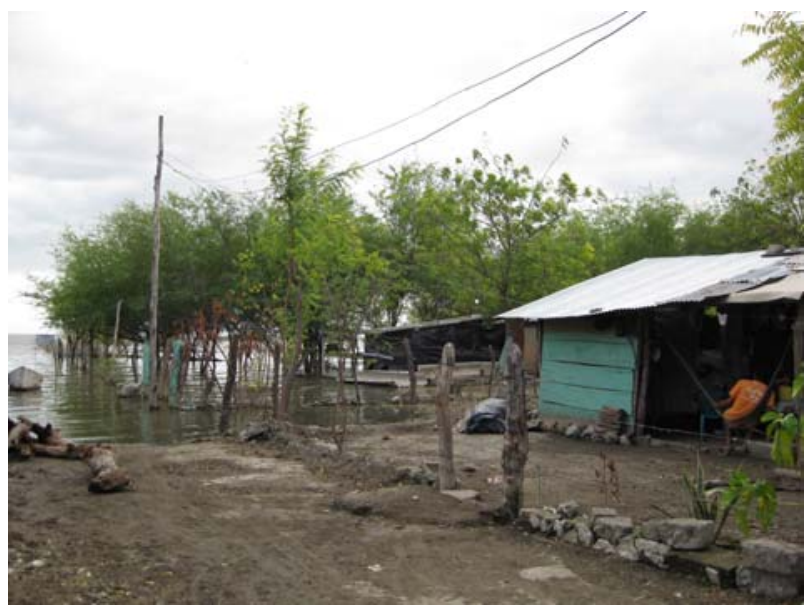

Figure 3 Lake Managua's increased water levels still encroach lakefront homes $\mathbf{1 1}$ years after Hurricane Mitch
The devastation caused by Mitch, with Figure 3 portraying its still present aftereffects 11 years later, magnified the municipality's political, social and economic weaknesses (Alcaldía Municipal de San Francisco Libre, 2003). However, "without people there is no disaster” (O'Keefe, Westgate, andWisner, 1976:566). As I will show throughout the chapters that follow, the negligent social, economic and political practices

carried out over the years created the space for these natural events to become disasters (Hinchliffe and Woodward, 2000; O'Keefe, et al., 1976; Rocha, 1999). Deforestation and soil degradation intensified the impacts of natural events, prolonging droughts and amplifying floods and landslides. For the same reasons, agriculture is no longer a substantial economic alternative for most people, further driving deforestation as their only economic resource. Political upheaval and economic difficulty left the people with few resources to prepare for these events, let alone to properly respond to them.

\section{Power in community associations and networks}

A double-edged sword, Hurricane Mitch brought with its chaos an influx of NGO aid and, in San Francisco Libre, a better understanding of its vulnerabilities. It provided the opportunity to build a more solid foundation based on the same socially and environmentally focused development principals once emphasized by the Sandinista Revolution. Before Mitch, the region struggled to cope with central governmental structural and policy changes, discontinued credit schemes and other investment programs supporting human capital, and the often lackluster efforts of NGOs. The mayor saw an opportunity for the municipality to start anew (Rocha, 1999). Subsequently in 2000, the mayor's office began a process of community-level administrative restructuring, that created a network of community leaders modeled on the Sandinista use of public organization as a strength. This process, carried out by a series of consultations and workshops within the municipality's 33 communities, 
resulted in the Integral Municipal Development Plan, or PID ${ }^{2}$. Recognizing the inextricable link between human development and natural resources, as well as the disparaging state of the municipality's natural systems, the PID called for a new management structure in the form of communal, regional and municipal committees, the generation of alternative sources of employment, and a better framework for reducing environmental vulnerability through the protection and sustainable use of San Francisco Libre’s natural resources (Alcaldía Municipal de San Francisco Libre, 2003). Subsequently, local NGOs with local and central government support worked to educate and train local actors, including a total of 202 families throughout nine communities, encouraging citizen participation in the conservation of and use of forests (INGESFORESTAN, 2005).

\section{Outline of Thesis}

Throughout the chapters that follow, I will detail San Francisco Libre's path and its citizens' experiences in the administrative restructuring undertaken by the municipality. Using a poststructural, co-constructivist framework, this thesis will show how it was not merely a political or social initiative, but co-created by the very relationships between the people, institutions and the environment it attempts to regulate. To better understand the workings of power in decentralized forestry initiatives, various works on actor network theory will be used to account for relevant actors and how they influence, and are influenced, by these relationships.

The new structure of administration, based on the FSLN's model of "mass organization," follows the school of thought that decentralization and devolution of decision-making power is the most effective means of conserving natural resources (Charnley and Poe, 2007). Community forestry initiatives experience the host of obstacles cited by literature because the technocratic paradigm many decentralization initiatives follow do not account for the diffuse nature of information, knowledge and power creation and sharing. Calling upon influential critical political ecology works and actor network theory scholars, I show how the unpredictable, dynamic network of influences in the experiences of San Francisco Libre made power an equally unpredictable, dynamic process that could not be owned, but shared and exerted through interaction amongst stakeholders, both human and non-human.

\footnotetext{
${ }^{2}$ Integral Municipal Development Plan is referred to as PID, or Plan Integral de Desarollo
} 


\section{Social dichotomy, natural commonality}

There is a big difference between the isolated nonhuman tree that falls in the forest, and the object tree that falls in the forest to smash in the head of the idealist confronting the realist in a pub across from King's College! What can we say about the former? That it falls, and falls by itself. Nothing more, nothing less. It is the second that responds, polemically, to a conflict of power over the respective rights of nature and politics. Only the object finds itself engaged in the conflict of loyalty between the new pope and the new emperor - not the nonhumans. Nonhumans deserve much better than to play indefinitely the rather unworthy, somewhat vulgar role of object on the great stage of nature... The social world is no more made up of subjects than nature is made up of objects. (Latour, 2004:51)

\section{Natural resource management}

Throughout time, people's livelihoods, cultures, societies and economies have depended on the services and resources, for lack of alternative vocabulary, provided by the earth. We have used them for our growth and well-being. As populations grew, markets developed, technology improved and demand for these resources and ability to exploit them grew exponentially (Dietz, Ostrom, andStern, 2003; Mitchell, 1997; Ostrom, 1999). As a result, many of the world's natural resources have been severely depleted, periling the natural systems that maintain these resources. Ever apparent in the 1960’s and 70’s, the environmental movement was born from developed populations concerned by the effects human consumption had on natural systems (Shellenberger and Nordhaus, 2007). The World Commission on Environment and Development (WCED) ${ }^{3}$ assembled a report concluding eminent ecological disaster should the threshold of resource use and population growth be surpassed. It recognized the inevitable change imposed on ecosystems by economic growth and development, but called for a new, "sustainable" manner of using these resources to relieve consumption pressure

\footnotetext{
${ }^{3}$ World Commission on Environment and Development: Our Common Future. United Nations report convened in 1983 to address the accelerating deterioration of the human environment and natural resources and the consequences of that deterioration for economic and social development. It explicitly recognizes a common good and future of humans and nature, taking one of the West's first political steps away from the dichotomous man-nature paradigm.
} 
(Mitchell, 1997; Shellenberger and Nordhaus, 2007). However, the institutions, or social organizations or patterns of behavior, used to address the problem have largely been cited as the fundamental failure in effectively preserving natural resources and their ecosystems services (Dietz, et al., 2003; Vatn, 2005). As I will show in more depth in the following chapters, prominent scholars including Bruno Latour and Arturo Escobar underscore the lack of recognition within modern paradigms of the commonality of humans and nature and the inherent unpredictability and dynamism of all natural systems.

Natural resources are primarily considered common-pool resources (CPR), as exclusion of users is difficult, and therefore difficult to govern their use (Ostrom, 1999). Similarly, there are high costs regulating access to forests, though they are highly depletable. Lack of conventional markets for their services and resources and inadequate ownership rights furthers overexploitation. (Acheson, 2006; Bellamy, Walker, McDonald, andSyme, 2001; Vatn, 2005). The mainstream environmental answer to this problem has been natural resource management (NRM), which attempts to harvest natural resources only to a point that allows the long-term survival of the resources and their services (Ostrom, 1999). Presumably, all stakeholders benefit if the destruction of the resource can be prevented. However, traditional CPR theory suggests that people often act without consideration of the bigger picture, leading to disastrous outcomes for the environment and the collective of beings that depends on it (Acheson, 2006; Ostrom, 2002). There is commonly international pressure on developing regions, such as San Francisco Libre, to conserve natural resources and their ecosystems, but also pressure to use forests products to drive development and improve its citizens' quality of life. Unfortunately, achieving both goals simultaneously has proved elusive (Carr, et al., 2006; Dahal and Capistrano, 2006; Taber, Navarro, andArribas, 1997). Protectionist schemes pit humans as destructors of the land, and integrated conservation development projects and community-based natural resource management ${ }^{4}$ are often seen as a way of exploiting local people, as well as a way of exploiting natural systems (Brechin, et al., 2002).

In addition, it fails to address whether we can truly know or manage the vast array of networks and interactions that take place in ecosystem processes. NRM, largely a

\footnotetext{
${ }^{4}$ Integrated conservation development projects (ICDPs) and community-based natural resource management (CBNRM) are an attempt to better address the social and political factors involved in conservation efforts, seeking "increase the development options of resource-dependent rural communities as a means of increasing nature protection.” (Brechin, Wilshusen, Fortwangler, andWest, 2002)
} 
Western concept, is underpinned by a technocratic paradigm, focusing on maximum utility and management of natural resources by humans, rather than holistically considering the web of factors influencing the effectiveness of a practice. For example, efforts using non-native, fast growing trees often have consequences as non-native species can overrun their new habitats or, conversely, do no flourish (Wunsch, 1999). We must subsequently ask of any NRM effort: what are the objectives of resource management, and who is granted power to regulate the use of resources? Three primary models are typically followed when addressing stakeholders, rights and power in NRM: including private property, state or government management, and local community management (Acheson, 2006; Vatn, 2005).

\section{Private property}

Regulation of the use of forest resources by granting individual ownership is often the mainstream method found in capitalist, democratic societies. This model is based on individual incentive to preserve one's property to ensure future profitability, as there is theoretically no risk of the resource being depleted by others (Acheson, 2006; Vatn, 2005). However, as the potential environmental consequences of privatization have become apparent, depletion has been far too common even in private property models if the regeneration rate of the natural resource is lower than the profit from harvesting it today. The often long time horizons forests need to regenerate make it "rational" to overexploit privately owned forests as the money invested in their conservation would gain much more from investment in other industries. In addition, uncertainty in environmental and economic conditions drive up the short-term value of a resource (Acheson, 2006), as in the case of San Francisco Libre where extreme environmental and weather patterns and economic pressures drive people to employ whatever means necessary to survive.

\section{Government}

Governments have effectively regulated many common property systems, and have shown promise in such conservation efforts as state parks and reserves. Conversely, many centralized regulation systems have not only failed to preserve natural resources, but themselves have caused tragedies due to corruption and ineffective bureaucratic practices which make it difficult for equitable consideration of all involved stakeholders (Acheson, 2006; Ostrom, 2002). 


\section{Community}

(Dietz, et al., 2003). The WCED promotes devolvement to local level actors and institutions because of their proximity to and knowledge of the resources. Local level, or bottom-up, approaches have the potential to solve the issue of legitimacy that topdown programs struggle to achieve because of insufficient consideration of local conditions, cultures, knowledges and/or norms In addition, it creates the opportunity to simultaneously promote equality and democracy (Acheson, 2006; Mitchell, 1997). Since the 1970's, NRM efforts have largely transitioned from focusing on a central regulation to community-based models that actively involve local people by transferring decision making power over local resources (Charnley and Poe, 2007; Dahal and Capistrano, 2006). In the following section, I will explore the goals, strengths and weaknesses of community-based models.

\section{Decentralization, devolution and democracy}

Community-based forestry resource management (CBFRM) has both conservation and development components, striving for ecologically sustainable forest use to provide local communities with economic and social benefits, such as distribution of decision making power, from the forests. Decentralized NRM has gained acceptance as state and private-regulated resource systems prove ineffective, particularly in developing countries where central governments have failed to conserve biodiversity and ecosystems or address people's needs and priorities (Dahal and Capistrano, 2006). Recent shifts in Latin America from colonial institutions historically rife with overexploitation of people and landscapes are now focusing on community-based natural resource management, or CBNRM (Larson and Soto, 2008). Theoretically, transfer of control to local level people facilitates more equitable distribution of benefits from the use of the resources and attempts to ensure that local knowledges and abilities are considered in the sciences and technologies employed (Acheson, 2006; Charnley and Poe, 2007; Tacconi, Siagian, andSyam, 2006). Dependent on the variables of the location of where the interaction takes place, it can help to increase the validity of local knowledge and acknowledges the influence of local people (Allen, 2004; Hesse-Biber and Leavy, 2004). 
In addition, decentralised resource management is argued to be more efficient than centralized governance. Local institutions are likely to become aware of and react much faster to environmental events and symptoms than, for example, centralized or socially detached ones (Vatn, 2005). Centralized governance can be very costly, where as employing locals for vigilance and enforcement can considerably cut costs. As local individuals are more intimately involved in social dynamics and networks, there is increased recognition of a broad range of stakeholders, including non-traditional or potentially marginalized individuals. Subsequently, property rights and illegal encroachment issues are more easily addressed. As the laws are, in theory, generated by the people, political relations across national, regional and local levels can often more effectively address stakeholders' needs, facilitating normative legitimacy and political stability (Charnley and Poe, 2007; Larson, 2002; Tacconi, et al., 2006).

However, the characteristics of natural resources and the relationship humans have with them make NRM a complex, context specific field, with the eco-socio-politicaleconomic situation playing a large role in the success or failure of an initiative (Larson and Soto, 2008). Decentralization's limitations in practice include failure to transfer decision-making power, insufficient funding, accountability problems, political and administrative organization inefficiency, regional inequities and conflict between stakeholders and various government levels (Dahal and Capistrano, 2006; Larson, 2002; Tacconi, et al., 2006). Also, there has been insufficient recognition of inherent diversity in communities (Charnley and Poe, 2007), underscoring a fundamental weakness in traditional CBNRM frameworks. The often static, universal models do not sufficiently account for the complex and dynamic nature of communities and other social structures (Steins, 2001).

Decentralization theory assumes democratic involvement and that all participants prioritize sustainable use of forests (Tacconi, et al., 2006). On the contrary, in areas with high levels of poverty, often survival subsistence takes precedence over concern of future resource availability. Drawing from Maslow's Hierarchy of Needs ${ }^{5}$, Nordhaus and Shellenberger (2007) account how environmental values and action arise in postmaterialist societies where the fundamental needs of shelter and security have been met. Many developing nations are struggling to fulfil even the most basic needs of their citizens. In addition, decentralization does not always result in full devolution of power

\footnotetext{
${ }^{5}$ Suggests that there are five hierarchically organized classes of needs, each level of physiological, security, belongingness, esteem and self-actualization as a prerequisite to the next. (Mathes, 1981)
} 
and equal benefits of natural resource management among all stakeholders (Charnley and Poe, 2007; Fisher, 2000). Devolution of power over low-value forest products, such as non-timber products, is much more common than the authority handed over with GDP raising timber products. To maintain control over natural resources, those in positions of power strive to prevent any real transfer of decision-making authority, or even increased central authority (Bellamy, et al., 2001; Larson and Zeledon, 2004; Raik, Wilson, andDecker, 2008). The "participation paradox" notes the irony in emphasizing local level participation and bottom-up empowerment in schemes which are decided upon by top-down processes (Quaghebeur, Masschelein, andNguyen, 2004). It is important to account for power dynamics, as well as involve actors across all scales to best incorporate the complex needs of multiple stakeholders and to improve chances of success on both community and environmental fronts (Larson, 2003).

\section{Participation and power}

Literature often explicitly distinguishes decentralisation from devolution, or democratic decentralisation. Decentralisation is typically a "transfer of responsibility from central authorities to lower levels in a political-administrative and territorial hierarchy” (Larson and Soto, 2008:44), whereas democratic decentralisation is a transfer of power and responsibility to lower-level governments. According to Fisher (2000), the level of involvement decentralization facilitates is on the lower rungs of Arnstein's Ladder of Participation (Arnstein, 1969), where Figure 4 below outlines how participation is granted not to foster sharing of decision-making resources but as therapy, manipulation, or even a form of tokenism informing, consulting and placating local individuals. 


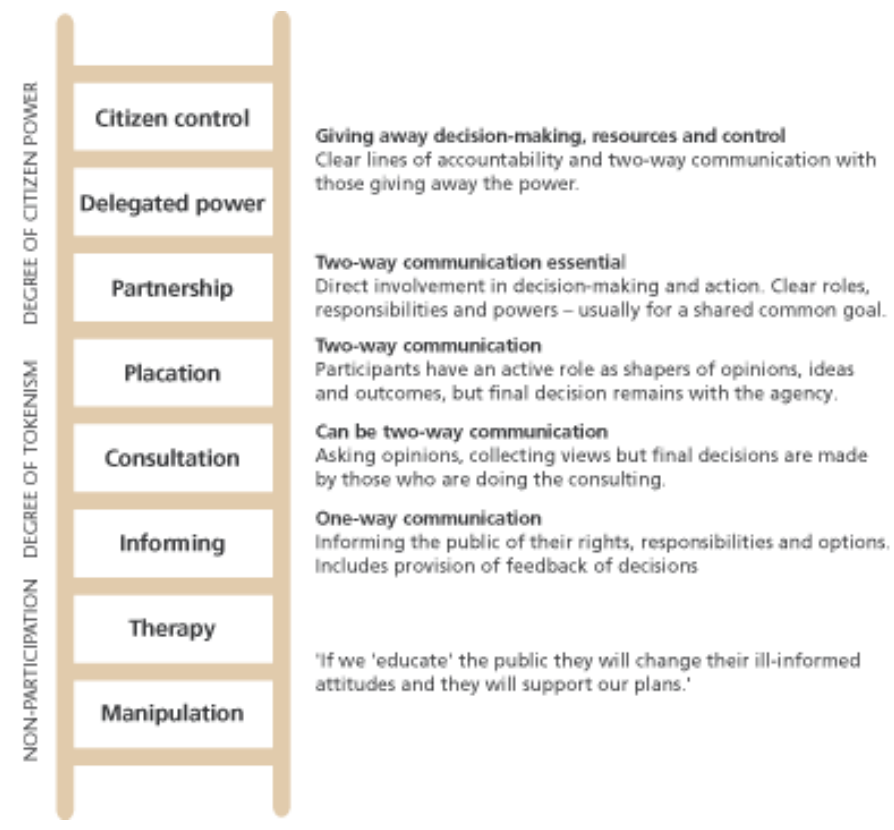

Figure 4 Arnstein's Ladder of Particpation. (Source: Forestry Commission Great Britain, 2009)

NRM is dominated by a focus on the use of technology to best manipulate resources, often for the benefit of those with technocratic knowledge and to the disadvantage of certain involved groups, making NRM fraught with power struggles (Fisher, 2000; Larson, 2003; Tacconi, et al., 2006). In instances where power is decentralized, though not democratically devolved to communities, inequitable distribution of benefits and creation of local elite is common. Social structures, values and preconditions can be influential in the ways inclusion of stakeholders is carried out and natural resources are managed (Raik, et al., 2008). However, power is never owned, but rather exerted through interaction (Allen, 2004; Latour, 2005). Though there has been much focus on the importance of technical capacity of natural resource management, little has been achieved in improving interactive capacity among stakeholders in collaborative arrangements. Throughout these failures, two major interrelated weaknesses include lacklustre policy and the inability to bridge policy with on the ground events (Dahal and Capistrano, 2006).

So what makes a decentralization initiative successful? A host of studies cite the importance of accountability of all actors involved, that the issue of subsistence and livelihoods is properly addressed, that capacity and resource building is sufficient and a sense of trust is established (Acheson, 2006; Charnley and Poe, 2007; Dahal and Capistrano, 2006; Larson and Soto, 2008). For it to be a truly democratic process, the top-down initiatives need to be met by a lower-level demand and creation of playing 
fields for local-level involvement (Larson and Soto, 2008). As subtle cultural norms are often less obvious than formal political structures, involving all actors assists in integrating already legitimate local structures and norms rather than forcing people into new hierarchies and rules. A sense of ownership, particularly if the project is initiated from the community members themselves, often results in higher success rates. (Dahal and Capistrano, 2006; Fisher, 2000).

Acheson (2006) underscores the need to recognise resource management institutions as part of complex socio-environmental systems, and that success depends on the interplay of various involved factors. Variables can be subtle, but the lack of one can be influential enough to result in the success in one community and its existence resulting in the failure in a community only 30 minutes away (Charnley and Poe, 2007). Too often processes and power are seen as linear and something to be controlled and possessed, but there needs to be more consideration of the emergence of power through interaction among actors in a given context. As each involved actor brings different objectives, resources, knowledge and skills to a CBNRM effort, research on the ways power is exerted among stakeholders and its effect on interaction is needed in on-theground cases that can help merge theory and practice (Larson, 2003; Raik, et al., 2008).

\section{Towards a more comprehensive account of participation and power}

Earlier, I highlighted the need to ask "What factors will be considered?" and "Who should be included in the decision making process?” Traditional political economy has been the primary framework to address such questions, but fell short because of its technocratic view of nature as a resource to serve people, insufficient consideration of subtle factors and positivist assumption of being able to know and predict nature. Environmental issues have had a disproportionate effect on the Third World, giving CBNRM a reputation for unreliability and calling attention to the hegemonic decision making processes often employed (Bryant, 2001; Castree and Braun, 2001; Quaghebeur, et al., 2004). Scholars began to highlight the questionable boundaries between nature and society and politics, and more specifically the social factors that contributed to the devastation occurring in extreme natural events like Hurricane Mitch (Bryant, 2001; Faber, 1999; Hinchliffe and Woodward, 2004). Political ecology arose from post-structural scholars attempting to better analyze socio-political, economic and environmental power relationships around issues like deforestation where causes and 
prevention efforts were simultaneously local and international (Charnley and Poe, 2007). Political ecology's focus to more critically understand actors and institutions in NRM magnified the debate between natural realists and social constructivists.

\section{Theoretical and epistemological dualisms - real or social nature?}

Understandings of nature determine the roles and values assigned to it, and ultimately how it is used (Demeritt, 2001; Nightingale, 2006). The realist, positivist understanding of a universal nature that can be known through objective scientific study is disputed by post-structural, social constructivists, who call upon the political nature of science and knowledge, and the inability to see nature outside of our social perspective (Asdal, 2003; Castree, 2003). Social constructivists argue that nature's attributes and potentials vary for different communities and societies, its uses depending on respective values and needs (Castree and Braun, 2001). Frameworks not acknowledging the social construction of nature are seen as intellectually and politically limited by not accounting for the bias of science's and policy's often technocratic knowledge base which can skew the values placed on human-environment relations.

Contrary to science's claim of objectivity, values and ethics are inherently entwined in environmental science. Poststructural works draw attention to the political incentives in NRM, seeing science as "knowledge by and for those with vested interest" (Castree and Braun, 2001:3). Young (1990:118) quotes Bookchin's explanation of NRM as a search for means "so that we can ravage the Earth with minimal effects on ourselves." Social constructivism has been applauded as a tool to expose the vested interests which attempt to invoke the idea of a pure, universal nature to justify new economic, social and ecological power arrangements (Castree and MacMillan, 2001).

Social constructivism has conversely been denounced as a slippery slope negating the physical reality and autonomy of nature from societies, and downplaying human responsibility for ethical treatment of the earth and its resources. However, a purist approach to a static, essential nature assumes humans' ability to know its thresholds or limits to growth, and is subject to the use of this "natural law" as an instrument of power and domination, as is sometimes the case in Third World conservation areas (Castree and Braun, 2001; Ivakhiv, 2002; Latour, 2004). Subsequently, it becomes impossible to distinguish "between the balance achieved by nature and that contrived by man [sic]" (Demeritt, 2001:28) Nonetheless, both positivists and constructivists hold an anthropocentric view of nature. On the opposite end of the spectrum, eco-centric 
theories claim relevance by placing a higher intrinsic value on the earth, striving for a pure, balanced Earth without the devastation caused by humans. Even James Lovelock's Gaia Theory that includes humans as biological constituents of the wider global ecosystem, views the earth as a pristine, pure environment upon which humans have come to infringe (Castree and MacMillan, 2001).

Dualisms are increasingly viewed as counterproductive in science, policy and NRM. Even amidst constructivist attempts to blur boundaries between society and nature, it has proven difficult to achieve and implement a truly non-dichotomous framework (Castree and MacMillan, 2001; Ivakhiv, 2002). Traditional political ecology has attempted to study how society, politics and economy affected the environment, but failed viewing each as separate, pure entities, rather than emphasizing the reflective, non-dichotomous, relationship they have (Hinchliffe and Woodward, 2004; Latour, 2004) and the diffuse scales at which discourses on property rights, control and power take place (Nightingale, 2003).

\section{The problem with dualities: blurred boundaries and static categories}

An era has been born where "nature is less natural than at any time in human history" (Castree and Braun, 2001:19). While ecology was initially intended to understand how any given organism related to its surrounding environments (Asdal, 2003), Forsythe (2003:268) cites political ecology’s “failure to acknowledge this mixture of scientific prediction and ideological ecologism" and "has led to a variety of environmental explanations and policies that do not address the biophysical complexity of many long term environmental changes in many locations around the world, or diverse institutional bases in which environmental problems are experienced." As a result, a rift has emerged between academia, natural sciences and social sciences.

This rift is problematic as human practices and processes have evolved in such a way that they are neither purely natural nor cultural, with "natural-technical-social-discursive hybrids” ozone holes and genetic engineering (Ivakhiv, 2002; Murdoch, 2001; Rudy and Gareau, 2005). Latour (1993b:6) describes these entities as "simultaneously real, like nature, narrated, like discourse, and collective, like society.” Understanding and addressing such "hybrids” requires interdisciplinary understanding of the processes and forces that go into creating them. Unfortunately, the divide between social constructivism and natural realism, and likewise the natural and social sciences, risk the 
domination or negation of valuable perspectives of each paradigm. To account for its weaknesses, Castree and Braun (2001:225) argue for a paradox paradigm that recognizes universal and relative truths that can be simultaneously contradictory and true. A critical approach is needed that abandons fixed equilibrium perspectives and recognizes processes’ dependence on a range of influences (Forsythe, 2003). Forsythe goes on to quote Watts and McCarthy, "there is surely need for a more social relational understanding of natural science itself (of the institutions of science and scientific regulation)... including a sensitivity to what one might call nature's agency or causal powers” (2003:22)

\section{Actor network theory: a relational understanding of non-duality}

According to Bruno Latour (2004:22) "political ecology... has not yet grasped either its own politics or its own ecology.” Dualistic perspectives often employed fail to recognize the co-dependence of nature and society, or the existence of "naturescultures" and "socionature" (Asdal, 2003; Latour, 1993a). By recognizing the instability of the categories and identities upon which many politics and practices are based the practice of ecology can realign with its roots, accounting for varied natural connections between organisms and their environments. Humans and non-humans perpetually co-construct nature and society, or "natures-cultures," creating the need to move into a sort of “critical political ecology” (Staddon, 2009). Haraway’s work with apes (1992) and Latour's (1993a) account of the microbes in Pasteur's petri dish expand the idea of participation in scientific discourse to include non-humans. Quoting Rouse, Asdal (2003:70) highlights that in rejecting the notion of a separate nature is not, contrary to many constructivist arguments, because people cannot see outside of a social reality, but "because we have never been 'inside' one in the first place.” Humans are intrinsically defined in relation to non-human entities (Latour, 1998). Widely accepted by political ecologists for its attempt to bridge the gap between constructivism and realism (Rudy and Gareau, 2005), actor network theory is paradoxically neither anthropocentric nor ecocentric, simultaneously embracing and rejecting constructivism and positivism. It strives to return not to a universal Nature, but natures that co-exist and interact with humans through co-constructed networks.

ANT explicitly attempts to address the nature-culture dualism by employing a counterintuitive view of environmental practices and relationships. A co-constructivist 
framework, it symmetrically recognizes human and non-human actors in a network of interactions which create a range of outcomes and possibilities (Steins, 2001). Recognizing the traditional distinction between society and nature as one with reason and language, therefore agency, and the other subsequently without, it strives to escape predetermined categories and re-describe real-world phenomena (Castree and MacMillan, 2001; Ivakhiv, 2002). To solve the dichotomy ingrained in scientific vocabulary, it employs what Callon and Latour (1992:354) call a "symmetrical metalanguage.” With this new vocabulary, dichotomies are abandoned and neutral “actants”, human or non-human, become integral to building networks that create the real world phenomena that sciences address. These actants "modify, displace and translate their various and contradictory interests" through "chains of translation” and “networks” (Latour, 1999:311).

Actor network theory draws on Foucauldian poststructural framework where knowledge and power are seen as social products (Steins, 2001), and therefore is useful in addressing NRM power discourses. A network, its associated actors and dynamics cannot be understood until they have been observed without presupposed distinctions. ANT rejects binarism, focusing on relations and associations so that things are only definable in relation to other entities. Figure 5 below displays how society, politics, economy and the environment are co-dependent in creating a common nature-society. In doing so, processes become the focal point of understanding the context specific factors of a given network.

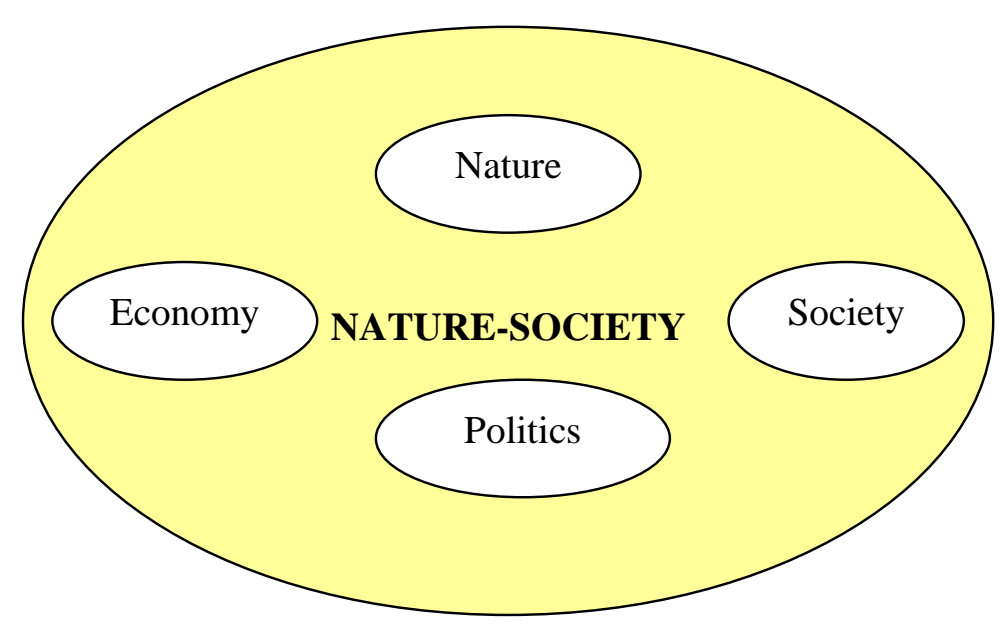

Figure 5 Interdependence of politics, economy, society and environment in creating a nature-society 
Doing away with duality between nature and society, it implicitly removes an asymmetrical focus on one entity or the other, creating a level playing ground where the social and the natural are co-constitutive. Addressing the issue of power centrality and the agency of actants, ANT considers all entities socio-natural networks in their own right, assigning each agency regardless of exhibited intentionality or speech. Castree and MacMillan (2001:213) discuss how "agency is a relational effect generated by.... interacting components whose activity is constituted in the networks of which they form a part.” By rejecting duality, and therefore anthropocentrism or eco-centrism, power is not inherently granted to either camp, but instead an "interintentioning" is played out between humans and non-humans (Staddon, 2009). Power becomes seen as an interactive achievement, being able to "enroll, convince and enlist others on terms which allow the initial actors to represent the others” (Castree and MacMillan, 2001).

\section{Power, agency and subjectivity - Opening up to a more inclusive democratic participation}

Incorporating actor network theory in the analysis of community-based sustainable forestry projects redefines the framework through which to understand democratic decentralization in developing nations. Democratic decentralization inherently reshapes power structures and processes, often reallocating value given to specific knowledges or sources of knowledge. ANT recognizes that scientific knowledge is not an a priori source of power, but should in itself require explanation through the processes and factors that create it. Redefining such power structures requires that one address what agency entails (Asdal, 2003). Defining something as "nature," or that which is not “social” or "cultural," often abandons any notion of agency or inherent power of nature, as political and social decisions are made for nature by those with the ability to communicate interests with language (Asdal, 2003; Ivakhiv, 2002). Whereas natural realists have defined nature as non-social, many "natural" systems and beings have exhibited highly social characteristics (Asdal, 2003; Demeritt, 2001).

Ivakhiv (2002:396) paraphrases Sanders reconsidering agency, “(animals and humans) are inherently potentials of objects, that is, as opportunities for action in the environment of an organism. As such, they can be taken as the 'analytical units of embodiment' making up the 'entire universe of potential action' for a situated actor.” Furthermore, that which is an object to something may also have objects of its own, creating a range of possible interactions between subject and object. These objects and subjects work in networks where the natural and the cultural are co-dependent and 
intertwined (Ivakhiv, 2002). Latour (1999:192) writes, "purposeful action and intentionality may not be properties of objects, but they are not properties of humans either. They are the properties of institutions...” The question is not whether a nonhuman "acts" or even "intentions," but what is the nature of the relationships of the processes in networks that give rise to “intentions” and “acts” (Staddon, 2009)?

True to the Foucauldian concept of power, ANT is a network-created effect, not something that humans wield over non-humans (Rudy and Gareau, 2005). Ultimately, "action is not done under the full control of consciousness; action should rather be felt as a...conglomerate of many surprising sets of agencies that have to be slowly disentangled” (Latour, 2005:44). In his study of mushroom collection in Bulgaria, Staddon (2009) found that the use of local knowledge of natural resources was intimately tied to the success and sustainability of a harvest. Both cultures and ecologies are in a constant state of flux, being remade through the change through the interaction between the two over time. Callon (1986:203) explained, “The simultaneous production of knowledge and construction of a network of relationships in which social and natural entities mutually control who they are and what they want”.

Both acclaimed and criticized for its agnostic take on science, actor network theory sees its "politics of impurity" as a solution where no entity is granted ethical nor agentic priority over another (Castree and MacMillan, 2001). Many argue complications arise when the dynamics between various actants in a network are over-simplified, insufficiently recognizing actants' varying degrees of agency. Castree and Macmillan (2001:222) argue that while agents are relational, power to influence others is often disproportionate where some actants "marshall the power of many others." Nightingale (2006) points out how considering non-human actors within relational networks significantly complicates the ability to understand processes when even human actors' agency are asymmetrical. It would be more useful to focus on where people draw the boundary lines between themselves and that outside of themselves. Nonetheless, by taking a weak approach of ANT, one can simultaneously recognize the agency of both human and non-human actants and the difference in scale of agency between them.

Turning to ANT as a form of critical or poststructural political ecology can help to shed light on how environmental knowledges and initiatives are created and entered into the realm of politics, or used as a form of agency and power (Staddon, 2009). Marginalized groups' power and autonomy have historically been muted through their association 
with nature (Asdal, 2003; Castree and MacMillan, 2001). Asdal (2003:67) quotes Latour, "Feminists have shown how the process of identifying women with nature played a key role in creating a context that legitimized their lack of political rights.” This is of concern particularly when one is confronted with interaction between societies and cultures with different notions of nature and community. Though the Western paradigm, and subsequently many CBNRM efforts, has been founded on the dichotomy between nature and humans, this concept is inapplicable to societies that do not perceive the division between the two (Ivakhiv, 2002). Therefore, especially when dealing with communities embedded within "natural environments," one might consider that denying the influence and agency of nature in creating environments and realities, results in nullifying the source of power of human actors whose knowledge is based up on a relationship with the "natural" when participating in decision making processes. Emphasizing the validity of such actors' knowledges and the right and duty to participate as citizens, encourages higher levels of participation, more responsible citizenry, and subsequently more effective initiatives (Lerner and Schugurensky, 2005). The expansion of participatory arenas, such as forest spaces, is essential in prioritizing participation in governance and including diverse political actors (Cornwall and Coelho, 2007).

\section{Conclusion}

This chapter has shown with theoretical works that by denying the inherent agency within nature, modern, technocratic institutions walk a fine line of denying the agency of marginalized peoples and communities. From the ground covered by the scholars and theorists cited, I will delve into a case study of community-based natural resource management initiative in rural Nicaragua where the boundaries between the natural and the social and the discourses around power are difficult to clearly delineate. We will see the often unpredictable nature of interactions amongst diverse range of actors and factors involved in ICDPs and the difficulty that arises when the opportunities created by these interactions between humans and non-humans are not allowed for in a flexible, context-appropriate manner. 


\section{Interacting networks of methods and methodology}

Throughout this chapter, I will outline the importance of the use of both theory and context in the creation of knowledge by calling upon actor network theory and grounded theory. I will show how this not only applied to my research, but also in the co-creation of research potentials as this very thesis topic materialized.

\section{Grounded theory and the importance of context}

A number of poststructural critical researchers recognize the importance of both general theory and empirical research in generating knowledge. Castree and Braun (2001) explain that theory is essential because it seeks to question conventional understandings and practices regarding nature, but theory can become irrelevant if it lacks direct connections to real world events. Schools of thought recognizing social and political phenomena as influential factors within conservation and environmental management have given rise to the interweaving of social and earth sciences, validating the use of qualitative methods in the field of natural resource management (Brechin, et al., 2002; Kellert, Mehta, Ebbin, andLichtenfeld, 2000). As the previous chapter just began to address, in a world full of natural-social "hybrids" any methods that set out to understand the world through a dichotomous lens will often provide faulty explanations. Traditionally, qualitative, non-statistical, methods are often used when studying reciprocal effects between individuals, organizations, laws and larger social processes, whereas quantitative research aims to remove the subjectivity inherent in understanding causal relationships involved with the complex, systemic nature of community-based natural resource management schemes (Gerring, 2007; Stake, 2003; Strauss and Corbin, 1990). Case studies have increasingly been accepted as a viable research method when researching human phenomena, as gathering empirical data based in real world events can often shed more light on a phenomenon than abstract theory and literature (Gillham, 2000).

However, some researchers argue that methodological rigor in case studies is not on par with the standards of other research styles (Gerring, 2007). Case studies are often 
criticized for the inevitable subjectivity of personal interpretation in qualitative fieldwork, seen as a flaw by more realist-based disciplines. Conversely, grounded theory establishes a methodological standard to which some would argue generates more empirical, factual data and theory. This subjectivity emerges at the forefront of the strengths of constructivist grounded theory. It recognizes the relativism of varying social realities in that the creation of knowledge is a reflexive phenomenon where the observer is also observed, supports interpretation of experiences, and ultimately the ability to understand contextual variables (Charmaz, 2003). Charmaz (2003:254) explains, “ a fundamental premise of grounded theory is to let the key issues emerge rather than force them into preconceived categories.” The methodology involved leaves the review and application of theoretical approaches to the last step to allow a more organic relationship between the researcher and the data. As data collection and analysis occur simultaneously in a grounded approach, the appropriateness of initial research interests and emerging themes are constantly reevaluated, allowing the researcher to pursue more salient issues at hand. As many poststructural scholars would agree, systems can exist within systems of varying sizes, negating the validity of hierarchical order, making it important to acknowledge the interactive relationship of the variables within a specific case. Latour (2004:25) notes how just as the dam can affect the snail's ecosystem, so too can the snail block the dam. Researchers subsequently need a comprehensive understanding of the nature of the case, its historical background and setting, relevant stakeholders, and important economic, political, religious variables to be able gather information about what make a case unique (Stake, 2003). As information specific to the site of my research, San Francisco Libre is not widely available, site specific field research was necessary.

Another critique of case studies is that they cannot be used to generate universal theory because they are limited in time and space, and cannot be a perfect representation of a population. For researchers such as Strauss and Corbin (1990), theory is the ultimate end of research, negating case studies' focus on context specifics. However, one of the main benefits of conducting case studies is its emphasis on what a single case can teach about important variables and causal relationships that influence a larger phenomenon (Gerring, 2007; Stake, 2003). According to Foucauldian theory, generalized theories have failed to understand the specificity of local social dynamics (Seidman, 2008). While the specific community-based forestry initiative in San Francisco Libre is significant in potentially explaining the varied results in integrated conservation and 
development projects (Carr, et al., 2006; Taber, et al., 1997), the lessons learned from this case study can be by no means used to generalize theory for all other cases. Instead, what I will provide a thick description and framework of patterns and commonalities in my findings of participants' experiences in the specific context of San Francisco Libre, showing that the relationships are fundamentally affected by their position in time and space. As Stake explains (2003, p. 142) “qualitative case researchers orient to complexities connecting ordinary practice in natural habitats to the abstractions and concerns of diverse academic disciplines.” Creating a shared social stage where examples of typical models of people and things are established is purely subject to the researcher's typification, or connection of common, enduring elements (Marshall, 1998). The issues brought to the forefront of a case study and how they are presented are chosen differently according to the researcher (Stake, 2003). As such, the field influenced the direction of my research and thesis as much as my own will.

\section{Choice of theory and epistemology: symmetry and non-dualism}

Scholars who have engaged with political ecology have called for a framework of understanding which does not ontologically privilege factors by taking for granted predetermined knowledges, institutions and categorizations. Staddon (2009) concludes that more "open-ended" ethnographic research into forest network activities is needed to help to understand what a more symbiotic relationships between humans and nonhumans entails. For many of the aforementioned political ecologists, actor network theory, even with its shortcomings, is a viable starting point. The work around ANT has helped researchers to re-evaluate anthropocentric perspectives and the roles of nature and other non-human actors. Subsequently, the workings of agency in any given exchange need reconsidering (Forsythe, 2003). ANT at times blurs the boundaries between human and non-human actants to the point where one could almost conceive of

them as interchangeable. However, the relationship is symmetrical, not interchangeable, just as various human actors are in a business agreement (Rudy and Gareau, 2005).

Its co-constructivist, poststructural framework is ideal in breaking free of traditional power discourses to understand causal relationships between variables (Steins, 2001). In doing so, it seeks to address four fundamental short-comings of traditional political 
ecology: duality of nature and society, asymmetry in the prioritization of involved actors, included stakeholders and centralized conception of power (Castree and Braun, 2001). Much of the political ecology work attempting to take the field one step further in "taking nature seriously" (Staddon, 2009) have failed to escape the dichotomy trap, for numerous reasons including language shortcomings (Murdoch, 2001). In addition, while it claims to protect nature for natures sake, much of its justification is based on the well-being of humans (Latour, 2004). Actor network theory has set out to create a neutral vocabulary and methodological tools that inherently avoids implicit dualism and a priori distinctions. Latour and other ANT contributors including Law and Callon avoid the words "nature," "society," "and environment," and instead use words such as networks, actants, hybrids, imbroglios, nature-society or nature-culture where translations, or relations between entities, result in a range of possibilities (Ivakhiv, 2002; Latour, 2005).

In addition, as is done in critical research approaches such as the grounded methods I have employed, ANT attempts to allow typifications and relationships to emerge from the research field, with an explanation emerging only once each network or actant has been observed (Castree and Braun, 2001; Murdoch, 2001). Murdoch (2001:126), mirroring Latour, states that a researcher of actor-networks should be "as undecided as possible on which elements will be tied together, on when they will start to have a common fate, on which interests will eventually win out over which.” By doing so, actants are enabled to be identified so that "agency is a relational effect generated by... interacting components whose activity is constituted in the networks of which they form a part” (Whatmore, 1999:28).

However, creating a level playing field for human and non-human actants is difficult to achieve when not in a controlled laboratory. Castree and Macmillan (2001) note that in traditional ANT, it is difficult to gain understanding of general processes as everything is overly contingent upon practical application. They suggest using a diluted form of ANT that accepts that established variables between similar networks need not always be different. Nonetheless, ANT in its varying forms holds promise in addressing and understanding variables in natural resource management efforts as it abandons rigid frameworks based on static rationality (Steins, 2001) that exists in juxtaposition to the constant evolution of both society and nature (Nightingale, 2003). ANT is a valid approach to examine the sustainable community forestry initiative in San Francisco 
Libre because it allows me to recognize the influence of each actant and the importance of contextual variables. Ultimately, recognizing the subjectivity of a number of actants acts as a reminder that there can be no positivist understanding of success, rather looking from each perspective helps to account for various goals and objectives (Law and Mol, 2002). Its inherent relation to ecology, or the study of an organism's relationships with its surroundings, recognition of how associations can change stakeholders' involvement and the co-constructivist paradigm make it an ideal framework with which to understand, or establish, the links and relationships between entities in sustainable community forestry networks (Murdoch, 2001).

\section{Topic and research site selection}

In the infancy of my thesis, I was still very new this level of academic and what factors needed consideration in conducting research. I had no idea of how difficult it can sometimes be to find a research project that is both feasible and is sufficiently interesting to spend a year researching it. I soon learned it was not simply a matter of finding a salient topic that interested me, but about the resources, networks and contacts available to carry out field research in another country, much less a developing country. After fruitlessly pestering any university staff who might have been able to support my aims in a topic related to natural resource use in urban Latin America, I was in the eleventh-hour put in contact with my now co-supervisor, Julie Cupples, a senior lecturer at Canterbury University. In the eleventh hour of topic selection, thinking I would have to abandon my topic, she gave life to what I'd relentlessly, yet until then fruitlessly, pursued. San Francisco Libre, Nicaragua: a small town on the shores of Lake Managua where I could address “community forestry combined with local government and NGO involvement and the development of a grassroots movement all in a somewhat complex political situation” (Cupples, 2008). She explained that access to communities and necessary contacts would be relatively simple considering her history and involvement in Nicaragua, particularly with INGES $^{6}$ who was actively involved in the forestry initiative in San Francisco Libre.

Even when the major obstacles seemed to have been overcome, new issues emerged as administrative issues and other considerations came into play, dangling my topic in

\footnotetext{
${ }^{6}$ Instituto de Investigastiones y Gestión Social, or Institute of Investigations and Social Management, based in Managua.
} 
sight, yet still out of reach. Fortunately, Victoria University of Wellington (VUW) was generous enough to accommodate my topic and field research in Nicaragua. While it was a source of personal stress, it was ironically appropriate in the way it underscored my naivety in academia and research and in the complex interplay of a range of factors and actors in carrying out my research, both reoccurring themes throughout my research.

\section{Positionality and reflexivity}

Recognizing the range of factors that affected the viability of carrying out research in San Francisco Libre and employing grounded methods as my fundamental approach of research, as much by default as intention, it is important that I outline not only what contextual variables influenced my research, but also personal ones. Rose (1997:308) points out "positioning is... the key practice grounding knowledge." Positioning impacts the topics one chooses to study, who is considered a source of knowledge or participant, the questions asked, the methods used, how its analyzed and how it is communicated (Hesse-Biber and Leavy, 2004). Researchers often address how colonial power, gender and class identities affect the outcome of their research and theory. While these factors are significant in my positionality, my identity as a new researcher was crucial in my choice of theory, methods, methodology. This being my first experience in the field, I was constantly reevaluating, and often struggling with, my role, preferences and validity as a researcher. Lacking a preexisting bank of experience and knowledge of theory and methodology, I allowed the field, networks and resources available to me to determine the specifics of my research.

In hindsight, this has had both positive and negative effects. On the one hand, it opened me up to whatever information and opportunities arose in and out of the field. The humility that is inherent in the role of a novice and learner is unassuming and nonthreatening, often encouraging trust and openness from participants. Not knowing what to expect, I did not have set expectations of what would or should happen in the field and often resorted to allowing my participants and networks to determine who would take part in interviews and what would be discussed; grounded theory in essence. While I would argue that it leveled the power relationship between myself and my participants, possibly even giving some of my participants the upper hand, conversely, this potentially put me in the position to unknowingly promote the methods and 
standpoints of the organizations through which I did my research, namely Victoria University of Wellington and INGES. Pursuing a masters in Environmental Studies, yet researching a topic that walked a fine line with Development Studies, I self-imposed a certain amount of pressure to ensure that my research would resonate with my program focus, wanting to redirect conversations to explicitly address deforestation rather than recognizing less-obvious, yet implicit connections between the relationships participants' had with the forest and their personal experiences. In one interview with the community committee of La Trinidad, participants were sharing their experiences in working with the government on some priority issues. Many of these issues involved infrastructure and health, but I wanted to redirect the topic to the environment and forests. In retrospect, it was salient although they weren't directly talking about their relationship with or regulation of the forests, but in having a better holistic view of what is important to the community members and how the institution of communal governance played out. INGES was the facilitator in providing me with a network in San Francisco Libre. The INGES technician and field coordinator in San Francisco Libre, briefed me on the municipality's background and the progress to date of the cooperative forestry project, and introduced me to many of the participants in my research. As such, the existing power relationships between NGO and community level organization played a role simply in the selection of participants, as well as my starting knowledge base.

My female and foreigner identities were also salient, having both positive and negative influences in my research and ability to best understand the culture in San Francisco Libre. Often called “chela”, a nickname for Caucasian females, by those who did not know me personally or by name, it was easy to get a sense of local citizens' perception of me. At first, many thought I was working with an NGO bringing aid. While this initially facilitated meeting people, it ultimately was a hindrance in gaining the trust of certain stakeholders involved in the cutting and sale of wood. One woman who was intimately involved in the supply chain of wood from the forests was at first very interested in talking to me, as many Nicas are with foreigners, but as soon as she found out that I wanted to know more about her business selling wood, she was frightened to speak with me. We had decided on a time to speak more in-depth, but she never showed up. Though I had explained that I was a student, only once I had become better known and trusted throughout the community, did she attempt to get in contact with me. Unfortunately, I never was able to meet with her as I was leaving within days, as the 
informal nature of making arrangements to meet can often take days to come together. No matter how warmly I was received or how much I was able to assimilate into the community over the three months I spent in San Francisco Libre, I was ultimately a chela.

As a young female, I was seemingly less intimidating to many citizens, and even caused some, particularly men acting on the machista cultural etiquette, wanting to be more helpful. Many men in authoritative positions were very keen to platicar, or chat, with me and introduce me to others for interviewing. However, as those involved in the project and the cooperative were mostly male, the majority of people interviewed were male. At times, being a chela in machista, male dominated surroundings, proved very intimidating. Cupples (2002:384) addresses how the "erotic subjectivity of the researcher” impact the research process. Throughout my time in San Francisco Libre and Nicaragua in general, for many of the men I did not know on a personal level, I was clearly a sexual object of interest, often enhanced by my exotic white skin. However, there were many honest, well-intentioned men who truly made great contributions to my time and research. In one instance, I was informally invited to chat with a carpenter involved in the cooperative one day the following week. It took me three separate attempts before I was brave enough to walk to the back of the workshop where they worked as I knew there were a number of men that I was not familiar with and was very intimidated. While this instance resulted in one of my most rewarding interviews, there are a number of other occasions where I potentially missed valuable opportunities to learn of unique perspectives because of my timidity around Nicaraguan men with whom I was not familiar.

\section{Methods}

\section{Data collection}

I employed a combination of data collection tools including semi-formal interviews, participant observation, and the use of local and national government and NGO documents, as well as immersion in Nicaraguan life. Following a purely qualitative grounded theory approach to research methodology, much of the research and informal data analysis was done simultaneously, helping guide interviews and interactions with participants (Charmaz, 2003; Strauss and Corbin, 1990). The entirety of the field data 
was collected from January through March 2009. I spent the majority of my time residing in the urban center of the municipality San Francisco Libre, but spent time in the community La Trinidad, as well as taking day trips to the communities Pacora and Laurel Galán for interviews, all small communities within the municipality of San Francisco Libre as located on the map in Figure 6 below. My research also took me to the capital, Managua, where many relevant NGOs and government ministries were located, including INGES.

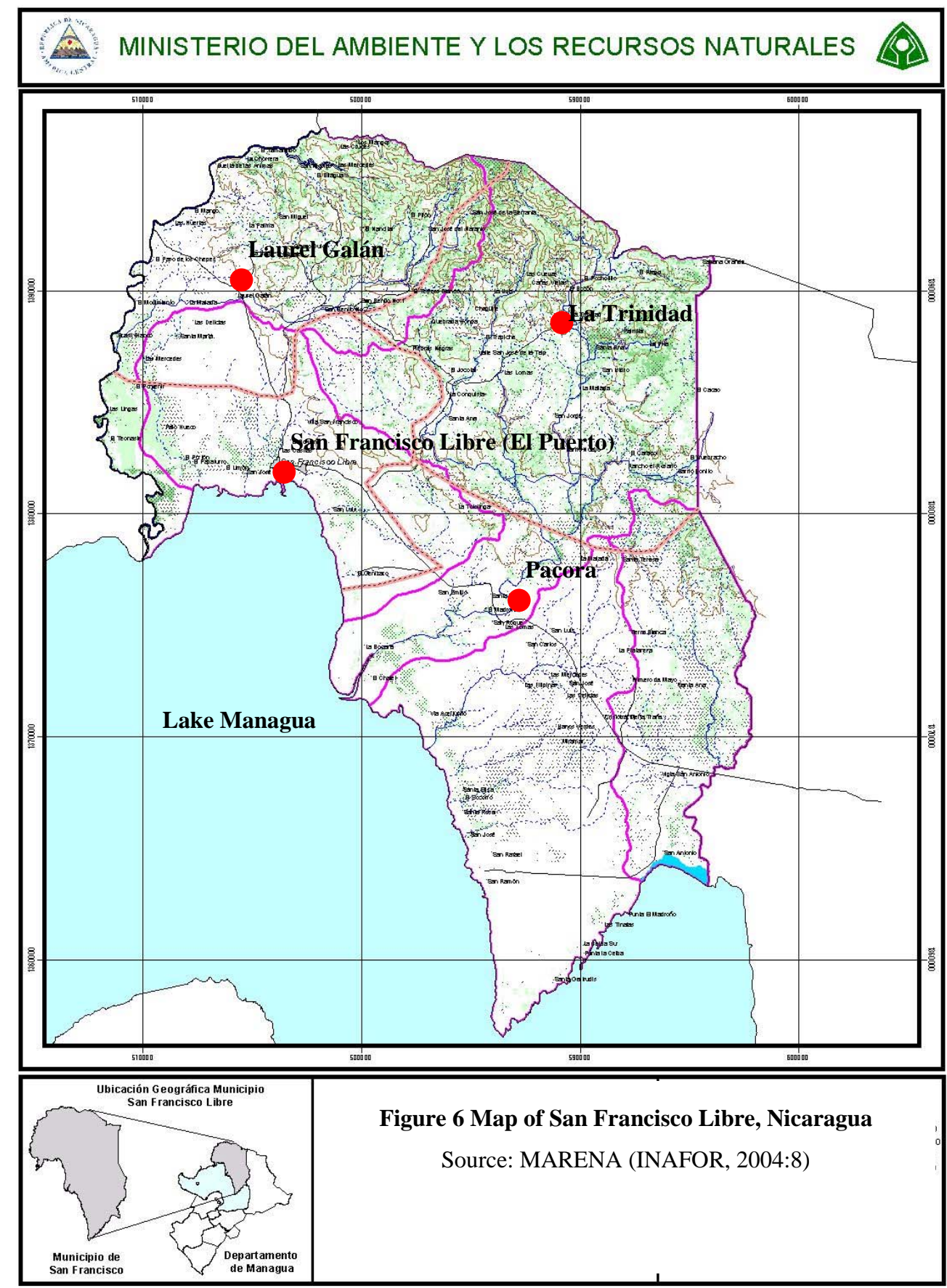




\section{Interviews}

The primary source of information in my research is twenty informal, non-structured interviews with a range of NGO employees, community leaders and citizens. In line with grounded methodology, I continued interviewing participants until I achieved “information saturation," where salient themes and messages become redundant, are similar to those in previous interviews and essentially no new information is gained (Charmaz, 2003; Hall and Hall, 2004). The common method of choosing participants was through the snowball effect, with each new participant connecting me to several more. All interviews took place in the San Francisco Libre's urban center, El Puerto, or communities of La Trinidad, Puerto Viejo, Pacora and Laurel Galán. Most interviews were carried out individually, but on two instances I spoke with more than one person at a time, including a couple of members of a forestry cooperative and a group of La Trinidad's community committee members.

\section{Table 1 - Interviews Cited}

Alberto Chaperno, El Puerto, 5 March 2009

Daniél Chiquirin, Pacora, 10 March 2009

Community Committee, La Trinidad, 23 January 2009

COPROFOR, La Trinidad, 25 February 2009

José Cornizuelo, El Puerto, 24 February 2009

Enrique Escobillo, La Trinidad, 23 February 2009

Javier Guazimo, El Puerto, 10 March 2009

Ana Madroño, El Puerto, 15 January 20090

Antonio Melero, La Trinidad, 23 February 2009

Alejandra Nacascolo, El Puerto 17 February 2009

Maria Palanca, El Puerto, 5 February 2009 
Cristiano Quebracho, Laurel Galán, 17 March 2009

Mario Sacuanjoche, La Trinidad, 22 \& 23 February 2009

Marco Talalate, El Puerto, 9 March 2009

Many of the participants were those centrally involved in community governance, relevant NGOs or government institutions. San Francisco Libre has very poor infrastructure and roads, making access to outward lying communities and remote individuals difficult. For example, the time I spent in La Trinidad was carefully planned as the only bus going from the urban center left at four in the afternoon, arriving at five in Las Lomas, from where members of the community La Trinidad would have to walk at least an hour into the dark evening along a rocky, dirt road as there were no buses that went directly. The only bus returning to the urban center left at Las Lomas 3:30 in the morning, which would involve leaving La Trinidad at two thirty in the morning along the same path by foot. Walking this path in the dark as a young foreign woman without a guide or host, not knowing the land or the route, would be imprudent, and as such my travel was largely dependent on the coordinator of the community committee, who was also kind enough to welcome me into his home, his family, and his forest.

While I gained invaluable information from the individuals I interviewed, had I better been able to reach out to more remotely located individuals, it is very likely that I would have found very different perspectives, as community inclusion and cohesion seemed to be influential in environmental and community values. However, allowing local citizens to introduce me to other members of the community allowed those most invested in the initiatives at hand to decide what experiences and knowledge were relevant. In addition, employing semi-structured interviews, I would often initiate conversation, but allow individuals to discuss what they felt were important when the conversation and rapport allowed. By doing so, one can acknowledge the reflexive relationship between researcher and participants in qualitative interviews, negating positivist approaches where the participant is often viewed as passive and powerless (Hall and Hall, 2004). At times, individuals were not as communicative and a more structured question and answer format was required. I did not employ methods such as surveys as I felt they would be too impersonal and contradictory to ANT's attempts to avoid predetermined categories and issues of importance. 


\section{Participant observation}

One of the most informative ways of learning about the subtleties of Nicaraguan culture and values was through immersion in the life of the communities where I carried out research. Residing in the urban center of San Francisco Libre, I developed relationships with local citizens, with whom I spent many candle-lit evenings chatting around the table, waiting for power to return. Through these more personal relationships, I learned about more subtle relationships with the land and view of the environment. Kearns (2005:192) notes “observation is fundamental to geographical research,” as it involves more than observing but also "touching, smelling and hearing the environment, and making implicit or explicit comparisons with previous experience.” I also was included in a number of committee and cooperative meetings where I observed the topics addressed, the tone of the conversations and the manner which they dealt with problems. However, as a foreigner my participation was always limited.

\section{Documents}

A range of local and national government and NGO reports and documents have been useful in understanding the normative context and the framework under which the forestry and cooperative project was initiated. All documents are written in Spanish, and at times needing translation depending on the level of technical difficulty of the vocabulary used in the document.

\section{Table 2 Documents Referenced}

Municipal Diagnoses and Laws:

Forestry Ordenance Plan of San Francisco Libre

Integral Municipal Development Plan

Fomenting Sustainable Forestry Management and An Overall Increase Value for Forest Producers in the Municipality of San Francisco Libre

Norms of Environmental Regulations

Legal Forestry Compendium of Nicaragua, 1998 - 2008

Central Government Legislation: 
Law 40: Law of the Municipalities

Law 217: General Law of the Environment

Law 475: Law of Citizen Participation

\section{Language issues}

Nicaragua is a Spanish-speaking country. Its proximity to the United States and the general globalization of English makes speaking English relatively feasible in its bigger cities, but English is not spoken in San Francisco Libre. Having access to English speakers to ease communication barriers on more difficult topics in the initial phases of my experience in the field would have been convenient. Forestry and cooperative vocabulary is not traditionally addressed in school language courses, nor commonly spoken on the streets of Madrid or the Bronx. Nicaraguan dialect is different than that which I was used to and involved a considerable learning curve to fine-tuning my listening abilities. However, even when in Managua where there might have been someone who understood English, I made a concerted effort to speak only Spanish. Speaking English would hinder my ability to immerse myself in the language and culture of the country. While my ability to understand and to speak Nicaraguan Spanish improved immensely over the three months I spent there, and partly due to, body language and intuition played a large part in understanding subtleties within conversations and colloquialisms, in developing personal relationships. My findings, as any researcher's, were subject to not only personal, but extra-cultural interpretation. As I briefly touched on above quoting Kearns (2005), there is important information to be gained in subtle gestures and practices that are not always explicitly available in words, so I relied learned practices though personal relationships to interpret the meaning as closely as possible.

\section{Ethical considerations}

"Qualitative researchers are guests in the private spaces of the world (Stake, 2003).” My research was aided by a number of generous Nicaraguans who invited me into their lives, communities, homes and families. While it would be considered unethical to provide payment for participation in my research, the sheer generosity of many of the individuals I came to know caused me to wish I had been able to bring something as a symbol of gratitude for their assistance or participation. The level of willingness to be of help was surprising to me, being from a less collective-oriented society, and I often 
found myself in the position where participants or people I met were sharing what they had with me, yet I had nothing to give back. At times, I was able to plan ahead to bring treats for kids, or vegetables and other food items that are unavailable in outer-lying communities when I would spend extended periods in La Trinidad. Others, I was unable to plan ahead as at times opportunities to go out to an outer-lying community sprung up unexpectedly, without the time to bring beverages or candies for the children. In addition, I was very careful to respect the daily lives of the people who invited me into their homes. When possible, I would help around the house washing the dishes, helping shred cabbage for salad or husking maize.

Victoria University's Human Ethics Committee (HEC) guidelines are intended to protect the rights of individuals involved in research. However, the guidelines followed by HEC were decided upon within a universal, static framework, causing some of the requirements to be unviable, or even counterproductive at times. Submission and subsequent approval of predetermined interview questions, as well as an informational sheet formalizing one's role as a student researcher and the rights of research participants, was required before research could begin. Rigid confinement using a predetermined set of interview questions was paradoxical to using a critically-framed grounded methodology. In addition, while the informative documents required by Victoria University of Wellington's HEC were intended to protect individuals' rights, it could not take into consideration cultural variables which make certain interactions or issues ethical or not ethical. Using formal consent forms and paperwork explaining my thesis and my role as a student researcher, would have been counterproductive to establishing an easy rapport with potential participants. Many Nicaraguans prefer a more informal manner of discussion, often apparent in the use of the word platicar, or to chat instead of entrevistar, or to interview. I was very straightforward about the use of a dictaphone to record conversations, and consent to be a part of my research was implicit in their continued participation. However, in keeping with the HEC's concern for anonymity, I gave all participants who have been quoted pseudonyms with tree names found throughout the region as surnames.

\section{Data analysis and presentation}

While I intended to transcribe interviews as they came, it was often difficult due to the unreliable power generation in the urban center and the total lack of electricity in the outer-lying communities. Consequently, much of the interview content was transcribed 
upon my return to New Zealand. This proved useful in refreshing my memory of the interviews as I began to write my thesis and my dexterity with the language had significantly improved from when I first began interviewing three months earlier, better enabling me to transcribe. However, certain interviews proved to be very difficult to understand due to significant background noise of passing wood-fill trucks, screaming carpentry saws or crowing roosters.

Back in New Zealand, the act of transcribing was the beginning of the formal analysis process, allowing me an opportunity to go through the material I'd collected in a removed context, giving me a different perspective. However, coding and close reading, were employed to find underlying messages from the research. While coding, a common technique used in qualitative research, I started by finding basic themes in each line of interview text, continually broadening the perspective to themes within paragraphs, then memos. I was careful to use fractured, segments of data only as a means to think outside of the box to gain a different perspective on potential reoccurring themes, and was careful to use information and quotes only after considering the context in which they were delivered. To preserve the language-bound meaning, the analysis was carried out purely in direct Spanish transcriptions. I have chosen to translate only the sections of data that will be quoted throughout the thesis. No matter what painstaking efforts are made to protect the intended messages communicated by participants, it is inevitable to have some meaning lost in translation as Spanish is not my first language. Writing itself was an important step in the analytical process, even though grounded theory outlines a system where analysis of data precedes application of theory. After an initial coding and close reading of the material, I conducted a review of the literature and relevant theory which helped to contextualize the data and gain perspective on the analysis I'd carried out to date. The photographs included throughout the thesis are personal pictures taken throughout my field research in Nicaragua.

\section{Conclusion}

In retrospect, my familiarization and knowledge of the unpredictable and diffuse workings of networks set in motion well before I began to research actor network theory. My experiences in researching and writing this thesis were a constant reminder 
of the co-creation of relationships, knowledge and events. Seeing how this thesis was influenced by myriad factors that I did not foresee, and equally how much this thesis and those other factors have affected me as a person and a researcher, actor network theory was a most fitting analysis framework. Nonetheless, three months was very little time to adequately pursue all avenues of research, and there are certainly themes I'd like to explore in more depth and people I'd like to speak with again but is not possible as they are on the other side of the Pacific Ocean, a drawback of international field research. However, for the timeframe available to me and requirement constraints, I am confident my analysis depicts the complexity of the situation and how it applies to overarching theory. 


\section{Co-creating context for the "universal law"}

Over the past fifty years, Nicaragua has implemented a series of hierarchical, technocratic laws governing citizens' rights and natural resources in attempt to address the ailing state of its people and forests. Legislation has been based on a static, universal "law" of nature whose equilibrium needed preservation as the base for human development, and failed to gain legitimacy because of their lack of grounding in context and reality. As a result, the people and the forests have been left wanting. Watts (1958:66) writes, "Scientists are increasingly aware of the fact that the laws of nature are not discovered but invented, and the whole notion that nature is obeying or following some innate pattern or order is being supplanted by the idea that these patterns are not determinative but descriptive." By recognizing the diffuse nature of agency, the asymmetrical power afforded to scientific knowledge and hegemonic policy practices can be better shared amongst the range of actors that co-create political legitimacy in the forests of San Francisco Libre.

\section{Parallel vulnerability of the people and ecology of San Francisco Libre}

San Francisco Libre grew as a municipality from the dynamic relationships between its ecology, geographic location, local constituents, and international influences. Originally a small port, it was known as San Francisco del Carnicero, or San Francisco of the Butcher, where a man named Francisco butchered livestock before shipment across the lake to Managua's markets (MOLISV, 1994; Rocha, 1999). With its economy growing internationally by the 1950's, Nicaragua paved the new PanAmerican Highway, connecting Managua with its neighboring countries to the north and south. Its role as a port became redundant, shifting regional livelihoods to meet opportunities and market demand (Rocha, 1999). Taking advantage of the available productive land and relative proximity to Managua and the Pan-American Highway, mass tracts of dry tropical forests were converted for agriculture and lumber (Faber, 2002; MOLISV, 1994; Rocha, 1999). Then President Somoza's export and revenueoriented policy left the land deforested and severely degraded from unsustainable landuse practices. The perpetual degradation of the landscape, as can be seen in the barren landscape of Figure 7, left fewer resources and means of subsistence for the already marginalized members of Nicaragua's population. By the time of the triumph of the 
Sandinista Revolution in 1979, the region's constituencies, both human and non-human, had so deeply felt the burden that San Francisco Carnicero was re-coined San Francisco Libre, or Free San Francisco symbolizing the hope inspired by the success of the revolution (Rocha, 1999).

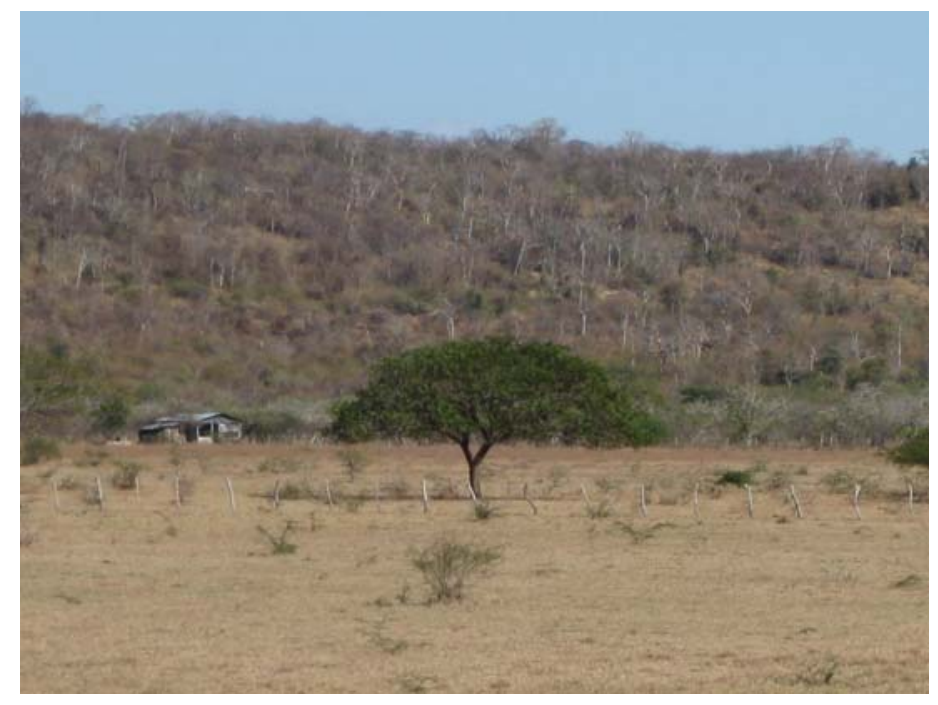

Figure 7 San Francisco Libre's dry landscape

As part of the reforms to establish an "ecological democracy," the Sandinistas implemented the Municipalities Law of 1988. Responding to Somoza's use of municipalities as tools of corruption and repression, the Municipalities Law, Law 40, was passed to reinvent them as a primary space of citizen participation. Echoing Allen's (2004) account of the whereabouts of power being identified by its very location, it designates municipalities as the unified political-administrative base of Nicaragua, and their function to carry out the redevelopment of Nicaragua through citizen participation and popular development. Law 40 declares municipalities autonomous through common election of their authorities, creation and coordination of municipal level administration, and the ability to manage the municipalities' resources. Underscoring the extensive corruption deployed in the commodification of natural resources throughout the Somoza Regime, Law 40 directly addresses the central relationship municipalities and their constituencies have with their natural resources. Furthermore, it expounds the unalienable right of access to common property of the municipality (La Asamblea Nacional de la República de Nicaragua, 1988). 
Despite Sandinistas' attempts, their reforms never materialized. With a complex network of local and international motivations ${ }^{7}$, Nicaragua's population elected the oppostions' Violeta Chamorrro into office in 1990. Though natural systems are immensely valuable as a social and political stage (Thrift, 2000) as the following chapters argue, Chamorro refocused economic policy on forestry as an export commodity to address immense international debt and repercussions from the Contra War throughout the '80's. The new government passed the General Law of the Environment and Natural Resources in 1996 to:

establish the norms for the conservation, protection, improvement and restoration of the environment and the natural resources that it integrates, assuring its rational and sustainable use, in accordance with that stipulated by the Political Constitution.

By public order, it proclaims not only citizens' right to participate, but their duty to protect natural resources and the environment. It declares that the preservation of the “ecological equilibrium” is a common responsibility by both the State and its citizens, and they must work together to most effectively do so. Law 217 requires the state to assist communities' activities which strive for the conservation and sustainable use of the environment and its resources.

\section{Asymmetrical discourses and elusive equilibriums}

Forestry initiatives in San Francisco Libre are centrally regulated by INAFOR (National Forestry Institute) guidelines of an essential state of nature, whose equilibrium can be known and preserved for the highest utility of humans. INAFOR's delegate in San Francisco Libre spoke of the difficulty to find balance between commercial use of resources as a primary supplier of Managua’s commercial grade and firewood and conservation of the forest (Interview: A. Nacascolo, 17 Feb 2009). There is large demand for firewood as it serves as the primary source of home energy in Nicaragua, making up 58 percent of consumption energy and 80 percent of the production of primary energy (INAFOR, 2008). In order for land owners who want to commercially profit from the trees on their land, they must go through a series of requirements to gain

\footnotetext{
${ }^{7}$ For more detailed account of the 1990 election, see: Close, David (1999). Nicaragua: the Chamorro years. Boulder: Lynne Rienner Publishers, Inc.
} 
permission by INAFOR, with a stipulation that they "replace" the forest resource that they extract. To begin, a forest owner must provide documents proving legal ownership of their property along with a form of solicitation explaining what actions he or she plans on carrying out and how they will improve his or her land. An INAFOR delegate then inventories the area's forestry resources to assess whether there are sufficient mature trees for the proposed actions to be considered sustainable, equaling 10 percent or less of the volume of existing trees. For commercial grade wood, inspections generally search for the volume of trees beyond a certain diameter at chest height, and mark those trees that can be extracted with low-impact. Clear-cutting or land-use change is strictly prohibited for commercial use, except in the case of extremely plagued or diseased vegetation. If approved, INAFOR will then allocate a General Forest Management Plan, or $\mathrm{PDM}^{8}$, guiding the landowner on legally authorized methods for sustainably extracting forest resources. PDMs are carried out through Annual Operative Plans, or $\mathrm{POA}^{9}$. Each POA has a time frame of one year that allocates permission for forest harvesting detailed in the initial solicitation form. The PDM and POAs are then entered into INAFOR's national registry. Extracting firewood on a commercial scale also requires permission, with the same solicitation process requiring proof of ownership, inspection, inventory, and designation of PDMs and POAs. Whatever the case may be, when extracting forest resources, one must always "minimize the damage inflicted on what vegetation and trees remain, natural regeneration, soil, bodies of water and all of biodiversity (MAGFOR, 2008:181)." In addition, forest owners must implement forest fire protection techniques, including anti-fire rounds, fire curtains and vigilance against fires (Interview: A. Nacascolo, 17 Feb 2009). While evidence shows that the volume of firewood harvested is considerably larger than the production of serrated wood, the majority of political and economic focus on forest development has been on the production of serrated wood, which is commercially more valuable (INAFOR, 2008), giving weight to McSweeney's (2005) findings that citizens' fear governments’ intentions to preserve resources merely for future profitability.

However, as "power is nothing outside of its effects" (Allen, 2004:10), a report by INAFOR affirms the schism between the daily reality of citizens and the laws governing their resources often highlighted by community forestry analyses (Larson and Zeledon, 2004). Regardless of its attempt to control use of forest products, a mere 0.8 percent of

\footnotetext{
${ }^{8}$ General Forest Management Plan will be referred to as PDM, or Plan de Manejo

${ }^{9}$ Annual Operative Plan will be referred to as POA, or Plan Operativo Anual
} 
the volume of residential and industrial firewood is under central authorization (INAFOR, 2008), highlighting the continued dependence of rural communities upon natural forest products. By 1998, San Francisco Libre had followed such an ad-hoc, reactive approach to pursuing economic opportunities it failed to proactively work with the strengths and weaknesses of the region in mind, leaving the municipality extremely vulnerable to the extreme weather events brought by Hurricane Mitch. Cloke and Pawson (2008) note that trees, no matter how strictly managed, are unruly, affirming Latour's (2000) view that the recalcitrant nature of ecology often makes "shambles of our pretentions of control.” Entire neighborhoods were forced to relocate, settling in and around regions of San Francisco Libre's urban center less prone to floods and landslides.

Scholarship informed by political ecology has often recognized that natural events become disasters once played out through a series of potentials; biophysical processes are given human meaning through personal experience, which can create a sense of disaster (Hinchliffe and Woodward, 2004; Oliver-Smith and Hoffman, 1999). The devastation that resulted from a complex interplay of poor planning, extreme weather events, environmental degradation, and neglected social vulnerabilities highlighted the municipality's weaknesses, and drove the mayor to initiate a series of structural reforms intended to address development and the management of high levels of risk and vulnerability in the region (Alcaldía Municipal de San Francisco Libre, 2003). The initiative resulted in the aforementioned Integral Municipal Development Plan, or PID $^{10}$, which explicitly addresses the social nature of many of these natural risks, and welcomed NGOs to implement projects that would decrease the municipality's socially created risk (Alcaldía Municipal de San Francisco Libre, 2003). It states,

We understand that 'disasters' are not the problem but the effect of the existing conditions of risk.... the result of a dynamic and continuous process, in which the factors of threat and the factors of vulnerability interact. These factors determine risk. Risk is the relation between threat of flood, contamination etc and the vulnerabilities or weaknesses, such as poverty, disorganization, inequalities, etc. As such, risk possesses a social character. (:11)

\footnotetext{
${ }^{10}$ Integral Municipal Development Plan is referred to as PID, or Plan Integral de Desarollo
} 


\section{Highlighting patterns of interactions}

Throughout San Francisco Libre and Nicaragua's history, a dichotomous, technocratic view of nature prevailed, and the forest had often been viewed merely as a resource to be exploited for the use of humans. Yet a much more involved, reciprocal relationship exists between the forest its inhabitants. The interdependence of the people upon the potentials created by the forest and institutionalized by normative frameworks, the forest's dependence on the people and the laws for these potentials to materialize, and laws need to be given meaning and context by the forest and the people shows how these types of processes often are not bottom-up or top-down, human nor nature imposed, but paradoxically each at the same time. Many geographers note the diffuse nature of power dynamics, calling for the recognition of the importance of location in the translation of a process (Allen, 2004; Hinchliffe, 2007; Staddon, 2009). NGOs and the local government played an influential role, but their involvement did not equate universal enrollment of human and non-human stakeholders in their initiatives who are also influential in power discourses, whether through enrolling in or resisting a process. A member of La Trinidad, a remote rural community north of the urban center, lamented oo the outcomes of Mitch and those who continue to abusively use the land and the forest, "He is creating a disaster for himself. Just like we have been affected by natural disasters, because we also had a part in what happened, the disaster that happened (Interview: Community Committee, 23 Jan 2009).”

As Bruno Latour's (1998) work explores in depth, the boundary between human and non-human has become difficult to determine with the dramatic increase of "hybrids" of society and nature. Many of the salient pressures and problems rural communities like La Trinidad experience are prime examples of the social, political, economic, and environmental co-creation of problems such as road access, unemployment, water issues including flooding and non-potable water, health services problems and production issues (Interview: Community Commmittee, 23 Jan 2009). Just as doctors use pigment to highlight blood flow in ultrasound images, these issues highlight the dynamic flow of information in San Francisco Libres’s forest interactions. 


\section{Infrastructure and inaccessibility}

Inadequate infrastructure has long been a problem throughout San Francisco Libre. Looking back to the building of the Pan-American Highway, its economy was affected by the lack of access to the essential artery linking its population to markets and economic alternatives. This separation played a large role in the municipality's underdevelopment, over-exploitation of the natural resources available to them and resultant poverty. Though Managua is only $80 \mathrm{~km}$ away, it is an exhausting, three hour, dust-filled bus ride on the dirt road portrayed in Figure 8 to any employment opportunities San Francisco Libre’s residents might secure in the nation's

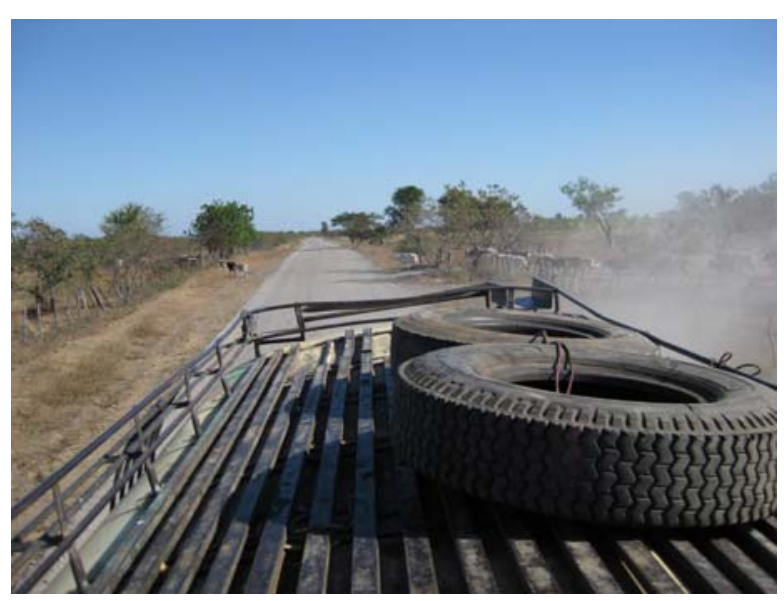

Figure 8 View from atop the bus of the only dirt road linking San Francisco Libre to the PanAmerican Highway capital.

Natural systems serve as a form of security or insurance in the alternatives they provide in the face of nature's dynamism (McSweeney, 2005). Pressured by lack of alternatives to forest-based work, people often either emigrate to other regions of Nicaragua or neighboring countries for work on coffee or cocoa plantations, or turn to the resources they have available to them: the forest. Referring to a dirt road leading to La Trinidad from San Francisco Libre's urban center, which requires a four-wheel drive vehicle to manoeuver, one citizen recalled, "When the government made this road, we came to the edge of the road and looked here at all of the wood, because we didn't know anything, and we would cut trees” (Escobillo, 2009). However, the accessibility stopped with this dirt path. The inadequacy of roads and pathways has partly been due to the dense forest and sloping landscape, partly due to poor municipal financial resources and planning. Once most of the easily-reached forest had been felled, some of the only large, in tact, segments of forest remaining were those kilometers outside of the urban center, including in the hills of La Trinidad. Many participants with whom I spoke attributed the fact that any forest remains are the result of a lack of accessibility and the high cost of accessing remote forests (Interviews: A. Chaperno, 5 Mar 2009; A. Madroño, 15 Jan 
2009; M. Sacuanjoche, 22 Feb 2009). One carpenter recounted how difficult it is to find commercial quality wood that is legal to fell:

(There is) a man who has a lot of property and very beautiful forests, intense forests, but they haven't approved the amount that we need at a certain time, there were some, I think ten or twelve trees that were under the Management Plan. It is very far, and there was a part where we had to walk... like an hour and a half on foot. We harvested it.... But it turned out very expensive for certain because of the distance. (Interview:

A. Chaperno, 5 Mar 2009)

\section{Unemployment and production}

The pressures of subsistence and means to livelihood is ubiquitously seen throughout San Francisco Libre. Many told me they feel pressured to choose between feeding their children or saving a tree (Interviews: J. Guazimo, 10 Mar 2009; M. Palanca, 10 Feb 2009). The cash-crop economies that drove the extensive deforestation that occurred in San Francisco Libre, and elsewhere in Nicaragua, crashed when the international market found alternatives to Nicaragua's commodities. The forest is a major source of subsistence security and both national and household level revenue, with numerous truck loads like in Figure 9 loaded and sold weekly. It has been depleted to the point

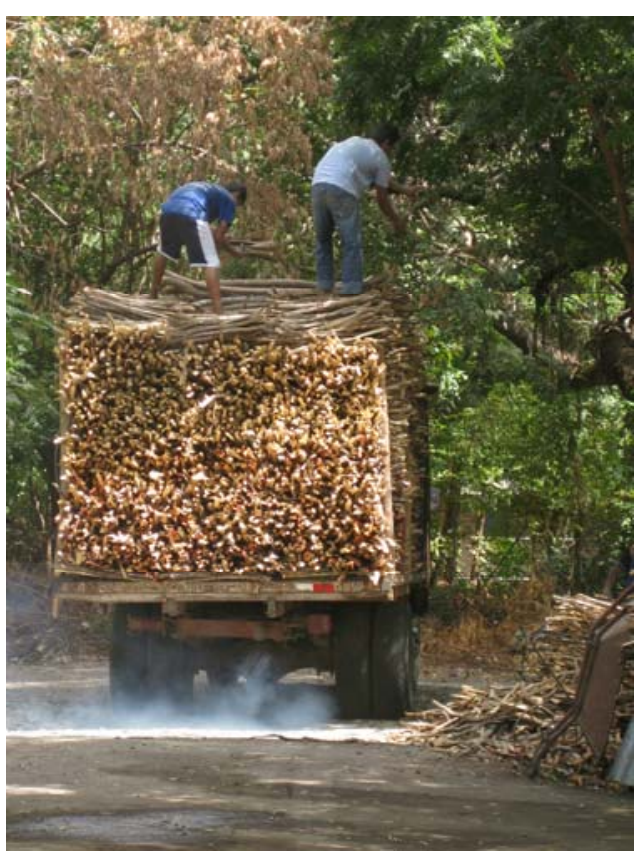

Figure 9 Workers loading the truck with firewood from San Francisco Libre's forests for transport to Managua's markets that it can no longer provide sufficient resources itself, and the deterioration of its processes has negative consequences for alternative means of subsistence and livelihood, such as agriculture. Deforestation and general poor land use practices have resulted in dramatic changes in the climatic cycles and environmental services (Alcaldía Municipal de San Francisco Libre, 2003). Due to soil and land degradation, farmers on sloped lands have had to abandon their harvests as 
a result of flooding and landslides. One of the community leaders explained people can no longer use some of their land for agriculture and the negative consequences associated:

One cannot have a farm in an area with a steep incline, it needs to be somewhat flat. Why? Because these areas, when it rains, all of the land runs downward and reduces every day. The people are poorer for it. The (land) you see over there more or less has been worked and worked for the last 50 years, but three years ago, the owner, stopped working in agriculture and now uses it as a cattle ranch. (Interview: M. Sacuanjoche, 23 Feb 2009)

Large scale deforestation in the region has also led to a notable decline in regular rains needed for a productive harvest, as well as to promote healthy forest re-growth. And while many people have turned to any alternative income they might find, they unanimously agree that at times they have no other option but to fell a few trees. Antonio Melero (Interview: 23 Feb 2009), a resident of La Trinidad, lamented, “It’s a place where there is not one source of work here. A person has needs. Because sometimes you cannot plant nor harvest because of bad winters... it's a very hot and dry zone.” And, when there are good harvests, it is difficult for some to get their products to markets for sale due to the poor roads. Agriculture as a primary means of livelihood has been problematic due to lack of access to markets, unpredictable rain patterns, degradation of soil quality and lack of financing options. For many, working in forestry is a more accessible and certain way means of livelihood (Interviews: J. Guazimo, 10 Mar 2009; C. Quebracho, 17 Mar 2009).

\section{Water issues}

The tropical dry climate of San Francisco Libre, compounded by the negative effect deforestation has had on rain levels, makes the survival of new forest generation and plants precarious at times. San Francisco Libre's climate typically has two seasons: winter and summer. In summer, the region can go months without rain, drying shallow riverbeds like in Figure 10, whereas winter is characterized by excessive amounts of rainfall. However, these natural cycles have become extremely erratic, leaving people's sources of subsistence and income vulnerable to the unpredictability of winter rain 
levels. Trying to manage an "essential" nature makes it extremely difficult for marginalized people to prepare for the ebbs and flows of nature when working within a rigid, modern system that does not focus on the alternatives natural systems can provide.

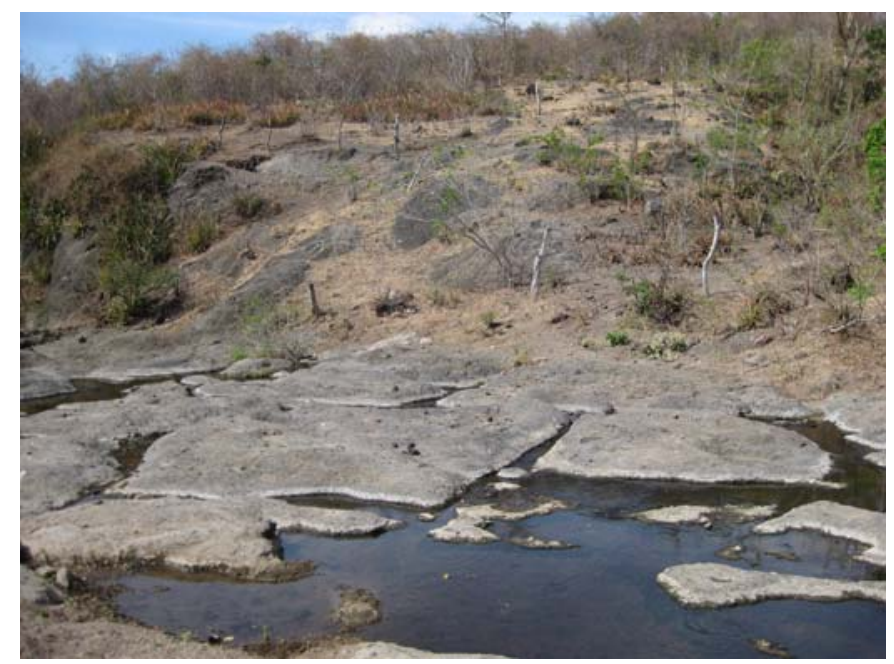

Figure 10 Dried riverbed in an outerlying community of San Francisco Libre

Staddon (2009) describes the invaluable, yet often invisible, processes that natural systems carry out in his account of mushroom harvesting in Bulgaria, implicitly highlighting the futility in employing management techniques based on superficial technical knowledge. Dry years hardly produce enough to store for later in the year, where wetter years bring bountiful harvests (Interviews: D. Chiquirin, 10 Mar 2009; M. Sacuanjoche, 22 Feb 2009). The high concentration of water in the winter is managed and stored by vegetation and trees. The dead leaves that fall from the forest trees enrich the soil, prevent flooding by stopping currents, and result in higher absorption of nutrients and of water. The fertile cap is also a very important player in the environmental services essential for the harvest and new trees to grow, but deforestation and excessive grazing on the fertile cap and other ground level vegetation by livestock have led to the disintegration of this important resource (Interview: M. Sacuanjoche, 23 Feb 2009). Livestock raising has been a primary source of income for decades, but in these times of limited economic alternatives, more people are turning to raising cattle and other farm animals out of need as people like the farmer mentioned above can no longer survive off their harvest. Unmanaged herds of livestock and the lower water absorption by the ground compound the situation by diminishing the water quality of rivers, which supply communities from their sources up in the hills all the way to the urban center of San Francisco Libre, and results in potable water and health issues. 


\section{Striking the hammer to the nail}

Though national laws existed, Nicaraguans often were unaware of their rights and responsibilities in the sustainable economic and human development of their municipality and nation, and the laws struggled to effectively make their practical application clear and effective to the complex forces at play. In an "ecological" approach to ANT where agency is seen to be dispersed through contextual interaction of actors and situations, (Gherardi and Nicolini, 2005) the co-created nature of social and environmental responses to Mitch were the proverbial hammer that drove in the nail on people's role as citizens. Though the Sandinistas attempted to address the extensive social and ecological issues in the '80s by tapping into the potential of the public, it inadvertently set in motion a process of paternalism with its central level reforms and NGOs handing out aid rather than building skills and fomenting a diffuse form of participation (Interviews: A. Madroño, 15 Jan 2009; M. Sacuanjoche, 23 Jan 2009). One INGES employee commented, "Many organisms came that helped a lot.... But what happened? The people became mal-adjusted. Because they gave and gave everything to the people, and the people didn't have to do anything” (Interview: A. Madroño, 15 Jan 2009). This process continued until San Francisco Libre’s municipal government and other local actors set out to respond to the social and ecological cries

for help after Mitch and created the PID. It paved the way for non-governmental organizations to implement projects focused on decreasing the population's socially created risk by empowering citizens through skill-building workshops, alternative, more sustainable sources of sustenance and livelihood, and encouraging more cooperation amongst community members and citizens. The events and human and non-human constituents of San Francisco Libre co-created a new space into being where humannature-administrative interactions were highlighted through forest interactions, bringing national legislation into every day life and forms of participation, and setting into motion the process of citizen participation in the management of their livelihoods, wellbeing and environment.

\section{Integral Municipal Development Plan - Human scale development and local management of risk}

Through "a real protagonism of the people and the search of creative, bottom-up solutions, parting from mechanisms that support the centralization of power” (Alcaldía 
Municipal de San Francisco Libre, 2003:8), a community-based model of development was created that emulated the Sandinista model of municipalities as indispensable spaces where local level democratic processes can be involved in economic and social development. While it is common for decentralization processes to focus on "bottomup solutions," power is never in possession to be handed over, nor does it move in a linear fashion; rather, it is exerted through repetitive daily interactions and moves in a diffuse pattern within a given network (Allen, 2004; Latour, 2005). Recognizing the contextual variability of communities mere kilometers apart, assemblies were carried out in each of San Francisco Libre's 30 communities to diagnose each community's history and map out the most salient problems of its area (as addressed above in the case of La Trinidad) to better understand the realities that constrain and enable processes within the municipality. Four main areas of work were identified in most communities, five in some, including Socio-economic, production, infrastructure and equipment, environment and prevention of disasters, and recreation in the latter communities. These areas made up the four, or five, Interest Groups (G.I. for Grupos de Interés) in each community. Community Committees (CC) were then created through the election of a committee coordinator by the community and approved by the municipal mayor, and three members of the coordinating commission of each Interest Group, including its coordinator. Together, the coordinator of each four, or five, Interest Groups along with the community coordinator made up Community Committees of five, or six, people.

Regional level organization mirrored community level organization where "Work Tables” (M.T. for Mesas de Trabajo) were formed in each of the aforementioned areas, production, environment, infrastructure and equipment, and socio-economic. Together, the municipality has a total of 16 "Work Tables," made up of the four different coordinators of each Interest Group, for each of its four counties including the urban center, Telpochapa, Laurel Galán and San Roque. In addition, a general regional coordinator was elected who, alongside the four regional interest group coordinators, formed the County Development Committee (C.D.C. or Comité de Desarrollo Comarcal). Representatives from the urban center's development committee, or the Urban Territory Committee (C.U.T. for Comité Urbano Territorial) and the other three Regional Development Committees from Telpochapa, Laurel Galán and San Roque comprise part of the Municipal Development Committee (C.D.M for Comité Desarrollo Municipal), together with representatives of municipal authorities, governmental institutions, involved NGO’s, and social and religious associations (Alcaldía Municipal 
de San Francisco Libre, 2003). This new administrative organization, displayed in Figure 12, was intended to streamline the administrative and communicative process in addressing San Francisco Libre's population's needs and the risks its faces. A number of social, economic, health and environmental issues were often hard to separate one from the other, as the forest interactions served as Massey's (2005) meeting space of multiplicity of potentials and differences. The environment emerged as a common denominator and a salient factor in both the source and solution of the municipality's problems. Subsequently, a forest inventory was undertaken to address what potentials and obstacles San Francisco Libre’s forests and main source of subsistence held.

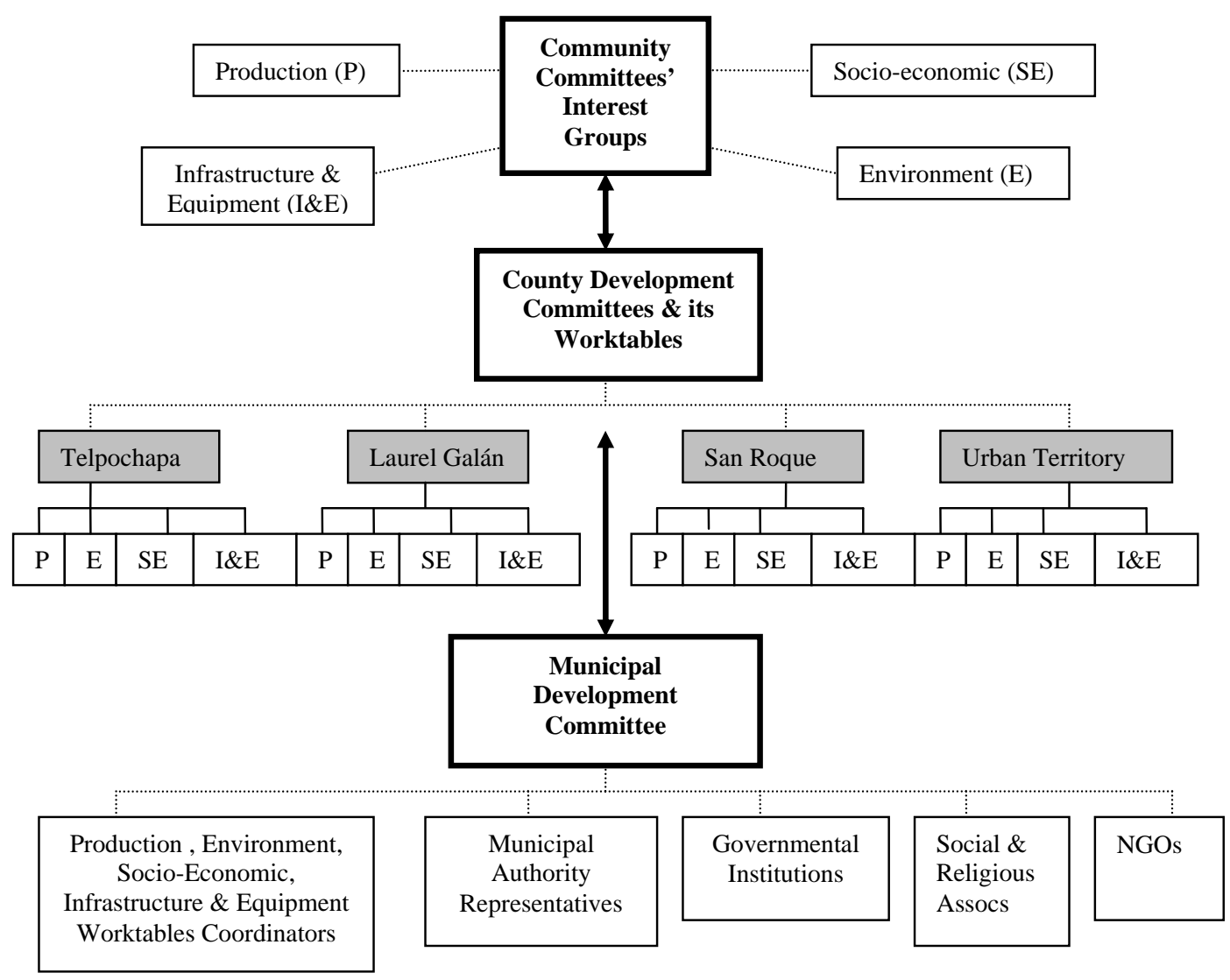

Figure 11 Administrative restructuring initiative of the Integral Municipal Development Plan 


\section{Forestry Plan Ordinance of San Francisco Libre - Diagnosis of the forests' potential}

The Integral Municipal Development Plan recognized the need to address the serious social and economic consequences of severe environmental degradation, land-use changes and indiscriminate deforestation. These impacts include continual loss of soil fertility, loss of biodiversity and deteriorating water sources for rural populations (Alcaldía Municipal de San Francisco Libre, 2003; INGES-FORESTAN, 2005). The Forestry Ordinance Plan of San Francisco Libre (POF-SFL for Plan Ordenamiento Forestal de San Francisco Libre) was initiated and carried out by a number of national and local institutions, including INAFOR, MARENA ${ }^{11} /$ POSAFII $^{12}$ and the municipal mayor's office, to better understand the potential the region's tropical dry forests provides and to regulate the uncontrolled illegal use of the forest's resources (Alcaldía Municipal de San Francisco Libre, 2004)

Ultimately, POF-SFL found 14,867 hectares, or 22.3 percent of the municipality, of forestry potential, but which held a number of limitations handicapping the municipality's ability to sustainably use the forest's resources. However, any attempt to calculate and regulate a "pure nature" will be flawed due to the ever-present hybridities of humans and non-humans (Hinchliffe, 2007). They include excess land-use change from disproportionate economic incentives to switch to livestock, increasing vulnerability to droughts in an extremely dry climate, lack of understanding by San Francisco Libre's inhabitants of the gravity of the problem, open access to natural resources coupled with a lack of support in alternative productive activities, ailing infrastructure making accessibility to services and subsistence alternatives difficult, and a weak system of control and regulation over forest resources. In addition, changes in legislation have been a factor in the difficulty regulating the use of resources, and it would help to devolve more faculty to the local authorities (Alcaldía Municipal de San Francisco Libre, 2004), where power processes in authoritative relationships, according to Allen (2004), can more effectively be carried out through proximity.

As they found the region's tropical dry forests fragmented and unable to fully provide its resource and protection service, POF suggested reserving 2,526 hectares for

\footnotetext{
${ }^{11}$ MARENA, Ministerio del Ambiente y Recursos Naturales or Ministry of Environment and Natural Resources

${ }^{12}$ POSAFII, Programa Socioambiental-Forestal II, or Environment and Social Forestry Project - a subsection of MARENA that was aborted in 2007
} 
conservation purposes and the remaining for production of forest products. Recognizing the population's inextricable link to the future of forest resources and the high costs in harvesting them, it suggested forest producers work in coordination to minimize costs of production and distribution, articulating the chain of production. It also prescribed projects that would empower and educate them in more effective ways to minimize costs while sustainably creating higher-value products. In wake of the inventory and it findings, the mayor's office and MARENA/POSAFII were eager to continue their support in carrying out their suggested paths of action, and enrolled NGO’s to implement projects based in these frameworks.

\section{Fomenting Sustainable Forestry Management And Increased Aggregated Value of Forest Producers In The Municipality of San Francisco Libre - NGOs' initiative}

INGES and FORESTAN ${ }^{13}$ together embarked on an initiative aimed to increase forest cover by incorporating conservation and production areas over 5,000 hectares, with areas of conservation and production, increasing the value along the chain of production of forest products by more effective use of more commercially valuable tree species, and creating permanent jobs through the aforementioned small and medium-sized enterprises (INGES-FORESTAN, 2005). Modeled on a hierarchical, linear model of information flow, the first year focused on capacitating and investing in local actors and processes, the second year consolidated the skills and knowledge imparted throughout the first year in small to medium sized forest-based enterprises. It employed a multipronged approach based in technical expertise and internationally trendy sustainable development aims, working within the new community-based administrative structure. Its five components included the management of forest in areas of permanent forest use, development of small to medium-sized enterprises, strengthening of local actors' capacity and citizen participation, conservation and promotion of forest certification and payment for forest services, and technical skill-building and assistance. To achieve this, INGES and FORESTAN implemented a scheme of forest management following INAFOR guidelines, developed simple judicial and legal mechanisms for forest management processes, coordinated with other projects and institutions, invested in individual or collective local initiatives, and strengthened local capacities through a series of workshops focusing on the actors involved in the forest chain of production. However, as is noted in the literature review, it is difficult to achieve both institutional and popular legitimacy. Latour (1986:265) wrote "the amount of power exercised

\footnotetext{
${ }^{13}$ FORESTAN, Forestadores Associados de Nicaragua - Associated Foresters of Nicaragua (NGO)
} 
varies not according to the power that someone has, but to the number of other people who are brought into the composition.” The project recognized the importance, and the associated difficulties, of carrying out these initiatives within the framework of national and municipal laws.

At times the people, with the laws, at times they were annoyed. But note that it is a fact that we have always worked to educate the people. Each person has their political opinion. But we tried to work with all of the community, to integrate everyone. Not because you're Sandinista and we're going to work with you.... More it was to seek how to integrate the population, each and every person in the community. (Interview: A. Madroño, 15 Jan 2009)

\section{The meaning in-between: embracing the importance of interaction}

With high hopes and perhaps a bit of nostalgia for the hopes inspired by the Sandinista reforms in the '80s, the restructuring model was incorporated into central legislation in 2003. The Law of Citizen Participation, Law 475, recognizes citizen participation as a fundamental right, as specified in the Political Constitution, and outlines the involvement of citizens in political, social, economic and cultural scenes through institutional mechanisms fostering interaction between the state and the population. In order to promote liberty and democracy, it names citizen consultations and associations as tools of participation and legally institutionalizes the role of the CDM (Committees of Municipal Development), outlined as part of the municipal administrative reform above. It defines citizen participation as:

The process of involvement of collective or individual social actors, with the objective and goal to affect and participate in decision making, management and design of public policies in the different levels and modalities of the national territory administration and the public institutions with the intention to achieve sustainable human development, in correspondence with the State. 
Two sets of legislation now address citizen autonomy and participation, though forest management is ironically still primarily centrally regulated by INAFOR with is a focus on exerting control through natural resources, passing liability along the chain of production as forest resources move from landowner to transporters. However, possession of physical resources is not what assigns power, but is merely a medium of agency (Allen, 2004). Instead, Feldman and Pentland (2005) emphasize that agency is acquired by being able to enroll enough actors in a process for it to become stabilized as an accepted norm.

Salient works by Haraway (1992), Staddon (2009), and Cloke and Pawson (2008) underscore how people's identities and perception of their circumstances are rooted in the surrounding land and ecology. For many people whose survival and livelihoods depend on forest products and services, especially in areas with high levels of poverty and unemployment, the forest can serve a source of security, with its stoic appearance and history that far extends humans' perception of time. Ana Madroño (Interview: 15 Jan 2009) of El Puerto commented, "We think that the resource will never end, that it'll never have needs," explained an INGES representative. However, when the forest, the base of a population's subsistence, shows signs of faltering, it can act as a driver for change in legislation, demographic and daily life (Mitchell, 1997). Subsequently, with the help of NGOs, forest owners, firewood cutters and community committees came together to create a set of environmental norms that citizens would know, understand, and be able to apply to daily life (Interview: A. Madroño, 15 Jan 2009). This initiative resulted in the approval of Norms of Environmental Regulation by the Municipal Council of San Francisco Libre, created by the people, calling upon the faculties based in Law 40 and Law 261, that all organizations in San Francisco Libre and the population in general to employ good conscience in the use of natural resources.

This community-based municipal edict addresses daily issues including citizen's responsibility to care for the environment, prevention of forest fires, respect for other's land and property and the responsibility to educate the youth on the importance of trees for the municipality. The norms also involved the creation of a Counter-Fire Brigade, which lawfully recognized responsibilities and methods of preventing forest fires. INGES supplied workshops on cleaning and pruning techniques, counter-fire rounds and other prevention methods. The diffuse nature of communication of the municipality-wide diagnoses and community committees allowed a form of interaction 
that accounted for the kind of power exerted through interaction between stakeholders detailed by Latour (2005) and Allen (2004). Ana Madroño (Interview: 15 Jan 2009) explained, "These norms were spread throughout the municipality. All of the actors were incorporated. And now it can be used as a tool that is legal in front of the municipality.”

The citizens of La Trinidad that I spoke with follow these norms religiously. In stark contrast to their prior unawareness of the laws and their rights and responsibilities, they have ensured that each and every household within La Trinidad has a copy of the threepage set of norms. With this awareness, if someone is not following the law, it's not because he or she does not know (Interview: Community Committee, 23 Jan 2009). These locally created norms are more practical for those in the community. One community member explains,

This is something new. Laws have existed above in the government, in the Environmental Commission of the National Assembly, but the people ignored these laws. If those in power ignored these laws, the people ignore the laws in the communities. Because the need was in the communities, those in power no. Those in power, they do wahatever they want. What we feel, the consequences are ours and this is what POSAF helped us to learn here in San Francisco Libre to harvest wood orderly. (Interview: M. Sacuanjoche, 23 Feb 2009)

Based in the forest, the citizens of La Trinidad see first hand the effects they have set in motion through their initiatives, which is recognized as agency within an ANT framework (Latour, 2005). Research has found when people feel in control, they are more likely to behave expansively and generously towards the collective (Shellenberger and Nordhaus, 2007), both human and non-human alike. There is unanimous agreement that efforts made by those who have been "concientizado", or made aware, citizens, have played a part in the improvements they've seen in winters, the fertile cap, and water quality (Interviews: Community Committee, 23 Jan 2009; E. Escobillo, 23 Feb 2009; A. Melero, 23 Feb 2009). Grateful for the workshops, one community committee member emphasizes, 
(the project) taught about the law, specifically Law 40, the Law of Citizen Participation, because the Law of Citizen Participation is very important that the population, the habitants, feel that the legal right of their need to participate... is one of the most important things. (Interview: Community Committee, 23 Jan 2009)

\section{Conclusion}

This chapter has recounted how the forests and their ecosystems have acted in the case of San Francisco Libre as the space where cultural, ecological, technological and economic processes and potentials are carried out. Though laws existed, they could not be effectively set in motion without a playing field conducive to the dynamic interactions between human and non-human actors, people, laws, organizations and trees included. Broad inclusion of stakeholders without predetermined categories helps normative processes achieve relevancy, legitimacy and a more participatory governance. In the coming chapter, outlining the respective experiences of community committees and those of a cooperative externally formed, the strengths of building processes around a model which is flexible to these dynamic and diffuse patterns of interaction will be apparent. 


\section{Fixed paradigms, broken processes}

The social and ecological aftermath of Hurricane Mitch in San Francisco Libre forced the municipality to recognize the schism between the daily experience of its constituents, national level policies and the natural environment. Based upon the recommendations of the Integral Municipal Development Plan and Forest Ordinance Plan to initiate "human-scale" development and minimize socially created risk, INGES and FORESTAN initiated a project that would work towards educating and empowering communities, improving relationships with the forest, and creating a cooperative of the chain of actors involved in the commercialization of forest products and services. Underscoring the shortcomings of the municipality to effectively integrate the contributions made by the various forces and actors involved in the municipality's development and well-being, their proposal stated:

The municipality does not have the necessary mechanisms to care for the municipality's forest heritage, as such the link between local government, central government and civil society is not based on solid relations and understandings with regards to the themes within the municipal legal framework, governability and municipal development, which makes necessary the incorporation of these elements with the forest chain actors, civil society, municipal government and equally INAFOR. (INGES-FORESTAN, 2005:58)

From 2006 to 2007, the project incorporated approximately 25 percent of the municipality's forest with productive potential, rolling out a process of sustainable forestry and focusing on payment for environmental services and orderly use of forest products. Based on INAFOR's understanding of nature as the base of all human activity, which can and should be protected at its equilibrium where its resources are most productive, INGES' and FORESTAN's project strove for

the articulation of the chain of value for forest products (firewood and wood) under a business framework that will help to achieve a higher aggregated value in the municipality, based in forest activity. Both technical processes will help conserve forest cover, create rural 
employment, and generate earnings for producers and benefits for the institutions, agreed objectives of POSAF II, the Mayor's Office and other local NGOs. (INGES-FORESTAN, 2005:36).

The NGOs, in coordination with San Francisco Libre’s Environmental Commission and Mayor's office, set out to identify the meta-groups involved in the chain of forest production. It identified forest owners, carpenters, lumberjacks, and truck drivers as primary actors, and together created COPROFOR, or Cooperative of Forest Products pictured at a stakeholders meeting in Figure 12 below, which would commercialize.

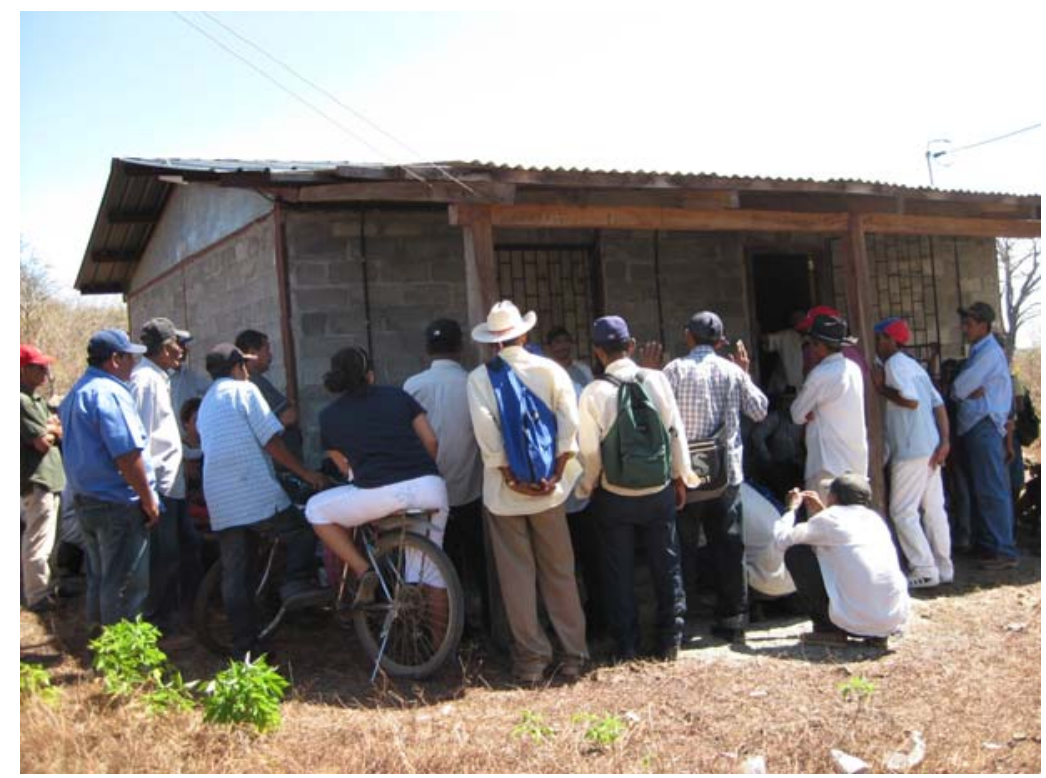

Figure 12 COPROFOR meeting at their workshop in San Francisco Libre's urban center

INGES and FORESTAN then created the normative and legal framework associated with business development, carried out inventories the forest potential in the cooperative, delivered workshops on the rights of citizens, forest use and "what it means to be cooperative," and donated the funds, tools and machinery needed for production (Interview: COPROFOR, 25 Feb 2009; A. Madroño, 15 Jan 2009). Yet, the central regulations and technocratic framework upon which legal use of wood products were based do not account for the dynamic and often unpredictable nature of both human and non-human, and take a modern approach in assuming that the ecology's systems could be calculated and dominated by humans (Hinchliffe, 2007).

Conversely, citizens are very familiar with the unpredictable dynamic of the seasonal cycles and acknowledge in times of need they turn to forest products, but do so in a 
legal manner. “It is understood that here things don’t stay at their level. They go up, they go down," one citizen commented. He went on to explain, "Here we have to find in what way we're going to survive. So, when there is need, what we do is sell a bit of firewood and potatoes... But it is not permanent, only when there is need.” Yet, to maintain the "ecological equilibrium" promoted by central forestry ministries he always plants a tree for any one he cuts down (Interview: E. Escobillo, 23 Feb 2009). In Laurel Galán, Cristiano Quebracho (Interview: 17 Mar 2009) spoke of the value of caring for the trees that exist, and said it has been a big success that people have begun to leave trees to grow. He said natural regeneration is better than plantations “... to best reestablish trees, so they have more life, they have more resistance, maybe than if we planted them." Rather than reforesting, he went on, "if you care for the regeneration then the tree speaks for itself.”

However, the nature of enrollment and processes in the creation of the cooperative included a range of new influences that differed from the traditional forestry chain as "things and actions take shape in place and are thereby liable to differ from any starting trajectory” (Hinchliffe, 2007:174). Contrary to the natural emergence of issues and actors and diffuse flow of information in the mapping of municipal issues throughout the PID process, the cooperative set out a framework which accounted for only those actors and processes which they hoped to improve within INAFOR's regulations, outlined in Figure 13 below.

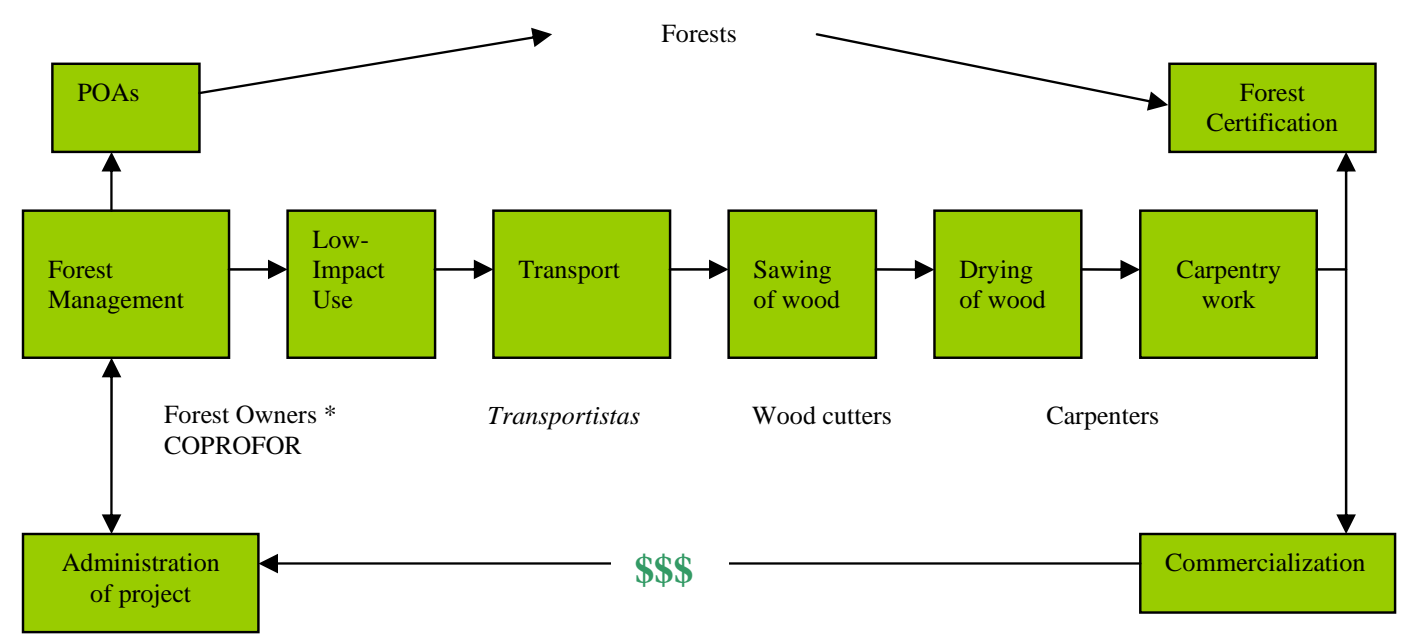

Figure 13 Articulation of chain of wood production 
However, Noren and Ranerup (2005) argue that tools intended to improve processes and create opportunities can have the inverse effect, where its preferences and structure ultimately shape, and sometimes limit, participants' autonomy and participation. The chain of production begins with the INAFOR process outlined in Chapter 4, where the land owner solicits permit for the exploitation of his forest. Members of the cooperative underscore the importance of their responsibility and the relationship with INAFOR:

We have to be responsible people and at the same time use the forest. It's an economic resource, but also we are clear that we need to not destroy it because we would be destroying the environment, our very own resource. Because we have to think of the future. So the management plan says how we are going to exploit it. If a tree is not of a worthy size, then it's not cut. We cut a tree if INAFOR authorizes it. But if INAFOR doesn't authorize it, we wont' exploit it. (Interview: COPROFOR, 25 Feb 2009)

The forest owner fells the authorized wood with the help of his family or hired work, and then contacts a courier, or transportista, who buys the wood from the owner and transports it to markets for sale. INAFOR's priorities are highlighted by the trail of liability that follows the natural resources as the responsibility of permit is transferred to the transportista. One transportista I spoke with said,

We buy whatever is cut... But first off, me as a driver, I require that (owners) go to the office so they can get their permit. Because without this, they charge me, and they detain me and I lose time... so we avoid it. INAFOR stops you in the highway, and it's always the problem of the driver. For this I say, you have to get permission. (Interview: J. Cornizuelo, 24 Feb 2009)

\section{Modern problems, no modern solutions}

Nevertheless, this linear notion of a chain of power from INAFOR to land owners and further along the processes between actors is problematic first in enforcing the asymmetry of agency that actor network theory attempts to resolve by placing emphasis 
on INAFOR and the forest owners, and second by not taking into consideration the diffuse nature of the creation and realization of context-specific potentials (Latour, 2005; Massey, 2005). One cooperative member I spoke with felt that those further along the "chain" of production were powerless without the inclusion and participation of certain landowners (Interview: A. Chaperno, 5 Mar 2009).

This issue is compounded as landowners often have more alternatives to forestry as a means of livelihood, with forests seen as a form of security and an investment for the future (McSweeney, 2005). Elements in the network of forest actors can be reassembled, allowing new economic and ecological alternatives to emerge. Communities are turning away from wood-based livelihoods to agriculture after seeing the ground-level impact their efforts at increasing forest coverage has had on the yield of their harvests, water levels in the rivers and rainfall (Interviews: E. Escobillo, 23 Feb 2009; A. Madroño, 15 Jan 2009; M. Sacuanjoche, 23 Feb 2009). For the goods that cannot be made or grown locally such as rice, oil, gasoline or batteries, they sell what they can produce including breeding animals in Figure 14, eggs from their hens, or, if their crop was plentiful enough, some of their harvest (Interview: D. Chiquirin, 10 Mar 2009; E. Escobillo, 23 Feb 2009). However, those without land do not have such accessible alternatives. When people feel they have the power to make choices and create alternatives in their lives, as often land tenure can provide, they are much more likely to act on behalf of the wider whole (McSweeney, 2005; Shellenberger

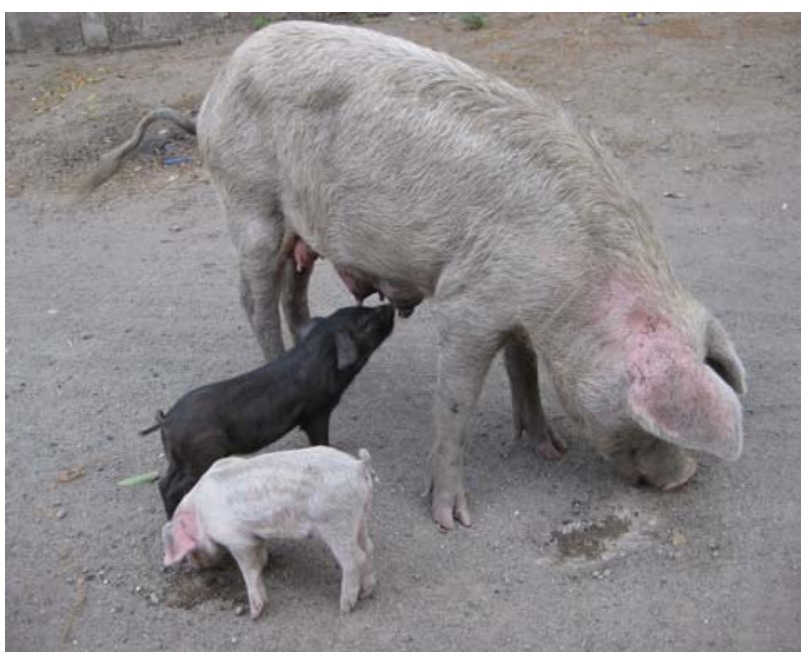

Figure 14 Livestock serve as an alternative means of earnings and Nordhaus, 2007).

While some organizations are deemed to hold power because of their history rather than current ability to enroll to achieve their aims, agency is created only if legitimized through interaction in actors' networks and processes (Allen, 2004). In ANT, processes become seamless only once they’ve been accepted and normalized by all actors 
involved, but when new actors or actants "come into play" or when there is a problem of translation between actors, these issues of translation become highlighted (Feldman and Pentland, 2005; Latour, 2005). When NGOs inventoried forests within the cooperative and set out to help COPROFOR obtain management plans that would give them a framework within which they could harvest their forest resources, they failed to adequately consider the preferences of participants. Unfortunately, the areas approved by the management plans were much smaller tracts of land and the owners had not been involved in forestry. The local INAFOR delegate commented,

They messed up when they did the projected and they gave management plans to people who don't work in their forests, they gave it to people who work with their livestock so when the came to do the inspection, they said it was better to conserve and not use, better for their livestock. So the cooperative is stuck a bit broken, and can't produce if the owner doesn't want to. (Nacascolo, 2009)

Furthermore, though they were able to harvest or purchase enough wood to begin production, COPROFOR encountered administrative problems involving machinery and electricity in the workshop, as is frequently the case in CBNRM efforts (Charnley and Poe, 2007).

It was a requirement that we had to fulfill that the electricity wasn't installed by just any electrician. A person from Fenosa ${ }^{14}$ had to come and install the transformer so that the machines would work, because they didn’t do what required, it was a setback. (Interview: COPROFOR, 25 Feb 2009)

The electrician was contracted by INGES and FORESTAN, and when they were called to repair the problems with the electricity, they were told that they would have to pay another fee. In addition, there were issues surrounding the machinery donated, as can be seen still in its packaging in Figure 15. One carpenter vented,

\footnotetext{
${ }^{14}$ Unión Fenosa is a Spanish firm that has been the primary provider of energy to Nicaragua since 2000, though it has faced extensive criticism in the rampant electrical blackouts and shortages throughout the country.
} 
They bought machinery without taking us in consideration; machinery that doesn't work for anything, well some do, I'll agree they are industrially excellent... For example, all the machinery that we asked for is good. But the rest were things we never wanted. If we are the carpenters, we know what we want.... They bought things that were not adequate, that we would have said we don't need. And we wanted to be there when they went to make the purchase, but they didn't want that... I don’t know why. (Interview: A. Chaperno, 5 Mar 2009)

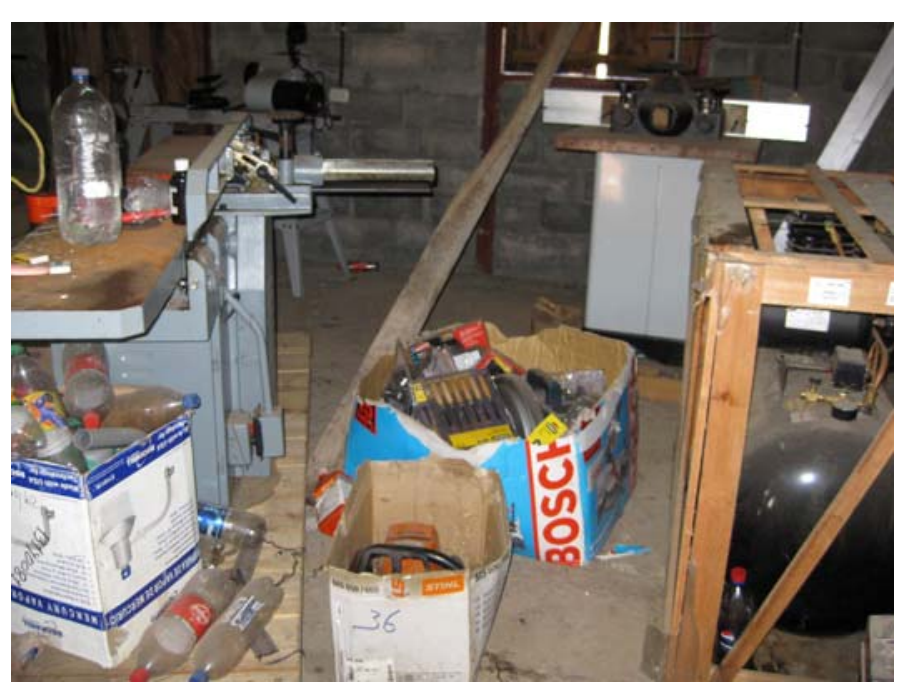

Figure 15 Much of COPROFOR's machinery out of production and still in their boxes

He acknowledged, "I in particular am very critical of some organizations

because they give priority to people that don't know, that waste a lot of money financed by countries that want to help Nicaragua." Claiming that only 57 or 60 thousand of the 400 thousand U.S. dollars that went into the project reached the cooperative, he went on to say, “... a lot of money came, but it stayed in the administration. So what happened? In the end I think it's wrong what they do.” For him, even though they must work within regulatory framework, the people involved with creating legal documents and addressing administrative formalities are "outside of reality." The outcome of the project is all too familiar for him. "It has been custom, as much for the project as it happens on a large scale, so it goes. Many organizations, many NGO's have been corrupted in the past” (Interview: A. Chaperno, 5 Mar 2009). On one hand, people appreciate the skill-building workshops, financial aid and incentives to act more conscientiously towards nature provided by organizations' involvement. One citizen said without their help, "the truth is we would live very badly" (Interview: Community Committee, 23 Jan 2009). 
These workshops proved to be very influential on the citizens' relationship with and use of the forests. Throughout the various communities with whose citizens I spoke, all told a similar story about past relationships they had living in a highly individualized manner, using whatever resources they could find, not caring for others', or even their own, properties. One La Trinidad land owner described how "people who had their own land would come and cause damage here,” on the property of the local land-owners cooperative, bringing their livestock to feed of the vegetation and the fertile cap on the forest floor (Interview: M. Sacuanjoche, 23 Feb 2009). They implemented knowledge and skill-building workshops that addressed citizens' right to participate, natural regeneration, conservation, "which wood is of use, which to conserve for the future and therefore not to touch. And the wood that is hurting the forest, you cut. This type of wood you use for subsistence” (Interviews: Community Committee, 23 Jan 2009; COPROFOR, 25 Feb 2009; C. Quebracho 17 Mar 2009). With the locally created norms described in the previous chapter, both community members and employees of INGES note a change in attitude that people involved in the project have towards their natural environs, with wood cutting down 50 percent and fire clearing practices as much as 80 percent (Interview: M. Sacuanjoche, 23 Feb 2009). Many of the community members I spoke with said they have a new perspective on the environment, viewing their common future with a sense of care and responsibility (Interviews: D. Chiquirin, 10 Mar 2009; A. Melero, 23 Feb 2009).

The population feels a responsibility... to care for the natural resources. It's a responsibility because if we do not care for our natural resources, we're talking about the forest and natural regeneration, then it will dry into a desert. Likewise, as a population, we don't want that. (Interview: Community Committee, 23 Jan 2009)

On the other hand, as the carpenter elucidated above, the history of NGO involvement has left citizens wary of the aims and processes of many of the projects carried out in the region. In the project addressed in this chapter, as well as past NGO initiatives, there have been many failures due to broken links in the linear, hierarchical model they followed from not effectively accounting for the dynamic, diffuse nature of involvement of stakeholders and influential factors in forestry relations. 
In creating effective conservation and development initiatives, one must take into consideration all the contextual variables and have knowledge of the situation. Latour (1999:69) points out that in creating knowledge, one must be able to progress and back track across spaces and times, from the world of matter to theory, with a circuit of information that "ceases to transport truth" if it is interrupted at any point. Tales were told about NGO's hapless involvement in projects where they planted seeds without taking into consideration common local knowledge of the impact rains and flooding have on the germination of plants, questioning local need for a carp pond, or even what the community members themselves want. One man accounted of the NGOs,

They help in a certain manner, but maybe not 100 percent. I was speaking one day with a technician, and I was saying that the best is that... they listen so that the community develops a bit better. What I was saying to you about natural regeneration, that works here. But they're interested in carrying out their program.... At the end, 75 or 80 percent is lost because the zone, although the producer plants (trees), but in March it gets dry, it heats up, so the plants die. If the plant grows on its own, from the fallen seed, this little plant doesn't die. (Interview: C. Quebracho, 17 Mar 2009)

\section{Repairing the fractured current}

The community committee sees its role to unite and educate the people on projects, and to act as a spokesperson for the people and natural processes upon which their community is dependent. In addition, it has taken on the responsibility of supervising these initiatives so that their citizens are protected and best served.

They won't cheat us again, coming here cheating the people, no. We're going with what's concrete. If they are going to help the producers, we want to see it, but if it is only lies, no... We won't support an organization that won't support the farm worker. (Interview: D. Chiquirin, 10 Mar 2009)

Still, they recognize projects bring knowledge and awareness, many people I spoke with feel that not enough of the help directly benefits the people in need. Guthman (1997:45) 
writes, "Production of environmental interventions is intimately connected to the production of environmental knowledge, both of which are intrinsically bound up with power relations." However, the knowledge that is imparted on them by the NGOs and the municipality is based on a modern paradigm supporting the dichotomous view of people and nature, where nature can be managed by people. Hinchliffe (2007:102) writes, “any attempt to be modern, any attempt to order nature's spaces, will itself already be impure, heterogeneous and practiced in many places, with many things and by many different kinds of actor.” A number of the NGO and INAFOR employees I spoke with suggested that the best source of information about the health of the forests and the effectiveness of central regulations' attempt to minimize illegal wood cutting were the community members, though ironically the forestry ministry was charged with creating guidelines based on knowledge of the forest that only the communities have (Interview: M. Talalate, 9 Mar 2009). For an institution to be creating regulations so removed from the multiplicity of potentials created contextually, it would be difficult for such a removed actor to account for all the hybrids of human and nature that only come into a given space and time (Latour, 2000; Massey, 2005). As the previous chapter outlined, when the people participate in creating regulations, they are considerably more effective.

The inherent adaptive dynamic of the community committees shows promise to address these issues, typically meeting on a monthly basis, but holding impromptu meetings for pressing issues that arise. Once they have discussed the issue with the larger community at hand, the coordinator of the CC passes it on to the Mayor's office, who then coordinates with central government if needed. When information needs to be communicated from above, the reverse process occurs. On the other hand, one citizen lamented, "Sometimes (the coordinators) ask, but there's nothing” (Interview: A. Melero, 23 Feb 2009). One man explained,

People here have to understand that there are problems that the Mayor's office can resolve... and also the community understands that the Mayor has trained us to deal with these problems...If we approach the mayor... and the mayor does not have the capacity to give us a response, then he needs to lobby the central government. And in this sense, we really understand what is within the reach of the mayor. (Interview: Community Committee, 23 Jan 2009) 


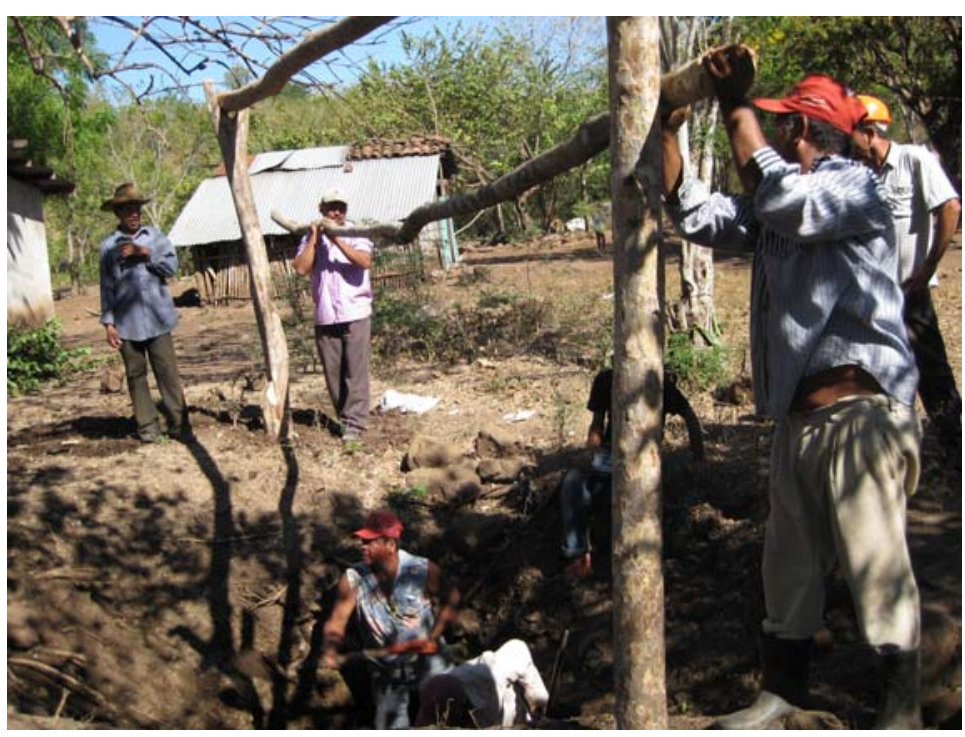

Figure 16 Members of the rural community La Trinidad work together to hand-dig a well

The community committee is seen not only as a medium to communicate with the government, but as an empowering tool to create solutions for the community's problems. Figure 16 shows a community and its committee members working together to dig a well. "Before it was more difficult to find things. Now, it's not. Now the group meets and talks about a need that exists, and they find a solution” (Interview: A. Melero, 23 Feb 2009). One example is the involvement of the community committee and its coordinator in the implementation and delivery of a national program designed to provide students who were particularly in need with access to the materials and uniforms for school. While the program had been carried out in urban areas with the help of NGOs, it finally came to the rural areas of San Francisco Libre, where each of the 32 communities' leaders worked with the NGO World Vision to decide which 68 students would receive the help. However, complications arose and the program was in danger of being canceled.

The people already had the hope and the ambition that this packet was about to come. So I told the manager...that in no manner could he throw it out because we came from the community to tell him... it was going to have a large impact from the community level to the municipal level... This special package would bring a little more success for these kids... So they took it into consideration, and the project continued. (Interview: M. Sacuanjoche, 23 Feb 2009) 
Many of the issues community committees must address are entwined with the environment (Interview: A. Madroño, 15 Jan 2009). This merging of social, political, and natural has given communities a sense of autonomy, organization and power, as the forest has provided a stage on which to collaborate and exert agency through interaction among humans and non-humans. Javier Guazimo, a resident of the urban center, notes

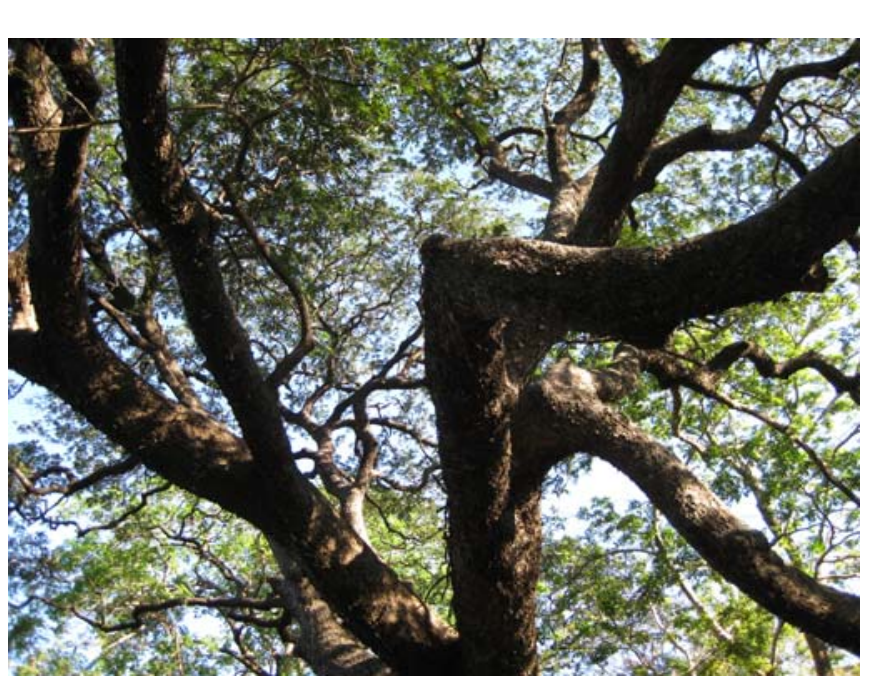

how organized the rural community of La Trinidad is, attributing it to the natural resources they live amongst. Contrasting it to the urban center's lack of trees and forest, he says, "Things need to be organized in order to participate in things. What in the hell are we going to organize here?

Figure 17 One of the few remaining Jeniceros in La You're going to organize what? Trinidad serves as a reminder of the common future they share with the forest

Produce what?” (Interview: J. Guazimo, 10 Mar 2009). Cloke and Pawson (2008:120) note, "tree places serve as spaces for more immediate practice and performance. Trees become implicated in the 'becoming co-constituted' performances of the nature-culture assemblage.” Incentivizing better use of natural resources, trees can serve as reminders of the intertwined past, present and future humans and the forests share, as the Jenicero tree in Figure 17 does in the community of La Trinidad. Another community member comments on what the committee brings to the community,

I feel there is a strength, there's a change that I feel, personally, helps me and serves me through the committee. More than anything, the committee helps us in what we do. So I feel that it helps me and I am grateful to them, and I feel appreciated. (Interview: E. Escobillo, 23 Feb 2009)

Above all, people feel more empowered having the means to work more directly with the municipal government and their Mayor whom they trust. 
(Organizations) give you 25 or 30 percent, and 70 percent goes into paperwork. Better for the producer to feel better supported a bit more directly... Now that we are working with the mayor's office, we think the program is going well, it is helping. Because they meet, explain how things go... then we as beneficiaries and the other producers, we know. There are organizations that aren't successful, but the mayor's office is... because the mayor's office works in coordination with the community. They see which person is capable, or which can carry out a reforestation project, that realistically is the producer of firewood and the land. (Interview: C. Quebracho, 17 Mar 2009)

\section{Whichever way its branches are pruned, so leans the tree}

While the community committees have shown substantial strength in their adaptive ability to interact and respond with government, citizens and the natural environs, and the cooperative was initiated with good intentions, its environmental and participatory outcomes have been hindered by the modern central framework by which they must abide. As Watts (1958:62) put it, "the complexity of nature is not innate but a consequence of the instruments used to handle it.” Though the initiatives are intended to be community-based, they are plagued with all the administrative problems and high costs of central regulation discussed in the second chapter. INAFOR's inflexible, technocratic framework has raised the costs and requirements of extracting wood, resulting in many administrative problems. One transportista agrees, "Before they gave permits without much, but now it's more complicated” (Interview: J. Cornizuelo, 24 Feb 2009). Permits are costly, and with the longer distances forest producers now need to go to find firewood and trees that they can legally use, the process has become more costly. Mario Sacuanjoche (Interview: 23 Feb 2009), a landowner, explains,

Truck drivers that are going to profit from carrying the firewood to the market do not negotiate to go to an area of less than 100 manzanas. If it's less than 100 manzanas, they don't go there because they say 'It doesn't give me results, because there is not enough wood and to obtain permission will be too expensive and almost not worth the effort. 
In the forests of La Trinidad, the land cooperative that was established from the land reform of the 80's holds ownership of 800 manzanas ${ }^{15}$ of forest, shown in Figure 18, comprising the majority of the forest included in COPROFOR forest product cooperative. Any tract of land over 500 manzanas requires, in addition to the standard prerequisites, a study of environmental impact of the proposed activities to obtain a management plan (MAGFOR, 2008). However, there have been extensive administrative and legal issues preventing them from using mature trees. As literature highlights, there are

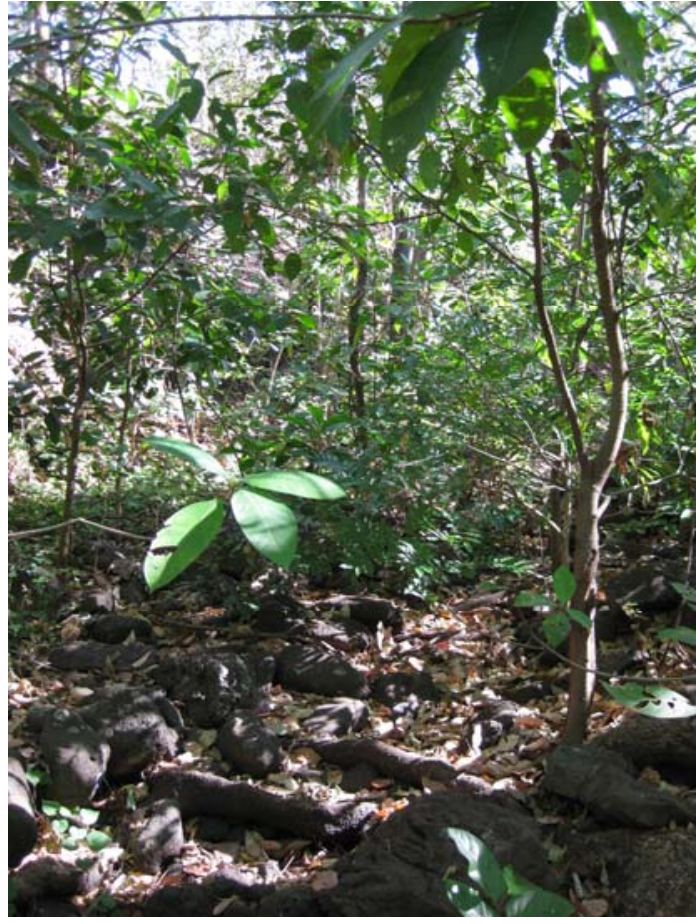

Figure 18 Tropical dry forest of La Trinidad often substantial administrative difficulties in CBNRM, and in the case of San Francisco Libre, particularly with land tenure formalities. Throughout the 1980's, the Sandinistas' series of land reforms, or agrarian reform, that intended to redistribute land acquired by Somoza and his supporters to groups of local landholders, or cooperatives. However, Sandinistas never distributed legal titles and while the group as a whole is recognized to own the land, individual owners do not have legal titles, creating obstacles for local producers to secure financing and being able to carry out any form of legal forestry as they are not recognized in INAFOR's national registry.

La Trinidad's committee coordinator has been working with the Mayor and INAFOR's representative to solve this issue so that the land owners have the option to use their land and the economically profitable resources it provides. An INAFOR representative said that the cooperative has not been able to fulfill some of the requirements due lack of the needed documents and the costs related to acquiring those documents. "For that they are a bit broken, and haven't been able to do anything without these documents” (Interview: A. Nacascolo, 17 Feb 2009). The lack of these documents have numerous

\footnotetext{
${ }^{15} 1$ hectare equals approximately1.4 Nicaraguan manzanas
} 
consequences for land owners and those involved in the cooperative as the legal paperwork is necessary for the stability of the network.

One of the problems here is that there are land owners in San Francisco Libre that can't enter into a forest management plan. Land ownership today in San Francisco Libre, 95 percent don't have legal paperwork that accredit them to do whatever type of management. It is an obstacle. The bank tells you they have financing with much flexibility, but if you do not have the paperwork they close their doors. (Interview: $\mathrm{M}$. Sacuanjoche, 22 Feb 2009)

A powerful tool against deforestation, the sense of power given by the alternatives one has with their land is being undermined by excessively rigid requirements (McSweeney, 2005). A study by INAFOR (2008) on the use of firewood as a primary source of energy in Nicaragua recognized the unnecessary administrative obstacles the process has created in helping Nicaraguans legally gain access to energy for their homes and a sustainable livelihood alternative. Resonating with community forestry literature and the experiences of those I spoke with, it states that the strategy should focus more on directly assisting forest producers to incorporate legal manners of forest production, and lists lack of property title or documents of ownership, high costs of security by the municipalities and of technical inspection by INAFOR as significant, yet avoidable, problems. Unfortunately for the land cooperative of La Trinidad, the ownership documents and inspections carried out previously by another project in 2000 have not been honored. "They already did all the work here, only that they need to come select which trees we are going to use. They said 'No, because its not registered in the national INAFOR registry,” explained one landowner in La Trinidad (Sacuanjoche4, 2009). Other cooperative members lamented,

They did the management plan in 2000 but it's not registered in the central registry of INAFOR. We truly thought that the process, that the solicitation of INAFOR was already carried out and that the general management plan was already registered.... If this plan had been incorporated, this project would already be producing. Until we get it incorporated, we don't have the right to cut wood nor firewood in any way. (COPROFOR, 2009) 
Excessively rigid requirements of modern, technocratic frameworks can be counterproductive even in the most inclusive, promising of initiatives. McSweeney (2005:1467) notes in the case of Northern Honduras, "while it is easy for authorities to clamp down on illegal - but ultimately small-scale - extraction by the poor, doing so risks alienating one of the most powerful constituents for long-term rainforest management.”

\section{Conclusion}

As we have seen, the adaptive nature of community committees show strength, yet cannot flourish when they are able to work with the potentials and actors created within the dynamics of a given locality. The leadership role and initiative taken on by the community committees, acting as a spokesperson for the human and non-human residents of the communities, have helped empower and educated San Francisco Libre's citizens, taking steps through its sustainable forestry project toward a more earnest participatory democracy and citizenry. Whereas sustainability was originally seen as a way for vested interests to continue to reap benefits and environmentalism had to come at the expense of democracy and equality, Escobar (2008:155) writes, “Sustainability may thus become a decolonial project: thinking from existing forms of alterity toward world and knowledges otherwise." The question is no longer whether democracy and environmentalism can coincide, but how can we avoid creating the pitfalls of hegemonic, technocratic frameworks which hinder the potential of CBFRM initiatives as in this case study? 


\section{Embracing a dynamic nature-society for participatory democracy}

Nicaragua's political, economic, social and environmental histories have been intrinsically entwined, co-producing the opportunities for the initiatives in San Francisco Libre outlined in the previous chapters. The parallel overexploitation of its countryside and population, fueled by modern, export-based politics, resulted in political and ecological revolutions seen in the Sandinista coup in 1979 and the events following Hurricane Mitch almost 20 years later. The Sandinistas recognized the need to create a more inclusive state working for and with the popular classes to achieve an “ecological democracy” where social and environmental movements could have "social governance of the means of production” (Faber, 1999:58). However, their policies merely addressed the symptoms of the problems created by the modern paradigm they continued to follow. Nicaragua's forests and other "natural resources," were still seen as merely means rather than a source of information, power, and heritage in their own right, as the Sandinistas claimed its people to be. Where the Sandinistas failed in effectively turning municipalities into spaces for citizen participation and autonomy (Larson, 2003), the local level effects of Hurricane Mitch have set in motion a score of actors and processes that have highlighted the voices San Francisco Libre's marginalized constituents, both human and non-human. These processes have resulted in the emergence of the forest not only as an actor in its own right, but as a stage for participatory democracy.

This thesis set out to better understand the workings of power in the community-based sustainable forestry project of San Francisco Libre, and account for how actors, marginalized or salient, human or non-human, influenced and were influenced by the context specific potentials that arose. Chapter Four shows though Nicaragua's central governing institutions try to maintain power over revenue generating forest resources while increasing participation among its human citizens in the case of San Francisco Libre, their attempts have failed as power only emerges through interaction and cannot be possessed and fixed in location. Instead, it has emerged through the interplay of opportunities that arise between human and non-human actors, including trees, roads and governmental institutions. Chapter Five goes on to discuss how the types of institutions, actors in their own rights, affect the interactions and potentials that arise. Higher levels of inclusion result in more democratic and effective institutions making it 
important for them to be open to diffuse forms of communication and transfer of knowledge so as to include as actors within a network as possible.

\section{A more inclusive "nature-society"}

Drawing upon the co-constructivist framework central to actor network theory outlined in chapter two, this analysis has worked to detail how the events in San Francisco Libre's forests, and more broadly Nicaragua's history over the past century, are a prime example of why "nonhuman elements of nature are increasingly seen as not merely inscribed upon by human culture but understood as active agents, relationally entwined in the reproduction of ecological, social, economic, cultural and political formations” (Cloke and Pawson, 2008:109). In light of its social, ecological and economic conditions, the municipal government felt the need to reassess the structure of their culture and society. In his political ecology and actor network theory work throughout the last two decades, Latour (2000) stresses society has never been a justifiable explanation on its own, but rather itself needs explanation by accounting for all the "natural" things that are not traditionally considered social, yet are the very building blocks of society. Refuting a dichotomous view of a nature separate to humans, he concludes on the existence of "one nature" in which humans and non-human co-exist, co-creating a "nature-society." As such, a framework is needed where a critical political ecology can openly account for the processes that unite all "things" in our nature-society, setting up the stage for a more inclusive participatory governance.

\section{New political structures: new participation opportunities}

San Francisco Libre’s Integral Municipal Development Plan was a first step towards a more critical political ecology framework, recognizing that human and environmental risk are entwined. It outlined the political and social circumstances that helped created the conditions that made Hurricane Mitch a disaster, and how, in turn, these environmental events and conditions affect the potential and quality of life of San Francisco Libres's citizens. It sought to initiate a process of development where the people were empowered as the 
drivers of their own fortune. It explicitly states that economic development is not the end, yet it implicitly promotes a modern, liberal approach of using economic development as a "motor" to achieve human-scale development. Following suit, the Forestry Plan Ordenance (POF) of San Francisco Libre inventoried the state of the forests, the nature of the uses they fulfill for the municipality and their productive potential based within INAFOR's technocratic regulatory framework. These municipal initiatives set the groundwork for a restructuring of the administration of the people, their needs and their livelihoods. The local government with INGES and FORESTAN together created community committee and cooperative initiatives based on the framework set out by the PID and POF. These new organizational structures hoped to increase social capital and citizen participation in the development of the municipality, incorporating all members of its society, including its previously marginalized youth and female segments. Organizational routines can be powerful if they are based in contextually legitimate processes, timeframe and area (Feldman and Pentland, 2005), but these processes have the most potential in enrolling a wide constituency when it is complements pre-existing wider-networks and processes, such as those of the forest. However, legitimacy has more to do with their effectiveness than exerted power, which depends on the context and dynamic of interactions between actors. As a result, democracy, like power,

requires rootedness in particular problems and places. Only in this way can meaningful public spheres be created and the kind of interpretive speaking through which the particular practices and identities might appear as worth attention of a mixed community be exercised. (Escobar, 2001:168)

In an actor network theory framework, the results of effectively addressing the issues surrounding the stakeholders considered, the symmetry among those involved, centralization of power, and the notion of duality were varied in San Francisco Libres's initiatives. In the case of the community committees, those involved were organically chosen through democratic processes that involved all of the community. The ecology historically had a hand in the development of these committees, as these communities settled around the life and livelihood 
supporting processes it provided throughout the last century. The communities' culture, identities, and needs have been bound up in their relationship with the forests, rivers, and landscape, and expressed a sense of personal loss for the past injustices committed on the region's forest, which they are still dealing the consequences. As a result, community committees feel it is their responsibility to accurately represent the people, and take it upon themselves to ensure the maximum transparency and participation of its constituents so that local level, practical needs are addressed. With many of their daily lives based within the forests, their relationship with the forest is a salient theme in these meetings, and the health and state of the environment is continuously relayed by these people whose lives are connected to it. Relationships between actors, though still asymmetrical, have improved with the creation of the committees as a forum of communication between marginalized members of society, including the economically poor rural citizens and the forest of La Trinidad, and government.

While the umbrella processes of administration are still limiting in their hierarchical nature because of the roles local and central government play, the flows of information, knowledge and power have become more dynamic, incorporating input from the people, the ecology, economic factors and political consideration. The aftereffects of Mitch not only highlighted environmental but social injustice, and "spoke” on behalf of marginalized people. Those very people for whom the ecology spoke now speak out for the forest through the community committees. They recognize that they have a common future with the forests, and being aware of the state of the forest is fundamentally in their interest as a community. Common amongst these committees, though particularly true in La Trinidad, the people hardly speak of themselves as an individual, but primarily refer to the community as a collective and the solidarity and trust that occurs in the relationship that occurs between the committees and the communities they represent.

\section{Rigid approaches, stalled initiatives}

The inclusion of actors as stakeholders in the COPORFOR cooperative was more of a top-down process, where members were approached and processes were institutionalized by INGES and FORESTAN, within INAFOR's central regulatory framework. It sought to bolster the chain of stakeholders in the 
forestry chain of production, but because the actors and stakeholders were defined rather than allowed to emerge organically, many influential human and non-human actors that were set in motion, yet not considered, in the project created obstacles. As the cooperative's structure was largely dictated by the institutions that set it up, their relationships and affiliations, such as with the energy company Unión Fenosa, affected the successful completion of tasks. Inadequate communication and consideration of all actors involved, including NGOs involved five years prior who helped fulfill INAFOR requisites, created many problems leaving the cooperative, as one cooperative member often said, "stuck in the air" (Interview: A. Chaperno, 5 Mar 2009). In addition, within the cooperative members, there is considerable asymmetry in decision making process and control over resources. The cooperative as a collective has a goal of producing furniture and other wood-based products, but the individual interests do not always align with the goals of the collective. Forest owners are the primary passage points without whose consent use of forest resources cannot take place. Due to inadequate consideration by part of the involved NGOs, several land owners that have been assisted in getting approval for use of the trees available in their forests, yet have no desire to engage in those activities. And those forest owners who own the largest tract of land with the most potential and want to engage in production, cannot because of central administrative and legal obstacles that even INAFOR (2008) deemed unnecessary at times. In addition, there was general distrust due to the lack of transparency in the financially intensive administrative and legal processes.

It is beyond the scope and the intent of this research to explicitly say either approach failed or succeeded, as it would be fundamentally paradoxical to my argument for non-dichotomy, the objectification of all things as ends in their own right, and the relational nature of all things which has "interminable and unforeseeable effects" (Watts, 1958:61). In a world where everything is interrelated, Mol and Law (2002:85) point out that labeling something as good or bad is tenuous because of "disentangled discursivity." However, it is evident that there was substantially more positive feedback and perceptions of empowerment and participation on the community committees than the cooperative. 


\section{Diffuse participation, inclusive governance}

As no network can be purely self-contained, the community committees and the cooperative overlapped considerably and to some extent co-constitute one another. There are clear trends of why COPROFOR experienced more problems than the community committee in the translation of processes. People spoke of empowerment and involvement and social cohesion and trust when talking of the committees, and of distrust, corruption, and entanglement when discussing the cooperative. When people feel a sense of control, security and freedom to create their lives, they are more likely to act on behalf of the collective (Shellenberger and Nordhaus, 2007), both human and non-human. The issue of equality and symmetry among actors was a central factor in effective communication of needs and processes. In the creation of these network structures, the initiative was carried out markedly more fluidly when relevant stakeholders were able to emerge organically rather than chosen by outside institutions. Latour (2004) sees ecological crises not as purely environmental problems, but as "crises of objective” where the once predictable, hierarchical categories we have developed can no longer be relied upon. It would behoove "natural resource management”" initiatives to recognize the hybrids of nature and society, humans and non-humans, that have existed in practice, though not theory, and accept "all their consequences and uncertainties to the people themselves” (Latour, 2000).

The municipal initiatives that the projects were based upon recognized the political and social factors that created the stage for the effects to take place after Hurricane Mitch, and similarly how the state of the environment influences the people and the economy. However, it did not sufficiently acknowledge how the bigger framework of political and social potentials was affected by its forests and the environment. Those more intimately linked with the forest became sources of knowledge, with local government and NGOs going to rural community members for information about the health of the forest and the success of the laws. Those involved in the bureaucratic, administrative processes such as those outside people given the task to draw up proposals and legal frameworks were seen as out of touch with the reality of the project. The

\footnotetext{
${ }^{16}$ I use quotations as my analysis has implicitly shown that there is no true management of natural resources, but use the term for lack of better options. See also (Nietschmann, 1997)
} 
more intimately involved actors were with the forest, the more legitimacy they were granted in the process of "human-scale development" and the more incentive it seemed they had to act on behalf of the collective. In San Francisco Libre, the forests are co-producers of circumstances and precedents that have together, and, through dispersed agency, created a stage where the diffuse and dynamic network of actors and their interactions can be openly accounted for. It not only has provided environmental and economic potential, but co-created legitimate political and social movements based in the context of existing conditions within the municipality. Nightingale (2009:315) argues in her description of Nepalese forestry, there is no insider or outsider view, but respectively different forests within the same space. The unifying trend the forest had as both an actor and a stage for the community committees and the issues that arose for COPROFOR around modern technocratic regulation contradict "an overblown sense of what centralized institutions are capable of bringing about at a distance” (Allen, 2004:9), echoed in a 2008 (INAFOR) report that found only 0.8 percent of the volume of industrial and subsistence level firewood consumed is authorized by INAFOR.

\section{Natural-izing politics through participation}

Community initiatives are prime opportunities for political ecology to study power relationships around global and local level economic, political, social and environmental processes. A majority of these initiatives have been framed around a modern paradigm, dualities abound: nature and society, constructivism or realism, top-down versus bottom-up (Allen, 2004; Nightingale, 2003). Similarly, Nicaragua's legislation on the environment and citizen participation is founded on a modern, dichotomous, hierarchical framework. Law 217 is a prime example with its technocratic emphasis on a static natural equilibrium to be maintained for sustainable, yet profitable use of natural resources. While there has been dispute in community-based natural resource management literature on the balance between development and conservation, this gap can be narrowed by moving away from modern, dichotomous frameworks. The majority of community forestry initiatives in Nicaragua and internationally have not sufficiently recognized the numerous connections that exist between humans and non-humans. 
Ironically, the primary advantages accompanied by decentralization of decisionmaking agency over natural resources are not ones that can thrive within a modern paradigm. These efforts founded on flexibility and democracy are often regulated by institutions using rigid and hierarchical methods. Oddly, where proponents of modernity touted it for being able to free society from the constraints of the natural world through science and technology, these community forestry initiatives and the very democracy they are attempting to foster, are being constrained by modern institutions that are incapable of recognizing the opportunity created by the vast networks co-created by humans and non-humans. It is essential in order to adapt to uncertain environments, the foundation of the processes and the tools used are equally flexible, and able to respond to the dynamic processes that make up natures-societies. Doing so will aid in giving preexisting norms legitimacy in everyday situations and help normalize inclusive participation in democratic governance.

\section{Potentials for community forestry and natural resource management}

An effective political ecology cannot exist within a modern paradigm focused on control and dichotomies, where natural objects (human and non-human) are "naturally recalcitrant, always resist, and make shambles of our pretensions of control” (Latour, 2000). In approaching community forestry with a postmodern, non-dichotomous framework, the appeal to nature no longer bears the controversy of anthropocentrism versus ecocentrism, centralized or devolved, social constructivism or natural realism, and makes way for a range of potential social and political movements, legitimized by contextual dynamics.

As this work has shown, ecological movements are not about putting nature over humans, or about belonging to merely a post-materialist society. Both anthropocentric or biocentric approaches are rejected by scholars in the field of critical political ecology (Asdal, 2003; Haraway, 1992; Ivakhiv, 2002; Latour, 1998) because they are based on a modern paradigm refuting the commonality of nature and society. These movements are no longer about nature at all, but rather democracy, and a single collective and common good. As we have seen in San Francisco Libre, democracy and ecology are mutually constituted. As 
actor network theory depicts, there is only uncertainty in the dynamic between associations, with even the most invisible actors impacting the range of potentials co-created. In highlighting the tangled networks of associations that have co-created possibilities and events, we "suspend our certainties concerning the sovereign good of humans and things, ends and means” but instead return to treating all things as ends on their own rights as we cannot define "the common good of a dehumanized nature” (Latour, 2004:229). Furthermore, power comes not from a centralized place of authority, but it occurs within place and timebased interactions. Prominent scholars' works, including those of Escobar, Cloke, Haraway and Allen, emphasize the importance of place in the framing of power relations. Escobar (2001:143) writes that political ecology "should reverse the long standing disempowerment of place” in both modern theory and social life - recognizing that "place is more of an event than a thing," one that is made up by dynamic relationships between humans and non-humans alike.

A new form of politics is needed that adapts to the unpredictability and dynamism of relations between actors and contextual factors; one that allows for the "cultivation of sensitivity to the information relayed from and to natural spaces” (Staddon, 2009:174). Further research into what processes have been most receptive to dynamic flows of information, and the creation of organizations adaptive to such network flows would be very useful. In addition, attention should be paid to how critical political ecology can begin to find new ways to integrate environmental, cultural and economic processes with ones more conducive to a unified nature-society. Finally, there needs to be a focus on how to best listen to the "voices" of the forest to bridge the gap between those with the loudest voice and financial resources and those with the local, contextual knowledge so as to implement projects complementary to the dynamic of actors within a given locality. By recognizing the dynamic in the co-creation of circumstances and agency, one can work accordingly to try to align goals and processes, thereby simultaneously increasing the agency of each actor involved, creating a new, more robust form of participation and democracy.

In the end, if agency (or animacy) is not some fixed property carried by some entities and not by others, if it is instead a 
circulating quality or force by which relations are enacted, then the normative criterion that most readily suggests itself is this one: that the networks we co-construct be such that agency/animacy can circulate freely, not be fixed and confined within rigid hierarchies of who is heard and who is silenced, who issues orders and who is to carry those orders out. An ethic of circulating agency, then is one of dialogue, relationality, and, in one sense or another, participatory democracy - an expansive democracy that includes various kinds of actors, some of whom vote in elections, others who vote with their feet (or fins), and others who enter silently into contracts but who alter those contracts in the process (Ivakhiv, 2002:402) 


\section{References}

Acheson, J. M. (2006). Institutional Failure in Resource Management. Annual Review of Anthropology, 35, 117-134.

Alcaldía Municipal de San Francisco Libre (2003). Plan Integral de Desarrollo Municipal.

Alcaldía Municipal de San Francisco Libre (2004). Plan de Ordenamiento Forestal del Municipio de San Francisco Libre.

Allen, J. (2004). The whereabouts of power: politics, government and space. Geografiska Annaler: Series B, Human Geography, 86, 19-32.

Arnstein, S. R. (1969). A Ladder Of Citizen Participation. Journal of the American Planning Association, 35(4), 216 - 224.

Asdal, K. (2003). The Problematic Nature of Nature: The Post-Constructivist Challenge to Environmental History. History and Theory(42), 60-74.

Barahona, T., Faurby, O., and Zeledon, V. (2003, March). Municipal Governments and Natural Resources: Swimming Upstream? Revista Envío.

Bellamy, J. A., Walker, D. H., McDonald, G. T., and Syme, G. J. (2001). A systems approach to the evaluation of natural resource management initiatives. Journal of Environmental Management, 63(4), 407-423.

Brechin, S. R., Wilshusen, P. R., Fortwangler, C. L., and West, P. C. (2002). Beyond the Square Wheel: Toward a More Comprehensive Understanding of Biodiversity Conservation as Social and Political Process. Society and Natural Resources, 15, 41-64.

Bryant, R. L. (2001). Political Ecology: A Critical Agenda for Change? In N. Castree \& B. Braun (Eds.), Social Nature: Theory, Practice, and Politics. Oxford: Blackwell Publishers Ltd.

Callon, M. (1986). Some elements of a sociology of translation: domestication of the scallops and the fishermen of St. Brieuc Bay. In J. Law (Ed.), Power, action and belief: a new sociology of knowledge. London: Routledge.

Callon, M., and Latour, B. (1992). Don't Throw the Baby Out with the Bath School! A reply to Collins and Yearly. In A. Pickering (Ed.), Science as practice and culture. Chicago: The University of Chicago Press.

Carr, D., Barbieri, A., Pan, W., and Iravani, H. (2006). Agricultural Change and Limits to Deforestation in Latin America. In F. Brouwer \& B. A. McCarl (Eds.), Agriculture and Climate Beyond 2015 (91-107). Netherlands.

Castilleja, G. (1993). Policy and legislation - Changing trends in forest policy in Latin America: Chile, Nicaragua and Mexico. Unasylva(175). 
Castree, N. (2003). Environmental issues: relational ontologies and hybrid politics.

Progress in Human Geography, 27(2), 203-211.

Castree, N., and Braun, B. (Eds.). (2001). Social Nature: Theory, Practice, and Politics. Oxford: Blackwell Publishers Ltd.

Castree, N., and MacMillan, T. (2001). Dissolving Dualisms: Actor-networks and the Reimagination of Nature. In N. Castree \& B. Braun (Eds.), Social Nature: Theory, Practice, and Politics. Oxford: Blackwell Publishers Ltd.

Charmaz, K. (2003). Grounded Theory: Objectivist and Constructivist Methods. In N. K. Denzin \& Y. S. Lincoln (Eds.), Strategies of Qualitative Inquiry. Thousand Oaks: SAGE Publications.

Charnley, S., and Poe, M. R. (2007). Community Forestry in Theory and Practice: Where Are We Now? Annual Review of Anthropology, 36, 301-336.

Cloke, P., and Pawson, E. (2008). Memorial trees and treescape memories. Environment and Planning D: Society and Space, 26, 107-122.

COPROFOR (2009). Personal Interview.

Cornwall, A., and Coelho, V. S. P. (2007). Spaces for Change? The politics of participation in new democratic arenas. In A. Cornwall \& V. S. P. Coelho (Eds.), Spaces for Change. London: Zed Books.

Cupples, J. (2002). The field as a landscape of desire: sex and sexuality in geographical fieldwork. Area, 34(4), 384.

Cupples, J. (2004). Rural Development in El Hatillo, Nicaragua: Gender, Neoliberalism and Environmental Risk. Singapore Journal of Tropical Geography, 25(3), 343357.

Cupples, J. (2008). Victoria University of Wellington Environmental Studies Master Student. In L. Sinreich (Ed.) (e-mail correspondence ed.). Wellington.

Dahal, G. R., and Capistrano, D. (2006). Forest governance and institutional structure: an ignored dimension of community based forest management in the Philippines. International Forestry Review, 8(4).

Demeritt, D. (2001). Being Constructive about Nature. In N. Castree \& B. Braun (Eds.), Social Nature: Theory, Practice, and Politics. Oxford: Blackwell Publishers Ltd.

Dietz, T., Ostrom, E., and Stern, P. C. (2003). The struggle to govern the commons. Science.

Equipo Envío (1984). Partidos y Movimientos Políticos en Nicaragua (Parte1 ). Revista Envío

Escobar, A. (2001). Culture sits in places: reflections on globalism and subaltern strategies of localization. Political Geography, 20(2). 
Escobar, A. (2008). Territories of Difference: place, movements, life, redes. Durham \& London: Duke University Press.

Escobillo (2009). Personal Interview.

Faber, D. (1999). La Liberación del Medio Ambiente: The rise and fall of revolutionary ecology in Nicaragua, 1979 - 1999. Capitalism, Nature, Socialism, 10(1), 45-80.

Faber, D. (2002). A Revolution in Environmental Justice and Sustainable Development: The Political Ecology of Nicaragua. In J. Byrne, L. Glover \& C. Martinez (Eds.), Environmental justice: discourses in international political economy (Vol. 8 3970). New Brunswick; London: Transaction Publishers.

Feldman, M., and Pentland, B. (2005). Organizational routines and the macro-actor. In B. Czarniawska \& T. Hernes (Eds.), Actor-Network Theory and Organizing. Malmo: Liber \& Copenhagen Business School Press.

Fisher, R. J. (2000). Decentralization and Devolution in Forest Management: A Conceptual Overview. Bangkok: Regional Community Forestry Training Center.

Forsythe, T. (2003). Critical political Ecology: the politics of environmental science. London: Routledge.

Gerring, J. (2007). Case Study Research. New York: Cambridge University Press.

Gherardi, S., and Nicolini, D. (2005). Actor-networks: ecology and entrepreneurs. In B. Czarniawska \& T. Hernes (Eds.), Actor-Network Theory and Organizing. Malmo: Liber \& Copenhagen Business School Press.

Gillham, B. (2000). Case Study Research Methods. London: Continuum.

González-Rivas, B., Tigabu, M., Gerhardt, K., Castro-Marín, G., and Odén, P. (2006). Species Composition, Diversity and Local uses of Tropical Dry Deciduous and Gallery Forests in Nicaragua. Biodiversity and Conservation, 15(4), 1509-1527.

Guthman, J. (1997). Representing crisis: the theory of Himalayan environmental degradation and the project of development in post-Rana Nepal. Development and Change, 25, 45-69.

Hall, I., and Hall, D. (2004). Evaluation and Social Research: Introducing Small-Scale Practice. New York: PALGRAVE MACMILLAN.

Haraway, D. (1992). The Promises of Monsters: A Regenerative Politics for Inappropriate/d Others. New York: Routledge.

Hawkesworth, S., and Pérez, J. D. G. (2003). Potentials and Constraints of the Farmerto-Farmer Programme for Environmental Protection in Nicargua. Land Degradation \& Development(14), 175-188.

Hesse-Biber, S. N., and Leavy, P. (Eds.). (2004). Approaches to Qualitative Research: A Reader on Theory and Practice. New York: Oxford University Press. 
Hinchliffe, S. (2007). Geographies of Nature. London: SAGE Publications Ltd.

Hinchliffe, S., and Woodward, K. (2000). The natural and the social: uncertainty, risk, change: Routledge.

Hinchliffe, S., and Woodward, K. (2004). The natural and the social: uncertainty, risk, change. New York: Routledge.

INAFOR (2008). Leña - el recurso forestal olvidado de Nicaragua: INAFOR.

INGES-FORESTAN (2005). Fomentando el Manejo Forestal Sostenido y un mayor Valor Agregado para los productos forestales en el municipio de San Francisco Libre. Managua: INGES-FORESTAN.

INIFOM (2007). Ficha Municipal - San Francisco Libre. from http://www.inifom.gob.ni/municipios/documentos/MANAGUA/san_franciscolib re.pdf.

Ivakhiv, A. (2002). Toward a multicultural ecology. Organization \& Environment, 15(4), 389.

Kearns, R. (2005). Knowing Seeing? Undertaking Observational Research. In I. Hay (Ed.), Qualitative Research Methods in Human Geography. Melbourne: OXFORD University Press.

Kellert, S. R., Mehta, J. N., Ebbin, S. A., and Lichtenfeld, L. L. (2000). Community Natural Resource Management: Promise, Rhetoric, and Reality. Society and Natural Resources, 13, 705-715.

Ley de Municipios (1988).

Larson, A. M. (2002). Natural Resources and Decentralization in Nicaragua: Are Local Governments Up to the Job? World Development, 30(1), 17-31.

Larson, A. M. (2003). Decentralisation and Forest Management in Latin America: Towards a Working Model. Public Administration and Development(23), 211226.

Larson, A. M., and Soto, F. (2008). Decentralization of Natural Resource Governance Regimes. Annual Review of Environment and Resources, 33, 4.1-4.27.

Larson, A. M., and Zeledon, V. (2004). Participation and Decentralized Forest Management: Social Effects of Local Government Initiatives. Paper presented at the Tenth Biennial Conference of the International Association for the Study of Common Property (IASCP).

Latour, B. (1986). The powers of association. In J. Law (Ed.), Power, Action, and Belief: A New Sociology of Knowledge? London: Routledge \& Kegan Paul.

Latour, B. (1993a). The Pasteurization of France. USA: First Harvard University Press. 
Latour, B. (1993b). We have never been modern. Cambridge: Harvard University Press.

Latour, B. (1998). To modernise or ecologise? That is the question. In B. Braun \& N. Castree (Eds.), Remaking Reality: Nature at the millenium. London: Routledge.

Latour, B. (1999). Pandora's Hope. Cambridge: Harvard University Press.

Latour, B. (2000). When things strike back: a possible contribution of 'science studies' to the social sciences. British Journal of Sociology, 51(1), 107-123.

Latour, B. (2004). Politics of Nature: how to bring the sciences into democracy. Cambridge: Harvard University Press.

Latour, B. (2005). Reassembling the Social: An Introduction to Actor-Network-Theory. New York: Oxford University Press.

Law, J., and Mol, A. (2002). Local entanglements or Utopian moves. In M. Parker (Ed.), Utopia and organization. Oxford: Blackwell Publishing.

Lerner, J., and Schugurensky, D. (2005). Learning citizenship and democracy through participatory budgeting: The case of Rosario, Argentina. Paper presented at the Democratic Practices as Learning Opportunities.

MAGFOR (2008). Compendio Jurídico Forestal de Nicaragua.

Marshall, G. (1998). A Dictionary of Sociology. Oxford: Oxford University Press.

Massey, D. (2005). For Space. London: Routledge.

Mathes, E. W. (1981). Maslow's Hierarchy of Needs as a Guide for Living. Journal of Humanistic Psychology, 21(69).

McSweeney, K. (2005). Natural Insurance, Forest Access, and Compounded Misfortune: Forest Resources in Smallholder Coping Strategies Before and After Hurricane Mitch, Northeastern Honduras. World Development, 33(9), 14531471.

Mitchell, B. (1997). Sustainable Development Resource and environmental management (26-49). UK: Longman.

MOLISV (1994). Entre La Gandería y el Corte de Leña: Descripción de diversos cambios acontecidos en el Municipio de San Francisco Libre. Managua: MOLISV.

Murdoch, J. (2001). Ecologising Sociology: Actor-Network Theory, Co-construction and the Problem of Human Exemptionalism. Sociology, 35(1), 111-133.

Nacascolo (2009). Personal Interview.

Nietschmann, B. (1997). Protecting Indigenous Coral Reefs and Sea Territories, Miskito Coast, RAAN, Nicaragua. In S. Stevens (Ed.), Conservation through cultural 
survival: indigenous peoples and protected areas. Washington, D.C.: ISLAND PRESS.

Nightingale, A. (2003). Nature-society and development: social, cultural and ecological change in Nepal. Geoforum, 34(4), 525-540.

Nightingale, A. (2006). Caring for Nature: subjectivity, boundaries and environment. from University of Edinburgh:

Nightingale, A. (2009). Nepal's Green Forests; A 'Thick' Aesthetics of Contested Landscapes. Ethics, Place and Environment, 12(3), 313-330.

Noren, L., and Ranerup, A. (2005). The internet web portal as an enrolment device. In B. Czarniawska \& T. Hernes (Eds.), Actor-Network Theory and Organizing. Malmo: Liber \& Copenhagen Business School Press.

O'Keefe, P., Westgate, K., and Wisner, B. (1976). Taking the naturalness out of natural disasters. Nature, 260.

Oliver-Smith, A., and Hoffman, S. M. (1999). The angry earth: disaster in anthropological perspective. London: Routledge.

Ostrom, E. (1999). Self-Governance and Forest Resources: Center for International Forestry Research.

Ostrom, E. (2002). Reformulating the commons. Ambiente \& Sociedad, 10.

Quaghebeur, K., Masschelein, J., and Nguyen, H. H. (2004). Paradox of Participation: Giving or Taking Part? Journal of Community \& Applied Social Psychology(14), 154-165.

Raik, D. B., Wilson, A. L., and Decker, D. J. (2008). Power in Natural Resources Management: An Application of Theory. Society and Natural Resources, 21, 729-739.

Rocha, J. L. (1999, January). San Francisco Libre: Giving It One More Try. Revista Envío.

Rose, G. (1997). Situating knowledges: positionality, reflexivities and other tactics. Progress in Human Geography, 21(3), 305-320.

Rudy, A. P., and Gareau, B. J. (2005). Actor-Network Theory, Marxist Economics, and Marxist Political Ecology. Capitalism, Nature, Socialism, 16(4).

Sabogal, C. (1992). Regeneration of Tropical Dry Forests in Central America, with Examples from Nicaragua. Journal of Vegetation Science, 3(3), 407-416.

Sacuanjoche4 (2009). Personal Interview.

Seidman, S. (2008). Contested Knowledge: Social Theory Today. Malden: Blackwell Publishing. 
Shellenberger, M., and Nordhaus, T. (2007). Break Through: From the Death of Environmentalism to the Politics of Possibility. New York: Houghton Mifflin.

Staddon, C. (2009). Towards a critical political ecology of human-forest interactions: collecting herbs and mushrooms in a Bulgarian locality. Transactions of the Institute of British Geographers, 34, 161-176.

Stake, R. E. (2003). Case Studies. In N. K. Denzin \& Y. S. Lincoln (Eds.), Strategies of Qualitative Inquiry. Thousand Oaks: Sage Publications Ltd.

Steins, N. A. (2001). New Directions in Natural Resource Management: The Offer of Actor-Network Theory. IDS Bulletin, 32(4).

Strauss, A., and Corbin, J. (1990). Basics of Qualitative Research: Grounded Theory Procedures and Techniques. Newbury Park: Sage Publications.

Taber, A., Navarro, G., and Arribas, M. A. (1997). A new park in the Bolivian Gran Chaco - an advance in tropical dry forest conservation and community-based management. ORYX, 31(3), 189-198.

Tacconi, L., Siagian, Y., and Syam, R. (2006). On the Theory of Decentralization, Forests and Livelihood. Canberra: Australian National University.

Thrift, N. (2000). Still life in the nearly present time. Body and Society, 6, 34-57.

Vatn, A. (2005). Resource Regimes Institutions and the Environment. Cheltenham: Elgar.

Walker, T. W. (Ed.). (1982). Nicaragua in Revolution. New York: Praeger Publisher.

Watts, A. W. (1958). Nature, Man, and Woman. London: Wildwood House.

Whatmore, S. (1999). Hybrid Geographies. In D. Massey, J. Allen \& P. Sarre (Eds.), Human Geography Today (22-39). London: Arnold.

Wilshusen, P. R., Brechin, S. R., Fortwangler, C. L., and West, P. C. (2002).

Reinventing a Square Wheel: Critique of a Resurgent "Protection Paradigm" in International Biodiversity Conservation. Society and Natural Resources, 15, 1740 .

Wunsch, J. (1999). Institutional analysis and decentralization: developing an analytical framework for effective Third World administrative reform. In M. McGinnis (Ed.), Polycentric Governance and Development. Ann Arbor: University of Michigan Press.

Young, J. (1990). Post Environmentalism. London: Belhaven Press. 